\title{
KASL clinical practice guidelines: management of chronic hepatitis B
}

\author{
The Korean Association for the Study of the Liver (KASL)*
}

Keywords: Chronic hepatitis B; Mangement; KASL guidelines

\section{PREAMBLE}

\section{Aims}

The clinical practice guidelines for the management of chronic hepatitis $\mathrm{B}(\mathrm{CHB})$ were first presented in 2004 by the Korean Association for the Study of the Liver (KASL), and were revised in 2007 and 2011. The American Association for the Study of Liver Diseases (AASLD) published their guidelines in 2015, the European Association for the Study of the Liver (EASL) in 2012, the Asian Pacific Association for the Study of the Liver (APASL) in 2015 and the World Health Organization (WHO) in 2015. These guidelines carry some variations due to ethnic differences and different medical environments. Therefore, there is a demand for Korean practice guidelines which reflect medical practice in Korea. Problems with emergence of drug resistant mutation are eminent in Korea and the KASL updated their guidelines regarding the management of antiviral resistant mutation in 2014.

In 2015, the objective of this manuscript was to update the recommendations for management of $\mathrm{CHB}$, including epidemiology, prevention, natural history, diagnosis, treatment, monitoring, drug resistance mutations and treatment of special populations discussed herein based on current evidences or if, evidences lack, on expert opinions after deliberation.

\begin{abstract}
Abbreviations:
AAR, AST/ALT ratio; AASLD, American Association for the Study of Liver Diseases: $A L P$, alkaline phosphatase; ALT, alanine aminotransferase; anti-HAV, hepatitis A virus antibody; anti-HBC, hepatitis B core antibody; anti-HBe, hepatitis B e antibody; anti$\mathrm{HBs}$, hepatitis B surface antibody; APASL, Asian Pacific Association for the Study of the Liver; APR, Antiretroviral Pregnancy Registry; APRI, aspartate aminotransferaseplatelet ratio index; ASPRI, age-spleen-platelet ratio index; AST, aspartate aminotransferase; $\mathrm{BCP}$, basal core promoter; $\mathrm{CBC}$, complete blood count; $\mathrm{CHB}$, chronic hepatitis $\mathrm{B}$; CK, creatine kinase; CPGRC, Clinical Practice Guideline Revision Committee; cpm, copies/mL; CTP, Child-Turcotte-Pugh; DAA, direct-acting agent; DMARD, disease-modifying antirheumatic drug; EASL, European Association for the Study of the Liver; GGT, gamma-glutamyl transpeptidase; GRADE, Grading of Recommendations, Assessment, Development and Evaluation; HAART, anti-retroviral therapy; $\mathrm{HBCAg}$, hepatitis $B$ core antigen; $\mathrm{HBeAg}$, hepatitis $B$ e antigen; $\mathrm{HBIG}$, hepatitis B immunoglobulin; HBsAg, hepatitis B surface antigen; HBV, Hepatitis B virus; HCC, hepatocellular carcinoma; $\mathrm{HCV}$, hepatitis C virus; HDV, hepatitis D virus; HIV, human immunodeficiency virus; IU, international unit; peginterferon, pegylated interferon; KASL, Korean Association for the Study of the Liver; NA, nucleos(t)ide analog; PC, precore; $\mathrm{PT}$, prothrombin time; $\mathrm{qHBsAg}$, quantity of $\mathrm{HBs} A g ; \mathrm{R}-\mathrm{CHOP}$, rituximab plus cyclophosphamide, doxorubicin, vincristine, and prednisone; SR, success rate; IQR, interquartile range; TACE, transcatheter arterial chemoembolization
\end{abstract}

Corresponding author : KASL (Committee chair: Kwan Sik Lee) Room A1210 MapoTrapalace, 53 Mapo-daero, Mapo-gu, Seoul 04158, Korea Tel: +82-2-703-0051, Fax: +82-2-703-0071

E-mail: kasl@kams.or.kr

\section{* Clinical Practice Guidelines Committee of KASL for the Management of Chronic Hepatitis B}

Kwan Sik Lee (Committee Chair, Yonsei University College of Medicine), Si Hyun Bae (Catholic University of Korea), Won Hyeok Choe (Konkuk University College of Medicine), Moon Seok Choi (Sungkyunkwan University School of Medicine), Woo Jin Chung (Keimyung University School of Medicine), Chang Wook Kim (Catholic University of Korea), Hyung Joon Kim (Chung-Ang University College of Medicine), Ja Kyung Kim (Yonsei University College of Medicine), Ji Hoon Kim (Korea University College of Medicine), Suk Bae Kim (Dankook University Medical College), Yoon Jun Kim (Seoul National University College of Medicine), Jae Sung Ko (Seoul National University College of Medicine), Byung Seok Lee (Chungnam National University College of Medicine), Jung II Lee (Yonsei University College of Medicine), Young-Suk Lim (University of Ulsan College of Medicine), Won Young Tak (Kyungpook National University School of Medicine), Jong Eun Yeon (Korea University College of Medicine), Ki Tae Yoon (Pusan National University School of Medicine). 


\section{Target population}

The main targets of this guideline are patients both newly diagnosed with CHB and those being followed up or treated for CHB. This guideline is also intended to facilitate management of patients under the following special circumstances: malignancy, transplantation, kidney dysfunctions, co-infection with other viruses, pregnancy, and children.

\section{Intended users}

This revised CHB guideline is designed as a resource for all Korean clinicians caring for patients with CHB. It also provides physicians undertaking training courses with practical information on the management of $\mathrm{CHB}$.

\section{Developer and funding}

The CHB Clinical Practice Guideline Revision Committee (CPGRC) comprising 17 hepatologists and 1 pediatrician was formed with support from the KASL. All of the required funding was provided by the KASL. Each member of the CHB-CPGRC collected and evaluated evidence, and contributed to writing the manuscript.

Conflicts of interest of the CHB-CPGRC members are summarized in Conflicts of interest.

\section{Evidence collection}

Relevant evidences obtained from a comprehensive literature search using MEDLINE (up to 2015) were systematically reviewed and selected. The languages were limited to English and Korean.
In addition to published articles, abstracts of important meetings published before 2015 were also evaluated. The following search terms were used: "hepatitis B", "hepatitis B virus", "HBV", "chronic hepatitis", and other key words related to clinical questions (see below). These clinical questions covered a variety of pertinent topics ranging from epidemiology, natural course, prevention, diagnosis, treatment, antiviral resistance, and special situations.

\section{Levels of evidence and grades of recommendation}

The evidence and recommendations were graded according to Grading of Recommendations, Assessment, Development and Evaluation (GRADE) system with minor modifications (Table 1). The levels of evidence were determined as the possibility of change in the estimate of clinical effect by further research, and were described as high (A), moderate (B) or low (C). The grades of recommendation were either strong (1) or weak (2), as determined by the quality of evidence as well as patient-important outcomes and socioeconomic aspects.

\section{List of the clinical questions}

The committee considered the following questions as key components to be covered in this guideline.

1. How does this guideline differ from previous guidelines?

2. What is the updated knowledge on the epidemiology?

3. What is the updated knowledge on the natural course of CHB?

4. How should the infection be prevented?

5. How are patients evaluated prior to treatment?

Table 1. Grading of Recommendations, Assessment, Development and Evaluation (GRADE)

\begin{tabular}{ll}
\hline Quality of evidence & Criteria \\
\hline High (A) & Further research is unlikely to change confidence in the estimate of the clinical effect \\
\hline Moderate (B) & Further research may change confidence in the estimate of the clinical effect \\
\hline Low (C) & Further research is very likely to impact confidence on the estimate of clinical effect \\
\hline Strength of recommendations & Criteria \\
\hline Strong (1) & Factors influencing the strength of the recommendation included the quality of the evidence, \\
& presumed patient-important outcomes, and cost \\
Weak (2) & Variability in preferences and values, or more uncertainty. \\
& Recommendation is made with less certainty, higher cost or resource consumption
\end{tabular}

NOTE. Of the quality levels of evidence, we excluded "very low quality (D)" from the guidelines for convenience. This was originally included in the GRADE system and indicates that the estimate of effect is highly uncertain. 
6 . When should treatment be considered?

7. What are the goals and endpoints of treatment?

8. What are the optimal first-line treatments for different disease status?

9. How should the treatment be monitored?

10. When can we consider stopping treatment?

11. What are the predictors of a treatment response?

12. What are the definitions of treatment failure?

13. How should we manage drug-resistant CHB patients?

14. What are the definitions of recurrence after treatment completion and how should these be managed?

15. How should we manage the following special groups:

- acute hepatitis B

- liver transplantation

- chemotherapy/immunosuppression

- chronic kidney disease

- coinfection [with hepatitis C virus (HCV), hepatitis D virus (HDV), and/or human immunodeficiency virus (HIV)]

16. How can we reduce vertical transmission in pregnant CHB patients?

17. What is the optimal management of CHB in children?

\section{Review of the manuscript}

Drafts of the revised guideline were thoroughly reviewed at separate meetings of the committee. A revised manuscript was reviewed at a meeting of an external review board, and at a symposium open to all KASL members, and was modified further prior to publication. The external review board comprised of 18 specialists in CHB who are members of the KASL. The final manuscript was endorsed by the board of executives of the KASL.

\section{Release of the guidelines}

The revised CHB guidelines of KASL were released on November 26, 2015 (http://www.kasl.org).

\section{Plan for updates}

Updates or full revision will be planned when major new evidence regarding the diagnosis and/or treatment of CHB becomes available. Detailed plans for updates will be posted on the KASL website at a later date.

\section{EPIDEMIOLOGY}

Hepatitis B virus (HBV) infection, as a causative factor of liver disease of 240 million patients globally and death of 600 thousand patients annually, ${ }^{1}$ is a major cause of acute and chronic hepatitis, liver cirrhosis, and hepatocellular carcinoma. It has been recognized as an important public health problem in Korea since the $1970 \mathrm{~s}^{2}$ and was designated a third-class communicable disease by law in 1982 and is now the target of a national vaccination program as a second-class communicable disease. ${ }^{3}$

The prevalence of HBV infection in the Korean population as estimated by positivity rates for hepatitis B surface antigen (HBsAg) was $8-9 \%$ for males and $5-6 \%$ for females before commercialization of an HBV vaccine in the early 1980 s; $^{4}$ thereafter, the prevalence of HBV infection tended to decline gradually due to the initiation of a vaccination program for newborn infants in 1991 and a national vaccination program in 1995. For example, in 2006 the prevalence of HBV among children aged 4 to 6 years had decreased to $0.2 \% .{ }^{5}$ Nevertheless, according to the 2005 National Health and Nutrition Examination Survey, the HBsAg positivity rate was $4.0 \%$ at $2009 .^{6}$ The Ministry of Health and Welfare reported that the HBsAg positivity rate was $3.4 \%$ for males and $2.6 \%$ for females, with $3.0 \%$ of the total population being infected with HBV in 2012. ${ }^{7}$ Positivity rates for HBsAg among pregnant females, which represents a major infection route for hepatitis B, declined steadily after 2004 , as did the positivity rates among females in the childbearing period. Given that HBsAg is detected in approximately $70 \%$ of patients with chronic hepatitis or cirrhosis, ${ }^{8}$ and in $65-75 \%$ of HCC patients, ${ }^{9,10}$ it can be concluded that CHB infection is a matter of importance for public health in Korea. Most Korean CHB patients are infected with HBV genotype $\mathrm{C2}^{11}$ and tend to have lower hepatitis $\mathrm{B}$ e antigen ( $\mathrm{HBeAg}$ ) seroconversion rates, more rapid progression to cirrhosis and HCC, reduced efficacy of interferon treatment, and are subject to higher rates of relapse after antiviral treatment, compared to those infected with other HBV genotypes. ${ }^{12,13}$

\section{Natural history}

The progression of CHB may be divided into the following five clinical phases: the immune-tolerant phase, immune-active phase, immune-control phase, immune-escape phase, and HBsAg-clearance phase. Individual patients do not necessarily experience these clinical phases in a continuous manner, and clinical phases are not always correlated with criteria or indications of antiviral 
Table 2. Natural course of chronic hepatitis B (CHB)

\begin{tabular}{|c|c|c|c|c|}
\hline Clinical phase & Serum marker & ALT & HBV-DNA & Histology \\
\hline Immune-tolerant phase & $\mathrm{HBeAg}(+)$ & Persistently normal & High level of viral replication & Minimal histological disease \\
\hline $\begin{array}{l}\text { Immune-active phase, } \\
\text { HBeAg-positive CHB }\end{array}$ & $\begin{array}{l}\mathrm{HBeAg}(+) \\
\text { may develop anti-HBe }\end{array}$ & $\begin{array}{l}\text { Raised or intermittently } \\
\text { raised ALT }\end{array}$ & Lower level of viral replication & $\begin{array}{l}\text { Histological necroinflammatory } \\
\text { activity present } \\
\text { Lobular hepatitis, bridging fibrosis } \\
\text { and fibrosis may be present }\end{array}$ \\
\hline $\begin{array}{l}\text { Immune-control phase } \\
\text { Inactive CHB }\end{array}$ & $\begin{array}{l}\operatorname{HBeAg}(-) \\
\text { anti-HBe (+) }\end{array}$ & Persistently normal ALT & $\begin{array}{l}\text { Low or undetectable HBV } \\
\text { DNA (HBV DNA levels } \\
\leq 2,000 \mathrm{IU} / \mathrm{mL})\end{array}$ & Risk of cirrhosis and HCC reduced \\
\hline $\begin{array}{l}\text { Immune-escape phase, } \\
\text { HBeAg-negative CHB }\end{array}$ & $\begin{array}{l}\text { HBeAg (-), with or } \\
\text { without being anti- } \\
\text { HBe positive }\end{array}$ & $\begin{array}{l}\text { Raised ALT (persistent } \\
\text { or intermittent } \\
\text { exacerbations }\end{array}$ & $\begin{array}{l}\text { Moderate to high levels of } \\
\text { HBV replication (HBV DNA } \\
\text { levels }>2,000 \mathrm{IU} / \mathrm{mL} \text { ) }\end{array}$ & $\begin{array}{l}\text { Older persons especially at risk } \\
\text { for progressive disease (fibrosis/ } \\
\text { cirrhosis) }\end{array}$ \\
\hline HBsAg-clearance phase & $\begin{array}{l}\operatorname{HBsAg}(-) \\
\operatorname{anti-HBC}(+) \\
\text { anti-HBs (+/-) }\end{array}$ & Normal & Not detected & \\
\hline
\end{tabular}

ALT, alanine aminotransferase; HBV, Hepatitis B virus; HCC, hepatocellular carcinoma.

therapy. ${ }^{14,15}$ HBV DNA positivity indicates an acute or chronic HBV infection, and negativity indicates resolution of infection. For this reason, the WHO decided to delete the term 'hepatitis B carrier.' The natural history of CHB is outlined below (Table 2).

\section{Immune-tolerant phase}

In cases of perinatal infection, the immune-tolerant phase is characterized by HBeAg positivity, high levels of serum HBV DNA (generally $\geq 10^{7} \mathrm{IU} / \mathrm{mL}$ ), normal levels of aspartate aminotransferase/alanine aminotransferase (AST/ALT), and mild or no liver necroinflammation. ${ }^{16-19}$ Elevation of ALT level was detected in $16 \%$ of patients in the immune-tolerant phase during 5 years of follow up. ${ }^{19}$

This phase may continue for more than three decades in patients infected with HBV genotype $C$, which is common among Korean patients, and the rate of spontaneous HBeAg loss is very low. ${ }^{20}$ Therefore, many females infected with this genotype are in the $\mathrm{HBeAg}$-positive immune-tolerant phase when they are of childbearing age. The absence of, or only mild histologic liver damage, despite high levels of HBV DNA, is attributed to immune tolerance to $\mathrm{HBV}^{21}$

\section{Immune-active $\mathrm{HBeAg}$-positive $\mathrm{CHB}$}

Most patients in the immune-tolerant phase will experience immune responses to HBV as they grow older, and finally reach the immune-active phase, which is characterized by HBeAg positivity, lower serum HBV DNA levels, and increased or fluctuating ALT levels. ${ }^{22,23}$ Histologic findings in this phase include moderate-tosevere liver inflammation and, in some patients, rapid progression of fibrosis. ${ }^{24}$ Such changes are due to enhancement of hepatitis $B$ core antigen (HBcAg) or HBeAg-specific cytotoxic T-lymphocyte activity and the resulting destruction of infected hepatocytes. ${ }^{25}$ Sustained HBV DNA suppression occasionally accompanies HBeAg seroconversion.

Once $\mathrm{HBeAg}$ seroconversion occurs, the natural course of the disease may have one of three clinical features: (1) repeated $\mathrm{HBeAg}$ reversion and seroconversion, (2) inactive state, or (3) HBeAg-negative CHB. ${ }^{26,27}$ Typically, $10-40 \%$ of patients who experience seroconversion revert to $\mathrm{HBeAg}$ positivity and then experience recurrence of seroconversion at least once with progression of hepatitis activity. ${ }^{24,28,29}$ In particular, reversion frequently occurs in patients with HBV genotype $C$, and the rate decreases with age. ${ }^{20}$ Hepatic decompensation, which occurs in $5 \%$ of patients with acute exacerbation, may be fatal. ${ }^{30}$

\section{Immune-control inactive $\mathrm{CHB}$}

Most patients who seroconvert during the immune-active phase progress to the immune-control phase, which is characterized by HBeAg negativity, persistent normal ALT levels, and HBV DNA levels of $<2,000 \mathrm{IU} / \mathrm{mL} .^{31-33}$ Typical histologic findings in this phase are mild liver inflammation and fibrosis, ${ }^{31}$ however, patients who have suffered from previous severe inflammation and fibrosis may continue to experience moderate-to-severe inflammation and fibrosis. This may result in even biochemical and histologic tests not being useful for differentiating these patients from those with cirrhosis who require antiviral treatment. ${ }^{32}$

This phase persists for a long time in most patients, but with a relatively good prognosis; however, an estimated $20 \%$ of them 
will reactivate to the $\mathrm{HBeAg}$-negative or $\mathrm{HBeAg}$-positive immuneactive phase, and might experience recurring periods of reactivation and inactivation throughout their lives, which can lead to cirrhosis or HCC. ${ }^{34,35}$ This is why the ALT levels of patients in the immune-control phase must be measured at least every 6 months for life because currently there are no predictors of which patients will remain in the inactive phase and which will revert to HBeAgnegative active hepatitis. ${ }^{15}$

\section{Immune-escape HBeAg-negative CHB}

Approximately $20 \%$ of patients who experience $\mathrm{HBeAg}$ seroconversion during their immune-active phase maintain $\mathrm{HBeAg}$ negativity and hepatitis B e antibody (anti-HBe) positivity but progress to the immune-escape phase, with findings of HBV DNA levels $\geq 2,000 \mathrm{IU} / \mathrm{mL}$, increased ALT levels, and active liver necroinflammation. ${ }^{26}$ These patients show HBeAg negativity since they harbor HBV variants in the precore $(\mathrm{PC})$ or basal core promoter $(B C P)$ regions of $H B V D N A$, resulting in failure to produce $\mathrm{HBeAg}{ }^{36-38} \mathrm{HBeAg}$-negative CHB is associated with low rates of prolonged spontaneous disease remission, and most patients in this phase will experience persistent hepatocellular inflammation and progress to hepatic fibrosis and cirrhosis. ${ }^{38-40}$ Severe fluctuations of HBV DNA and ALT levels can make it difficult to differentiate these patients from those in the immune-control phase. ${ }^{41}$ Accordingly, for the first year after a patient is diagnosed as being in the immune-control phase, HBV DNA and ALT levels should be measured every 3 months to identify HBeAg-negative CHB patients who require antiviral treatment. ${ }^{15,42}$

\section{HBsAg-clearance phase}

Patients in the immune-control phase subsequently progress to the HBsAg clearance phase at a rate of $1-2 \%$ annually. ${ }^{41,43,44}$ According to Liaw's data, HBsAg loss occurs in $1.9 \%$ of CHB patients, and $0.8 \%$ of those with chronic HBV infection regardless of gender and virus genotype, with age being the only known influencing factor. ${ }^{45,46}$ It has been reported that Korean patients experience a relatively low rate of HBsAg loss ( $0.4 \%$ annually). ${ }^{47}$ HBV DNA is not detectable in the serum during this phase, while hepatitis B core antibody (anti-HBc) with or without hepatitis B surface antibody (anti-HBs) is detectable. HBsAg loss is associated with a reduced risk of cirrhosis but a sustained, significant risk of HCC development. ${ }^{34,43,48-53}$

\section{Risk factors that influence the natural history of CHB}

The accumulated incidence of cirrhosis developing from CHB is generally reported to be $8-20 \%{ }^{54,55}$ In Korea, the reported annual and 5 -year accumulated incidences of cirrhosis are $5.1 \%$ and $23 \%$, respectively, while those for $\mathrm{HCC}$ are $0.8 \%$ and $3 \% .^{54}$ The risk factors for hepatitis B progressing to cirrhosis or HCC can be divided into demographic, environmental, social, and viral factors (Table 3). ${ }^{56}$

Regarding demographic factors, the risk of developing HCC is

Table 3. Risk factors associated with the development of hepatocellular carcinoma (HCC) and/or cirrhosis in persons with chronic hepatitis B

\begin{tabular}{|c|c|c|}
\hline & Increased risk of HCC & Increased risk of cirrhosis \\
\hline \multicolumn{3}{|l|}{ Demographic } \\
\hline Male sex & $3+$ & + \\
\hline Increasing age $>40$ years & $3+$ & $3+$ \\
\hline Family history of HCC & $3+$ & + \\
\hline \multicolumn{3}{|l|}{ Social and environmental } \\
\hline Alcohol & + & + \\
\hline Aflatoxin & $3+$ & Unknown \\
\hline Smoking & + & + \\
\hline Coffee & Decreased risk of HCC & Slower progression of liver fibrosis \\
\hline \multicolumn{3}{|l|}{ Viral factor } \\
\hline Genotype C & $3+$ & $2+$ \\
\hline HBV DNA >2,000 IU/mL & $3+$ & $3+$ \\
\hline BCP mutation & $3+$ & + \\
\hline
\end{tabular}

BCP, basal core promoter; HBV, hepatitis B virus.

Modified from McMahon. ${ }^{56}$ 
three- to fourfold higher for males than for females, and the risk of HCC and cirrhosis is low among those younger than 40 years, then increases exponentially with increasing age after the fourth decade of life. ${ }^{33,57-59}$ Those with a family history of HCC also have a higher risk of contracting $\mathrm{HCC}{ }^{60,61}$ Environmental and social risk factors for progression to cirrhosis or HCC are alcohol consumption, exposure to aflatoxin, ${ }^{62}$ and smoking. ${ }^{63}$ It is suggested that obesity, metabolic syndrome, and fatty changes in histologic tests increase the risk of CHB patients progressing to hepatic fibrosis or HCC ${ }^{64-67}$ Many epidemiological research studies have found that coffee exerts protective effects against the development of hepatic fibrosis and $\mathrm{HCC}^{68-72}$

Viral factors that may influence the progression of CHB patients to cirrhosis or HCC include high levels of serum HBV DNA $(\geq 20,000 \mathrm{IU} / \mathrm{mL}$ ), genotype C, BCP variants, and coinfection with other viruses. ${ }^{57,59,73-75}$ According to the Taiwanese Risk Evaluation of Viral Load Elevation and Association Liver Disease/Cancer-Hepatitis B Virus (REVEAL-HBV) study, the risk of developing HCC during the study period among subjects aged at least 40 years was significantly higher in those with an HBV DNA level of $\geq 10^{4}$ copies $/ \mathrm{mL}(\mathrm{cpm})$ at the start of observation and $10^{5} \mathrm{cpm} 11$ years later than among those with an entry HBV DNA level of $<10^{4} \mathrm{cpm}$. Likewise, the incidence of cirrhosis was significantly associated with HBV DNA levels higher than $10^{4} \mathrm{cpm}$ at study entry. ${ }^{58,59}$ If the HBV DNA level decreased during the follow-up period, the risk of developing HCC or cirrhosis decreased. Subsequent research highlighted the clinical importance of careful evaluation of patients with an HBV DNA level $>2,000 \mathrm{IU} / \mathrm{mL}$ who are older than 40 years (especially those $\mathrm{HBeAg}$ positive) for the development of fibrosis ${ }^{57}$ and $\mathrm{HCC} .74,75$ Therefore, intervention with antiviral therapy should be performed when appropriate, as recommended by established practice guidelines. ${ }^{56}$

Unlike HCV infection, the HBV genotype exerts a profound effect on the clinical outcome but-with the exception of interferon-little effect on the treatment outcome. ${ }^{76}$ Eight HBV genotypes have been identified, and that with the worst prognosis is genotype $\mathrm{C}$, which is the most common in Korean CHB patients. ${ }^{77}$ Genotype $\mathrm{C}$ is associated with delayed natural seroconversion and rapid progression to liver cirrhosis and HCC. Therefore, it is an independent risk factor for $\mathrm{HCC}$ development. According to a cohort study in Alaska, patients infected with A-, B-, and D-genotype hepatitis $B$ typically experience seroconversion from $\mathrm{HBeAg}$ to anti-HBe before the age of 20 years, whereas in those infected with the $\mathrm{C}$ genotype this occurs at a mean age of 47 years. ${ }^{20}$ This implies that those infected with genotype $\mathrm{C}$ would on average expe- rience a much longer period of infection with high HBV viral loads, and may in part explain why the risks of HCC and cirrhosis are so high in patients infected with genotype $C$.

Two important genetic mutations of HBV that affect the natural history of CHB infection are the BCP and PC mutations. ${ }^{42,45,75,77-79}$ BCP mutations are A1762T and G1764A mutations in the HBV $\mathrm{BCP}$ regions, and multiple cross-sectional and prospective studies have indicated that they increase the risks of cirrhosis and $\mathrm{HCC}^{42,45,77,78}$ According to the results of the REVEAL-HBV study, 359 and 1,149 individuals without and with BCP mutations, respectively, developed HCC among a population of $100,000 .{ }^{80}$ PC mutation typically appears near the time of HBeAg seroconversion. The mutation results in an amino-acid change that creates a stop codon at site 1896 on the HBV genome, which results in the virus being able to transcribe hepatitis $B$ core protein but not HBeAg. ${ }^{45}$ Patients infected with PC mutants are characterized by HBeAg negativity and HBeAg positivity, but high levels of HBV DNA. ${ }^{81,82}$ However, the observed effects of $P C$ mutants on the natural history of $\mathrm{CHB}$ have been inconsistent; a recent analysis of the role of PC in the prospective population-based REVEAL-HBV study revealed the opposite to the findings of cross-sectional clinic-based studies - that the presence and absence of the PC mutation decreased and increased, respectively, the subsequent annual incidence of HCC (269 and 996 per 100,000, respectively). ${ }^{80}$

\section{PREVENTION}

Because HBV infection is endemic in Korea, any person at high risk of liver disease or has suspected liver disease is recommended to have their HBsAg and anti-HBs statuses checked. ${ }^{14}$ CHB patients can transmit virus to others, and hence they should be counseled regarding how to modify their lifestyle so as to prevent $\mathrm{HBV}$ transmission. Epidemiologic studies found that the daily consumption of $40-80 \mathrm{~g}$ of alcohol is associated with liver damage and the progression of liver disease, ${ }^{83-88}$ and a long-term prospective cohort study of patients with chronic HBV infection showed that alcohol consumption increases the risks of liver cirrhosis and HCC development. ${ }^{57,59}$ No data are available on the threshold level of alcohol consumption required to significantly increase the risks of liver cirrhosis and HCC in patients with chronic HBV infection. In the general population, a daily alcohol intake of $24 \mathrm{~g}$ in males and $12 \mathrm{~g}$ in females significantly increases the risk of liver cirrhosis. ${ }^{89}$ So, abstinence or a very limited consumption of alcohol is recommended in patients with chronic 
HBV infection. ${ }^{89}$ According to a long-term prospective study of patients with chronic HBV infection, smoking also increases the risks of liver cirrhosis and HCC, and so non-smoking is recommended in patients with chronic HBV infection. ${ }^{57,59,90}$

Vertical infection is the most important route of HBV transmission. Following initiation of the HCV vaccination program, the HBsAg positivity rate among pregnant females was 3.32\% (308/9281) and the vertical transmission rate was 1.59\% (4/252) in 2014. Therefore, the vaccination program is effective for control of vertical transmission. ${ }^{91} \mathrm{HBV}$ immunoglobulin and vaccination after delivery can prevent $90-95 \%$ of vertical transmission to newborns from HBsAg-positive mothers. ${ }^{92-94}$ Therefore, such infants should receive $0.5 \mathrm{~mL}$ HBIG and scheduled HBV vaccination within 12 hours of birth and after. Adding immunoglobulin is more effective than vaccination only. The introduction of HBV vaccination did not result in the rate of HBV infection among newborns differing between breast- and formula-feeding HBsAg-positive mothers ( $0 \%$ vs. $3 \%$, respectively). ${ }^{95}$

In patients negative for $\mathrm{HBsAg}$ and anti-HBs, vaccination is recommended. Isolated anti-HBc positive patients negative for HBsAg and anti-HBs should consider vaccination, especially if liver function results are abnormal. As HBV is endemic in Korea, patients negative for HBsAg and anti-HBs should be vaccinated, ${ }^{92,93}$ particularly the household members and sexual partners of patients with chronic HBV infection, as such persons are at increased risk of HBV infection. ${ }^{96,97}$ Patients with chronic HBV infection are not candidates for vaccination because of its lack of effectiveness. Sexual partners who have not been tested for HBV serologic markers, have not completed the full immunization series, or who are negative for anti-HBs should use barrier protection methods, such as condoms. The three doses constituting the hepatitis B vaccine series administered intramuscularly at 0,1 , and 6 months induce a protective antibody response (anti-HBs $>10 \mathrm{mlU} / \mathrm{mL}$ ) in $>90 \%$ of recipients. Most non-responders (44-100\%) subsequently respond to a further three-dose revaccination. ${ }^{92,93}$

Although serologic testing for anti-HBs is not necessary after routine vaccination in immunocompetent adults, post-vaccination testing of anti-HBs status is recommended in some subjects, such as newborns of HBV-infected mothers or 9-18 months old young infants whose family members has CHB. Healthcare workers, dialysis patients, workers in dialysis units and operation rooms, immunocompromised subjects (e.g., HIV infection, hematopoietic stem cell transplants, patients with chemotherapy), and sexual partners of patients with chronic HBV infection should be tested 1-2 months after their completion of the HBV immunization se- ries. ${ }^{92,93}$ While anti-HBs levels can decline or disappear over several decades, vaccinated subjects remain protected against HBV infection and there is no need for booster vaccination in immunocompetent individuals. However, an anti-HBs level of $<10 \mathrm{mIU} / \mathrm{mL}$ in dialysis patients indicates an increased risk of HBV infection, and so a booster vaccination is needed if annual testing reveals an antiHBs level of $<10 \mathrm{mIU} / \mathrm{mL}^{92}$ This also applies to immunocompromised patients. ${ }^{92,93}$ A person without protective anti-HBs exposed to HBV-contaminated blood or body fluids should receive hepatitis B immunoglobulin ( $\mathrm{HBIG}, 0.06 \mathrm{~mL} / \mathrm{kg}$ ) and hepatitis B vaccine as soon as possible; preferably within $24 \mathrm{~h}$, otherwise postexposure prophylaxis should be initiated within 7 days for percutaneous exposure or within 14 days for sexual exposure. ${ }^{98}$

Coinfection with hepatitis A in HBV carriers increases the risk of mortality by 5.6 - to 29 -fold.$^{99}$ Therefore, hepatitis A vaccination is recommended for persons negative for the protective hepatitis $A$ virus antibody (anti-HAV). ${ }^{100}$

\section{[Recommendations]}

1. HBV vaccination is recommended for persons negative for HBsAg and anti-HBs. (A1)

2. Abstinence from alcohol and smoking is recommended for patients with chronic HBV infection. (A1)

3. Newborns of HBV-infected mothers should receive HBIG and hepatitis $B$ vaccine at delivery and complete the recommended vaccination series. (A1)

4. Hepatitis A vaccine should be given to patients with chronic HBV infection negative for anti-HAV. (A1)

\section{DIAGNOSIS AND INITIAL EVALUATION}

CHB is defined as the presence of $\mathrm{HBsAg}$ for longer than 6 months. The initial evaluation of CHB patients should include a thorough history-taking and physical examination, with emphasis on risk factors such as alcohol consumption or drug use, HAV, HCV, HDV coinfection, and family history of HBV infection and HCC. The causal relationship between HBV infection and liver disease has yet to be established. Appropriate longitudinal long-term follow-up is crucial for patients with CHB. Serologic tests, virologic tests, biochemical tests and/or liver biopsy are used to assess HBV replication and the degree of liver injury in patients with CHB. 


\section{Antigen/antibody test}

HBsAg immunoassay is a necessary and accurate test for diagnosis of CHB. By definition, patients who remain positive for HBsAg for longer than 6 months have progressed to chronic infection. Quantitative measurement of HBsAg is now possible and the combination of HBsAg quantification and HBV DNA level is an integral component of monitoring the response to antiviral therapy. Serologic tests, including anti-HBs and anti-HBC, can assist in screening of populations for HBV infection and differentiating among acute, chronic, and past infections. In acute HBV infection, HBsAg appears 1-10 weeks after exposure to HBsAg and disappears 4-6 months after recovering from HBV infection. ${ }^{101}$ Acute HBV infection is diagnosed by being HBsAg positive and anti-HBC IgM positive. Anti-HBC IgM is the only marker present during the window period, the interval between disappearance of HBsAg and appearance of anti-HBs.

Anti-HBc typically persists for life, but IgM anti-HBc is detectable for 6 months, and anti-HBc is detectable thereafter in patients with resolved acute HBV infection. IgM anti-HBc can be detected at low levels during chronic HBV infection. ${ }^{93}$ Persistently positive anti-HBC is shown when anti-HBs titer from the past HBV infection becomes undetectable over time or in cases with occult hepatitis B infection. ${ }^{102-105}$ Measurement of the serum HBV DNA level might be helpful in these settings. Patients with these serologic patterns should be followed with repeated testing of $\mathrm{HBsAg}$, anti-HBs, and anti-HBC for 3-6 months. Patients who recover from HBV infection will test negative for HBsAg and positive for anti-HBs and anti-HBC. Patients who respond adequately to hepatitis $B$ vaccines will test negative for anti- $\mathrm{HBC}$ and positive for anti$H B$, since anti-HBc emerges only after HBV infection and persists for life.

Laboratory tests for patients with $\mathrm{CHB}$ should include $\mathrm{HBeAg}$ and anti-HBe. HBeAg positivity generally indicates a high level of viral replication, and anti-HBe positivity a low level. Serum HBV DNA and AST/ALT levels are important parameters in HBeAg-negative patients. HBeAg-negative, anti-HBe-positive patients with a normal ALT level and an HBV DNA level of $<2,000 \mathrm{IU} / \mathrm{mL}(<10,000 \mathrm{cpm})$ may be in the inactive phase. These patients usually have mild or no liver necroinflammation and no or slow progression of fibrosis, but some patients with severe liver damage during the immune-active phase may present with a cirrhotic liver. HBeAg-negative CHB patients have an elevated ALT and an HBV DNA level of $>2,000 \mathrm{IU} / \mathrm{mL}$. HBe-negative $\mathrm{CHB}$ is associated with viral mutants in the $\mathrm{PC}$ and/or $\mathrm{BCP}$ regions that are unable to produce or produce only low levels of HBeAg. ${ }^{40}$ They have severe liver necroinflammation with a low rate of prolonged spontaneous disease remission and a high risk of subsequent complications, such as decompensated cirrhosis and HCC. ${ }^{106}$

Acute hepatitis A co-infection in chronic hepatitis B patients can result in increased icteric manifestation, longer recovery time, and increased risk of fulminant hepatic failure. Underlying chronic liver disease is an important risk factor for fulminant hepatic failure and death in patients with acute HAV infection. ${ }^{106-108}$ Therefore, CHB patients younger than 50 years should undergo testing for IgG anti-HAV, and all patients with a negative immune status for hepatitis A should receive HAV vaccine. Laboratory tests should include tests for coinfection with HCV and/or HIV in those at risk.

\section{Serum HBV DNA test}

Serum HBV DNA testing provides a direct measure of the level of viral replication. This quantification is essential for characterizing the status of infection, diagnosing the disease, making the decision to treat, and subsequent monitoring of patients. It is also important for predicting the risks of cirrhosis and HCC. Therefore, it should be applied to all patients diagnosed with CHB. The introduction of the international unit (IU) (1 IU is equivalent to $5.6 \mathrm{HBV}$ DNA copies) as a recommended reporting unit for HBV DNA has facilitated standardized reporting and comparison of serum HBV DNA levels. ${ }^{109}$ The methods used to quantify HBV DNA levels have evolved rapidly. Real-time PCR-based assays have been introduced and demonstrate both high sensitivity and a broad linear range $\left(10-10^{8} \mathrm{IU} / \mathrm{mL}\right)$ of quantification. ${ }^{110}$ The same test should be specified each time when monitoring HBV DNA levels for a given patient in clinical practice to ensure consistency.

\section{HBV genotypes}

HBV genotypes appear to influence the progression of disease, risk of HCC, and response to therapy (including interferon therapy). ${ }^{75,11,112}$ Some studies in Asia have suggested that genotype $C$ is associated more frequently with HBV reactivation, severe liver disease, and HCC than is genotype $B .^{111,113-115}$ The specific genotype has also been shown to affect the response to interferon therapy, with the rate of an antiviral response to pegylated interferon (peginterferon) therapy being higher for genotypes $A$ and $B$ than for genotypes $C$ and $D .{ }^{116}$ In CHB, examina- 
tion of genotyping is recommended selectively to help identify patients who might be at greater risk of disease progression, and routinely to determine the most appropriate candidates for peginterferon therapy. ${ }^{117}$ However, genotyping is recommended as being unnecessary in Korea because Korean patients are almost exclusively infected with genotype $\mathrm{C}$.

\section{Biochemical test}

Assessments of the severity of liver disease should include biochemical markers such as AST, ALT, gamma-glutamyl transpeptidase (GGT), alkaline phosphatase (ALP), prothrombin time (PT), and serum albumin. A progressive decline in the serum albumin level and prolongation of the PT, often accompanied by a decrease in the platelet count, are characteristically observed after cirrhosis develops. The serum ALT level has been commonly used in assessments of liver disease and as an important criterion for defining which patients are candidates for therapy. ${ }^{118}$ The ALT level is usually higher than that of AST, but the ratio may be reversed when the disease progresses to cirrhosis. HBVinfected patients with normal or mildly elevated ALT levels have been thought to have mild-to-no or significant necroinflammation on liver biopsy, respectively. However, there is no correlation between the degrees of liver cell necrosis and ALT level. ${ }^{119}$ ALT activity might also be affected by other factors such as body mass index, gender, abnormal lipid and carbohydrate metabolism, and uremia. ${ }^{19,120}$ Therefore, relying solely on the finding of elevated ALT as a prerequisite for treatment candidacy has limitations. Data from clinical studies have shown that the true normal level of ALT is significantly lower than the previously established limits: $40 \mathrm{IU} / \mathrm{mL}$ for males and $30 \mathrm{IU} / \mathrm{mL}$ for females. Moreover, data from cohort studies indicate that the upper limit of normal (ULN) ALT and AST levels should be decreased to $30 \mathrm{IU} / \mathrm{mL}$ for males and $19 \mathrm{IU} / \mathrm{mL}$ for females. ${ }^{119,120}$ Clinical studies have shown that patients with ALT levels of $40-45 \mathrm{IU} / \mathrm{mL}$ have a high risk of significant liver disease and mortality from complications. ${ }^{121}$ According to the treatment algorithm for CHB suggested by Keefee et al., serum ALT levels of 30 and $19 \mathrm{IU} / \mathrm{mL}$ for males and females, respectively, should be used as the ULN levels when deciding to commence treatment. ${ }^{117}$ Further prospective studies are needed to clarify this issue.

A recent prospective study in Korea involving 2,000 liver donors suggested that healthy serum ALT values should be $33 \mathrm{IU} / \mathrm{L}$ for males and $25 \mathrm{IU} / \mathrm{L}$ for females. ${ }^{122}$ Ninety thousand males and 40,000 females aged 35 to 59 years in the prospective NHS co- hort exhibited upper limits of AST and ALT values for prediction of liver diseases of $31 \mathrm{IU} / \mathrm{L}$ and $30 \mathrm{IU} / \mathrm{L}$, respectively. ${ }^{121}$

\section{Liver biopsy}

A liver biopsy is recommended for determining the degree of necroinflammation and fibrosis in patients with elevated ALT, an HBV DNA positive or both, because liver histology is useful when deciding whether or not to commence treatment. A liver biopsy is invasive but the rate of serious complications is very low $(1 / 4,000-10,000) .^{123}$ Several recent clinical studies found that $12-43 \%$ of patients with persistent normal ALT levels had histologic evidence of significant fibrosis or inflammation in a biopsy, particularly those older than $35-40$ years. ${ }^{116-121,124} \mathrm{~A}$ retrospective study of the relationship between ALT level and fibrosis in CHB patients reported similar results: of the $59 \mathrm{pa}$ tients with persistent normal ALT levels, $18 \%$ had stage 2 fibrosis and $34 \%$ had grade 2 or 3 inflammation, with $37 \%$ of all patients with persistent normal ALT levels having significant fibrosis and inflammation. ${ }^{125}$ Subgroup analysis also demonstrated that most of the patients with fibrosis had high normal ALT levels. These results indicate that the ALT level in CHB patients with high normal ALT levels should be interpreted in conjunction with the serum HBV DNA level, age, and liver histology results when deciding to commence treatment. Therefore, in HBsAg-positive patients with HBV DNA levels of $\geq 20,000 \mathrm{IU} / \mathrm{mL}$ and normal ALT levels, a liver biopsy should be considered in those older than 35 years since they are less likely to be in the immune-tolerance phase of infection. Treatment should be considered if a liver biopsy reveals fibrosis at stage 2 or greater and/or necroinflammation. When deciding whether to commence treatment in this patient population, it must be recognized that long-term therapy is likely to be needed due to the low probability of HBeAg seroconversion occurring within 1 year. A liver biopsy is usually not required in patients with clinical evidence of cirrhosis or when treatment is indicated irrespective of the grade of activity or the stage of fibrosis. This is because only a small portion of the liver is sampled, and the low intra/interobserver reliabilities. Therefore, the efficacy of noninvasive methods such as the Fibroscan device or serum markers in assessing fibrosis in CHB has increased.

\section{Noninvasive fibrosis test}

The severity of liver fibrosis and determination of ALT and HBV 
DNA levels have essential roles in treatment decisions. Noninvasive methods to estimate liver fibrosis have been developed and used. These methods include the aspartate aminotransferaseplatelet ratio index (APRI), AST/ALT ratio (AAR), Forns' fibrosis index (age, platelets, GGT, cholesterol), FIB-4 (platelets, ALT, AST, Age). Also, the FibroTest that uses indirect markers ( $\alpha-2$ macroglobulin, haptoglobin, r-globulin, apolipoprotein A1, and GGT), the FibroSpect II Enhanced Liver Fibrosis test that uses direct markers (Hepascore, FibroMeter, hyaluronic acid and tissue inhibitor of matrix metalloproteinase-1, 2) are available. ${ }^{126}$ The agespleen-platelet ratio index (ASPRI) is the most accurate in predicting liver fibrosis in chronic HBV infection. ${ }^{127}$ APRI is useful for diagnosis of not only for liver fibrosis but also liver cirrhosis, while FIB4 is useful for mild fibrosis. However FIB4 has limitations in terms of predicting fibrosis of stage F2 and above as it has low sensitivity and specificity. ${ }^{126}$

Transient elastography using Fibroscan ${ }^{\circledR}$ has a high degree of accuracy for assessment of advanced liver fibrosis. It is the most commonly used method for chronic liver diseases because of its noninvasiveness and high reproducibility. ${ }^{128}$

Fibroscan ${ }^{\circledR}$ can be perform rapidly (5 min) in the outpatient clinics of hospitals and produce a result immediately after the test. ${ }^{129,130}$ However, only procedures involving $\geq 10$ successful measurements are considered reliable. Moreover, a success rate (SR) of at least $60 \%$ and an interquartile range (IQR) of less than $30 \%$ of the median value are required (Interquartile range/median value (IQR/M), ${ }^{131}$ Fibroscan $^{\circledR}$ has limitations in subjects with ascites, obesity, or narrow intercostal spaces. Moreover, the system may yield false-positive results in subjects with acute hepatitis and extrahepatic biliary tract obstruction. ${ }^{132-134}$

Fibroscan ${ }^{\circledR}$ has greater diagnostic accuracy than APRI or FIB-4 for liver cirrhosis in a study that compared liver biopsy, $A A R$, APRI, Fibroscan ${ }^{\circledR}$, and FIB-4 in patients with chronic hepatitis. ${ }^{135,136}$ Also, Fibroscan ${ }^{\circledR}$ was more predictive of liver fibrosis and liver cirrhosis in a study that compared Fibroscan ${ }^{\circledR}$ and APRI in 567 subjects with chronic hepatitis (Area under Receiver Operating Characteristic: F3 0.849 vs. 0.812 , F4 0.902 vs. 0.707$){ }^{137}$

\section{Screening for hepatocellular carcinoma}

The initial evaluation of patients with CHB should include tests for HCC. Periodic surveillance is also needed in these patients to ensure early detection of HCC during follow-up. The issue of HCC is treated in detail in the "Practical Guidelines for Management of Hepatocellular Carcinoma 2014." ${ }^{138}$ Standard tools for HCC screening include measuring the $\alpha$-fetoprotein level and ultrasound. Magnetic resonance imaging and computed tomography might be preferred for some patients with severe cirrhosis or obesity, since ultrasound has poor sensitivity in those conditions. Patients at a high risk of HCC include those older than 40 years, ${ }^{139}$ patients with cirrhosis, those with a family history of HCC, and any carriers older than 40 years exhibiting persistent or intermittent ALT elevation, a high HBV DNA level $(>2,000 \mathrm{IU} / \mathrm{mL})$, or both. ${ }^{14}$ Keeffe et al. recently recommend earlier screening (at $30-$ 35 years of age or even younger) in Asian patients with presumed infection at the time of birth or in early childhood due to the higher risk of HCC in this patient population.

The use of antiviral therapies improves liver function and increases survival rates of patients with liver failure (liver decompensation).

Consistent inhibition of HBV replication with antiviral therapies delays progression of liver fibrosis, induces reversal of advanced liver fibrosis, reduces the incidence of liver cirrhosis, and prevents diseases including hepatocellular carcinoma in patients with advanced liver fibrosis or liver cirrhosis. ${ }^{140}$

Recently developed treatments can decrease the incidence of liver diseases or delay their progression but cannot prevent all possible complications. Therefore, surveillance and screening for hepatocellular carcinoma are required at regular intervals for early diagnosis and a complete recovery.

\section{[Recommendations]}

1. The initial evaluation of patients with $\mathrm{CHB}$ should include a thorough history-taking and physical examination, with emphasis on risk factors such as coinfection, alcohol consumption, and the family history of HBV infection and liver cancer. (A1)

2. Laboratory tests to assess liver disease should include the complete blood count (CBC), AST/ALT, ALP, GGT, bilirubin, albumin, creatinine, and PT. (A1)

3. Tests for HBV replication include $\mathrm{HBeAg} / \mathrm{anti}-\mathrm{HBe}$ and quantitative serum HBV DNA levels. A real-time PCR quantification assay is strongly recommended for quantifying the HBV DNA level. (A1)

4. An anti-HCV test is necessary to rule out coinfection with HCV. (B1)

5. An anti-HAV test is necessary in CHB patients younger than 50 years. $(A 1)$

6. Liver biopsy is useful for determining the degree of liver in- 
flammation and fibrosis. (A1)

7. Noninvasive tests such as serum markers and liver elasticity are used for diagnosis of the degree of liver fibrosis. (B1)

8. Standard tools for HCC screening include ultrasound and serum a-fetoprotein measurement. (A1)

\section{TREATMENT GOALS}

The goals of hepatitis B treatment are to decrease the mortality rate and increase the survival rate by alleviating hepatic inflammation and preventing the development of fibrosis, which ultimately reduces the frequency of progression of hepatitis to liver cirrhosis or HCC. ${ }^{141-145}$ The optimal treatment result would be the loss or seroconversion of HBsAg, but since intranuclear cccDNA persists despite treatment, complete clearance of HBV is almost impossible to achieve. ${ }^{146}$ This is why indices such as ALT level normalization, undetectable HBV DNA, loss or seroconversion of HBeAg, and histologic improvement are used (rather than the loss or seroconversion of $\mathrm{HBsAg}$ ) to predict the treatment response in the clinical context. Therefore, a realistic virologic goal of antiHBV therapy is the suppression of viral replication.

Most guidelines state that antiviral treatment is required for patients with acute liver failure, decompensated liver cirrhosis or in the acute phase of severe chronic HBV hepatitis regardless of HBV DNA and ALT levels, and the treatment has almost no complications, although few controlled studies have been performed. ${ }^{147}$ Antiviral therapy decreases the rate of recurrence of viral infection in patients who require liver transplantation. ${ }^{148}$ The HBV DNA and $\mathrm{HBeAg}$ levels in CHB are indices of viral replication and active hepatitis, respectively, and patients with $\mathrm{HBeAg}$-positive hepatitis $B$ with high levels of HBV DNA have an increased risk of developing liver cirrhosis or HCC. 57,59,74 Patients with disappearance or conversion of serum HBeAg have a low risk of liver cirrhosis and hepatocellular carcinoma, and so have a good prognosis. ${ }^{26,149}$

The loss or seroconversion of $\mathrm{HBeAg}$ during the natural course of hepatitis B or after IFN- $\alpha$ treatment indicates a favorable longterm outcome with a decreased probability of liver cirrhosis or HCC development. ${ }^{26,53,149,150}$ Therefore, clearance or seroconversion of $\mathrm{HBeAg}$ is an important goal of antiviral treatment in patients with $\mathrm{HBeAg}$-positive active hepatitis. A decrease in the HBV DNA level has recently been suggested to be even more important. The decrease in the HBV DNA level after antiviral treatment in active hepatitis with elevated HBV DNA levels results in histologic improvement, seroconversion of $\mathrm{HBeAg}$, and normalization of ALT levels, and thus a slowing of the progression of hepatitis. ${ }^{151,152}$ However, even in cases with HBV DNA levels of less than $10^{4}$ copies $/ \mathrm{mL}$, which is considered to be inactive hepatitis, the hepatitis can still progress to liver cirrhosis and HCC. Therefore, a decrease in HBV DNA to an undetectable level is recommended for patients on antiviral treatment. ${ }^{153}$

\section{[Recommendations]}

1. The treatment goals in hepatitis B are to decrease the mortality rate and increase the survival rate by alleviating hepatic inflammation and preventing the development of fibrosis, which would ultimately reduce the frequency of progression of hepatitis to liver cirrhosis or HCC. (A1)

2. To achieve HBsAg clearance, which is the ideal treatment goal, long-term maintenance of an undetectable HBV DNA level is recommended. (B1)

3. The ultimate treatment goals in patients with $\mathrm{HBeAg}$-positive hepatitis are normalization of the ALT level, undetectable HBV DNA level, and the clearance or seroconversion of $\mathrm{HBsAg}$ and $\mathrm{HBeAg}$. In patients with HBeAg-negative hepatitis the treatment goals are normalization of the ALT level, an undetectable HBV DNA level, and the clearance or seroconversion of HBsAg. (B1)

\section{TREATMENT INDICATIONS AND STRATEGIES}

Long-term viral suppression by drugs with potent antiviral activity and high genetic barrier to resistance is a current paradigm of antiviral treatment for CHB aimed at the prevention of disease progression and improvement of survival. Since eradication of HBV infection is rarely achieved with currently available drugs, long-term treatment is necessary in most cases. Treatment protocol should be individualized according to various factors: host factors such as mode of infection, disease status, and immunity; viral factors such as genotypes, prior antiviral treatment, mutation, and susceptibility level; and drug factors such local availability, cost, and reimbursement policy. ${ }^{35}$ The durations of currently available antiviral trials are insufficient to assess the effects of treatment on long-term survival. ${ }^{35}$ Long-term treatment with oral nucleos(t)ide analogs (NAs) ameliorates histologic abnormalities such as necroinflammation and/or fibrosis, both in HBeAg-positive $\mathrm{s}^{35,154,155}$ and HBeAg-negative ${ }^{155-158}$ CHB. Therefore, long-term antiviral therapy may prevent disease progression and reduce the 
risk of liver cirrhosis. ${ }^{145}$

\section{Immune tolerance phase}

Antiviral therapy is not indicated for patients in the immune-tolerant phase despite $\mathrm{HBeAg}$ positivity and a high level of HBV DNA, because of the benign natural course of the disease and such treatment results in minimal histologic changes. ${ }^{159}$

\section{[Recommendations]}

Patients in the immune-tolerant phase (HBeAg positive and persistently normal ALT level as recommended by this guideline rather than local laboratory ULNs) are not indicated for antiviral therapy. (B1)

\section{Chronic hepatitis B}

CHB patients with active viral replication and significant inflammation and/or fibrosis are appropriate targets for antiviral treatment. Early guidelines generally agreed that antiviral treatment could be recommended for CHB patients (especially those without liver cirrhosis) with serum HBV DNA level > 20,000 IU/mL and serum ALT level> 2 ULN. ${ }^{160,161}$ However, recent guidelines suggest that the indications of antiviral treatment should be expanded to those with lower serum HBV DNA levels and/or lower serum ALT levels. ${ }^{35,162,163}$

Serum HBV DNA level is a marker of viral replication and an indicator of the efficacy of antiviral treatment in individuals with CHB. Progression to cirrhosis in HBV-infected patients is reported to be strongly correlated with the level of circulating virus. ${ }^{57,59}$ However, an HBV DNA level of $10^{5} \mathrm{cpm}$ or $20,000 \mathrm{IU} / \mathrm{mL}$ was arbitrarily chosen by early guidelines as the cut-off level for indication of antiviral treatment. Some patients with lower serum HBV DNA levels (300-10 cpm), especially those with HBeAg negative hepatitis and/or cirrhosis, frequently show progression of liver disease and hence may need treatment. ${ }^{35,161,164}$ A serum HBV DNA level of $\geq 20,000 \mathrm{IU} / \mathrm{mL}$ has been suggested as the cut-off for HBeAg-positive CHB. ${ }^{164}$ However, the distinction between HBeAgnegative $\mathrm{CHB}$ and inactive carriers is not clear due to the fluctuating course of HBeAg-negative CHB. ${ }^{164}$ A population-based cohort study revealed increased risks of liver cirrhosis and HCC when the serum HBV DNA level exceeds $2,000 \mathrm{IU} / \mathrm{mL}^{57,59,165}$ therefore this level is widely accepted as the cut-off for indicating antiviral therapy.

Serum ALT has been used as a convenient surrogate marker for liver injury, and elevated serum ALT is indicated as a risk factor for disease progression in $\mathrm{CHB}^{57}$ A serum ALT level > 2 ULN was suggested as a suitable indication of antiviral treatment for $\mathrm{CHB}$ by early guidelines, especially in CHB patients without cirrhosis. ${ }^{160,161,166}$ However, an increased risk of developing liver cirrhosis and HCC has been documented in patients with mildly elevated serum ALT and even in those with serum ALT levels in the upper normal range. ${ }^{119,121,167}$ About two-thirds of CHB patients with mildly elevated ALT (1-2 ULN) show significant hepatic fibrosis (F2 or higher), ${ }^{168}$ and CHB patients with persistently normal ALT levels and HBV DNA levels of $>20,000 \mathrm{IU} / \mathrm{mL}$ may actually have significant fibrosis or inflammation, ${ }^{125,168,169}$ which are indications for antiviral therapy. A cohort study in Hong Kong demonstrated that the risk of liver-related complications in CHB patients was higher for ALT levels of 0.5-1 ULN and 1-2 ULN than for those $<0.5$ ULN. Thus, previous ALT criteria might exclude some patients with existing or potentially significant disease. ${ }^{170,171}$

Liver biopsy has three major roles: diagnosis, assessment of prognosis (disease staging), and assistance in making therapeutic decisions. ${ }^{172}$ In CHB, liver biopsy is especially useful for patients who do not meet definite criteria for treatment but still have a possible risk of significant disease. ${ }^{35}$ Age of the patient, serum HBV DNA level, serum ALT level, and family history of HCC should be considered before deciding whether to perform a biopsy. ALT and HBV DNA levels may miss cases of histologically significant disease, ${ }^{169}$ and so histologic confirmation should be considered, especially in patients of advanced age with serum AST/ALT levels in the upper normal range or higher.

Peginterferon- $\alpha$ and NAs including lamivudine, adefovir, clevudine, telbivudine, entecavir, and tenofovir, have been used for antiviral treatment of CHB. Drug of choice can differ according to various factors, including effectiveness, safety, risk of resistance, and cost of drugs, preference of patients and physicians, and any plans for pregnancy. ${ }^{35}$

Lamivudine and telbivudine are not preferred due to their weak antiviral potency and high frequency of drug resistance, unless a good response is predicted or the anticipated duration of treatment is short. Adefovir is not an ideal option due to its weak antiviral activity and high frequency of drug resistance after 48 weeks. There are insufficient long-term follow-up data on the efficacy and safety of clevudine. Entecavir and tenofovir are safe agents with potent antiviral effects and low frequency of drug resistance. Due to convenience of usage, peginterferon- $\alpha$ is preferred over interferon- $\alpha$. To date, there has been no report confirming the superiority of combination therapies over monotherapy 
in treatment-naïve patients.

Currently, monotherapy with entecavir, tenofovir, or peginterferon- $\alpha$ is the preferred initial therapy for CHB. Other NAs might be used in patients with good predictors of response, and can be continued or modified according to on-treatment response.

In patients treated with lamivudine, the predictive factors for a good response to therapy are increased initial serum ALT level and high histologic activity index score. ${ }^{118}$ During telbivudine treatment, a combination of pretreatment characteristics (low HBV DNA level; HBV DNA $<10^{9}$ copies/mL (HBeAg positive $\mathrm{CHB}$ ) or HBV DNA $<10^{7}$ copies/mL (HBeAg negative CHB) and ALT level $\geq$ 2 ULN ) plus non-detectable serum HBV DNA at treatment week 24 is suggested to be the strongest predictor of optimal outcomes at 2 years. ${ }^{173}$ Of CHB patients receiving lamivudine or telbivudine treatment, those with a virologic response at week 24 ( $<300$ copies $/ \mathrm{mL}$ ) achieved a high rate of HBeAg seroconversion at week $52 .^{125}$ Less resistance was reported in patients with low serum HBV DNA levels ( $<1,000$ copies $/ \mathrm{mL}$ ) at week 48 during long-term therapy with adefovir. ${ }^{157}$

\section{[Recommendations]}

\section{HBeAg-positive CHB}

1. $\mathrm{HBeAg}$ positive $\mathrm{CHB}$ patients with $\mathrm{HBV}$ DNA $\geq 20,000 \mathrm{IU} /$ $\mathrm{mL}$, plus serum AST or ALT $\geq 2$ ULN or significant histologic changes such as inflammation or fibrosis ( $\geq$ moderate necroinflammation; $\geq$ periportal fibrosis) on biopsy should be considered for treatment. (A1) Treatment can be delayed for 3-6 months if spontaneous $\mathrm{HBeAg}$ seroconversion is expected. (B2) However, patients with apparent or anticipated liver failure (i.e., those with jaundice, prolonged PT, hepatic encephalopathy, and ascites) should be treated promptly. (B1)

2. For those with HBV DNA $\geq 20,000 \mathrm{IU} / \mathrm{mL}$ and serum $A S T$ or ALT $<2$ ULN, observation or liver biopsy can be considered. Antiviral treatment is recommended for those showing subsequent elevation of serum ALT or AST, or significant histologic changes such as inflammation or fibrosis on biopsy. (A1)

3. Monotherapy with tenofovir, entecavir, or peginterferon- $a$ is preferred. (A1)

\section{HBeAg-negative CHB}

1. $\mathrm{HBeAg}$ negative $\mathrm{CHB}$ patients with $\mathrm{HBV}$ DNA $\geq 2,000 \mathrm{IU} / \mathrm{mL}$ plus serum AST or ALT $\geq 2$ ULN or significant pathologic changes such as inflammation or fibrosis on biopsy should be considered for treatment. (A1)

2. For those with HBV DNA $\geq 2,000 \mathrm{IU} / \mathrm{mL}$ and serum AST or ALT $<2$ ULN, observation or liver biopsy can be considered. Antiviral treatment is recommended for those showing subsequent elevation of serum ALT or AST, or significant pathologic changes such as inflammation or fibrosis on biopsy. (A1)

3. Monotherapy with tenofovir, entecavir, or peginterferon-a is preferred. (A1)

\section{Compensated liver cirrhosis}

Liver biopsy has been considered the gold standard for diagnosis of liver cirrhosis. Whereas use of liver biopsy is limited in real clinical practice; imaging studies such as CT, abdominal ultrasound, and MRI are helpful for the diagnosis of liver cirrhosis. Typical image findings of liver cirrhosis include nodular liver surface, splenomegaly, and the presence of intra-abdominal collateral vessels, which indicate increased portal venous pressure. If esophageal or gastric varices is observed in upper gastrointestinal endoscopy, liver cirrhosis can be diagnosed. ${ }^{174}$ With imaging studies, laboratory findings such as albumin, bilirubin, or prothrombin time and platelet values are helpful for the diagnosis of liver cirrhosis.

Patients with compensated cirrhosis and elevated serum HBV DNA (HBV DNA $\geq 2,000 \mathrm{lU} / \mathrm{mL}$ ) can benefit from treatment with long-term oral NAs, because such treatment may prevent disease progression $^{141}$ and the development of HCC. ${ }^{144,145,175-178}$ Compensated cirrhosis patients with a low viral load, although HBV DNA $<2,000 \mathrm{IU} / \mathrm{mL}$, are at considerable risk for HCC, and antiviral treatment in these patients was suggested to reduce the risk of $\mathrm{HCC}^{179}$ Antiviral therapy is recommended in $\mathrm{CH}-\mathrm{B}$ patients with significant hepatic fibrosis regardless of AST/ALT levels. $35,162,163,180$ The levels of AST/ALT should not be used as criteria for starting antiviral therapy in patients with liver cirrhosis, because they already have significant hepatic fibrosis and frequently have nearly normal AST/ALT levels.

In a cohort of $\mathrm{HBeAg-positive} \mathrm{liver} \mathrm{cirrhosis} \mathrm{patients,} \mathrm{long-term}$ follow-up data after interferon- $\alpha$ therapy showed that the HBeAg seroconversion rate was similar (67\% vs. $60 \%$, respectively) but the ALT normalization rate ( $62 \%$ vs. $47 \%$ ) and HBsAg loss rate ( $23 \%$ vs. $3 \%$ ) were better in the interferon- $\alpha$ treated group than in the control group. ${ }^{181}$ Interferon- $\alpha$ treatment in cirrhotic patients requires careful monitoring because it may cause acute exacerbation of hepatitis, which leads to hepatic failure. ${ }^{182}$ After treating 
CHB patients with peginterferon- $\alpha-2 b$ alone or in combination with lamivudine for 52 weeks, the virologic response rate (as indicated by HBeAg seroconversion and an HBV DNA level of $<10,000$ copies $/ \mathrm{mL}$ ) was superior in those with cirrhosis than in those without cirrhosis (35\% vs. $14 \%$, respectively). ${ }^{183}$ However, acute exacerbation of hepatitis (33\% vs. $12 \%$, respectively) and requirement for dose reduction (63\% vs. $30 \%$ ) were more common in cirrhotic patients than in noncirrhotic patients. ${ }^{183}$ Therefore, interferon- $\alpha$ can be used with caution in cirrhotic patients with preserved liver function.

In patients with decompensated liver cirrhosis, long-term lamivudine treatment significantly reduced the complications and hepatocellular carcinoma compared to placebo. However, the benefit was less in patients with lamivudine resistance. ${ }^{141}$ Entecavir treatment of patients with advanced hepatic fibrosis or cirrhosis for 48 weeks showed improvements in the liver histology in 57\%, 59\%, and $43 \%$ of patients with $\mathrm{HBeAg}$-positive, HBeAg-negative, and lamivudine-resistant $\mathrm{CHB}$, respectively. ${ }^{184} \mathrm{~A}$ study including a small number $(n=40)$ of patients showed that telbivudine effectively decreased HBV DNA levels in patients with compensated liver cirrhosis, and HBV DNA was undetectable after 48 weeks of telbivudine treatment in $92.5 \%{ }^{185}$ A study comparing the effects of clevudine treatment for 48 weeks found that the virologic response rate (HBV DNA <1,000) $(87.1 \%$ vs. $71.4 \%$, respectively) and biochemical response rate $(83.9 \%$ vs. $80.9 \%)$ did not differ significantly between patients with $\mathrm{CHB}(n=21)$ and those with liver cirrhosis $(n=31) .{ }^{186}$ A phase III clinical trial of tenofovir adopting paired liver biopsy at baseline and at week 240 revealed that, of the $96(28 \%)$ patients with liver cirrhosis (Ishak score 5 or 6 ) at baseline, 71 (74\%) no longer had liver cirrhosis ( $\geq 1$ unit decrease in score) at follow-up biopsy. ${ }^{187}$

Since long-term antiviral therapy is generally required in patients with liver cirrhosis, the AASLD and EASL guidelines recommend the use of entecavir or tenofovir due to their potent antiviral efficacy and high genetic barrier to drug resistance.

\section{Decompensated liver cirrhosis}

Decompensated liver cirrhosis is defined as liver cirrhosis complicated with ascites, variceal bleeding, hepatic encephalopathy, or jaundice. ${ }^{174}$ Patients with decompensated liver cirrhosis should be treated at an institution that can provide appropriate management for complications of liver cirrhosis. Liver transplantation should be considered in patients with decompensated liver cirrhosis. Oral NAs may improve hepatic function ${ }^{142}$ and decrease the need for liver transplantation in Child-Turcotte-Pugh (CTP) class C cirrhosis. ${ }^{188}$ The use of interferon- $\alpha$ in patients with decompensated liver cirrhosis is contraindicated due to the risk of serious complications, such as infection or hepatic failure. ${ }^{189}$ Lamivudine treatment for longer than 6 months was shown to improve or stabilize liver function and prolong the time to liver transplantation in patients with decompensated liver cirrhosis. ${ }^{190-192}$ A study comparing the effects of telbivudine and lamivudine in patients with decompensated liver cirrhosis found a higher rate of HBV DNA undetectability ( $47 \%$ vs. $36 \%$, respectively) and a lower viral breakthrough rate ( $29 \%$ vs. $39 \%$, respectively) in the telbivudine group than in the lamivudine group. ${ }^{193}$ A study of the effect of adefovir in lamivudine-resistant cirrhotic patients $(n=101)$ found that the virologic response rate was lower in decompensated cirrhotic patients $(n=53)$ than in compensated cirrhotic patients $(n=48)(50.9 \%$ vs. 83.3\%, respectively), whereas ALT normalization and HBeAg loss did not differ between the two groups. ${ }^{194}$

A randomized study comparing the effects of entecavir $(1 \mathrm{mg} /$ day) and adefovir (10 mg/day) in patients with decompensated liver cirrhosis found that the rates of HBV DNA undetectability at weeks 24 and 48 were higher in the entecavir group than in the adefovir group (week 24, 49\% vs. 16\%, respectively; week 48 , $57 \%$ vs. $20 \%$ ), while HBeAg seroconversion at week 48 did not differ significantly between the two groups (6\% vs. $10 \%) .{ }^{195}$ Entecavir therapy showed improvement of the CTP score (to $\geq 2$ ) in almost half (27/55) of treatment-naïve patients with decompensated liver cirrhosis $(n=55)$ and a 1-year transplantation-free survival rate of $87.1 \%{ }^{142}$

A randomized trial comparing the effects of tenofovir $(n=45)$, tenofovir plus emtricitabine $(n=45)$, and entecavir $(n=22)$ in patients with decompensated liver cirrhosis showed that the requirement for early withdrawal of drug $(6.7 \%, 4.4 \%$, and $9.1 \%$, respectively) and elevation of serum creatinine $(8.9 \%, 6.7 \%$, and $4.5 \%$ ) did not differ among the three groups. The rates of HBV DNA undetectability at week 48 were $70.5 \%, 87.8 \%$, and $72.7 \%$, respectively, and those of $\mathrm{HBeAg}$ loss/seroconversion were $21 \% / 21 \%, 27 \% / 13 \%$, and $0 \% / 0 \%$. ${ }^{143}$

Because prompt treatment is required in patients with decompensated liver cirrhosis, oral antiviral therapy is the treatment of choice if HBV DNA is detectable by PCR tests. ${ }^{35,162,180}$ An antiviral drug with a potent antiviral efficacy and high genetic barrier to drug resistance should be used. Since clinical improvement often requires 3-6 months of antiviral therapy, progression to hepatic failure is possible even during antiviral therapy in some patients. Hence, liver transplantation should be considered together with 
antiviral treatment. ${ }^{192}$ Pre- and post-transplantation antiviral therapy has been reported to reduce the risk of reactivation of hepatitis after liver transplantation.

\section{[Recommendations]}

\section{Compensated liver cirrhosis}

1. Antiviral therapy should be performed if HBV DNA level is $\geq 2,000 \mathrm{lU} / \mathrm{mL}$ regardless of AST/ALT levels. (A1)

2. Antiviral therapy can be considered when HBV DNA is HBV DNA is $<2,000 \mathrm{IU} / \mathrm{mL}$ to reduce the risk of decompensation regardless of AST/ALT levels. (C1)

3. Oral antiviral therapy is recommended. Monotherapy with tenofovir or entecavir is preferred. (A1)

4. Peginterferon-a may be used with careful monitoring of impairment of liver function and drug side effects in patients with compensated liver cirrhosis with preserved liver function. (B2)

\section{Decompensated liver cirrhosis}

1. Prompt antiviral therapy is recommended if HBV DNA is detectable by PCR test regardless of AST/ALT levels. (B1)

2. Oral antiviral therapy is recommended. Monotherapy with tenofovir or entecavir is preferred. (A1)

3. The use of peginterferon- $a$ is contraindicated due to the risk of serious complications, such as hepatic failure. (A1)

4. Liver transplantation should be considered. (B1)

\section{TREATMENT MONITORING}

\section{Monitoring prior to antiviral treatment}

After diagnosis and initial evaluation of patients with $\mathrm{CHB}$, their serum HBV DNA, ALT, HBeAg, and anti-HBe levels should be regularly monitored until they are considered for treatment. $35,168,196,197$ The HBV genotype test is not recommended in Korea because most Korean patients are known to have HBV genotype C. ${ }^{198,199}$

Applying a quantitative HBsAg (qHBsAg) assay before or during antiviral treatment may assist prediction of the treatment response. ${ }^{200-203} \mathrm{HBsAg}$ is generated by transcription and translation of cccDNA or HBV DNA integrated into the genome, and can be detected on the surface of infective virions and on circular and linear non-infective particles. The quantity of $\mathrm{HBsAg}$ (qHBsAg) showed a positive correlation with the amount of cccDNA in he- patocytes, which enabled a standardized qHBsAg assay. ${ }^{204,205} \mathrm{HB}$ sAg quantity is highest during the immune-tolerant phase (4.5$5.0 \log _{10} \mathrm{IU} / \mathrm{mL}$ ), starts to decrease during the immune-active phase (3.0-4.5 $\left.\log _{10} \mathrm{IU} / \mathrm{mL}\right)$, and decreases gradually after $\mathrm{HBeAg}$ seroconversion. The HBsAg quantity is lowest in the immune-control phase $\left(1.5-3.0 \log _{10} \mathrm{IU} / \mathrm{mL}\right)$, and starts to increase in HBeAgnegative CHB (2.5-4.0 $\left.\log _{10} \mathrm{IU} / \mathrm{mL}\right){ }^{206-208}$ During long-term lamivudine treatment, a low level before treatment and large decrement during treatment of qHBsAg were predictors of $\mathrm{HBsAg}$ seroconversion. Several studies reported that the decrement of qHBsAg correlated with the decrement of HBV DNA level. ${ }^{203,209,210}$

\section{[Recommendations]}

1. Chronic hepatitis (HBeAg positive or negative)

1) In patients with persistently normal AST/ALT levels, liver function should be tested and serum HBV DNA should be measured by real-time PCR at 2-6-month intervals, plus $\mathrm{HBeAg}$ status (HBeAg and anti-HBe) should be checked every 6-12 months. (C1)

2) If AST/ALT levels increase above the normal limit, liver function should be tested every 1-3 months, and serum HBV DNA should be measured by real-time PCR plus HBeAg status should be checked every 2-6 months. (C1)

2. Compensated liver cirrhosis Liver function should be tested every 2-6 months, and serum HBV DNA should be measured by real-time PCR plus HBeAg status should be checked every 2-6 months. (C1)

3. Decompensated liver cirrhosis

Liver function should be tested every 1-3 months, and serum HBV DNA should be measured by real-time PCR plus HBeAg status should be checked every 2-6 months. (C1)

\section{Monitoring during antiviral treatment}

\section{NAs}

In a compliant patient with a primary non-response (decrease in serum HBV DNA of $<2 \log _{10} \mathrm{IU} / \mathrm{mL}$ after 6 months or more of NA treatment), changing to or adding a more-potent drug should be considered. Serum HBV DNA should be measured every 1 to 3 months for the first few months to ascertain the virologic response, and then every 3 to 6 months. Serum HBV DNA reduction to an undetectable level by real-time PCR (i.e., $<10-15 \mathrm{IU} / \mathrm{mL}$ ) should ideally be achieved to avoid resistance. Serum HBV DNA monitoring is thus critical to detect treatment failure. 
Table 4. Nucleos(t)ide analogue dosage adjustment for adult patients with altered creatinine clearance

\begin{tabular}{|c|c|c|}
\hline Creatinine clearance $(\mathrm{mL} / \mathrm{min})^{\mathrm{a}}$ & \multicolumn{2}{|l|}{ Recommended dose } \\
\hline \multicolumn{3}{|l|}{ Nucleoside analogues } \\
\hline \multicolumn{3}{|l|}{ Lamivudine } \\
\hline$\geq 50$ & \multicolumn{2}{|l|}{100 mg q 24 h } \\
\hline $30-49$ & \multicolumn{2}{|l|}{$100 \mathrm{mg}$ first dose, then $50 \mathrm{mg} \mathrm{q} 24 \mathrm{~h}$} \\
\hline $15-29$ & \multicolumn{2}{|l|}{$100 \mathrm{mg}$ first dose, then $25 \mathrm{mg} \mathrm{q} 24 \mathrm{~h}$} \\
\hline $5-14$ & \multicolumn{2}{|l|}{$35 \mathrm{mg}$ first dose, then $15 \mathrm{mg} \mathrm{q} 24 \mathrm{~h}$} \\
\hline$<5$ & \multicolumn{2}{|l|}{$35 \mathrm{mg}$ first dose, then $10 \mathrm{mg} \mathrm{q} 24 \mathrm{~h}$} \\
\hline \multicolumn{3}{|l|}{ Telbivudine } \\
\hline$\geq 50$ & \multicolumn{2}{|l|}{$600 \mathrm{mg} \mathrm{q} 24 \mathrm{~h}$} \\
\hline $30-49$ & \multicolumn{2}{|l|}{$600 \mathrm{mg} \mathrm{q} 48 \mathrm{~h}$} \\
\hline$<30$ (not requiring dialysis) & \multicolumn{2}{|l|}{$600 \mathrm{mg} \mathrm{q} 72 \mathrm{~h}$} \\
\hline End-stage renal disease ${ }^{b}$ & \multicolumn{2}{|l|}{$600 \mathrm{mg} \mathrm{q} 96 \mathrm{~h}$} \\
\hline Entecavir & NA naïve & Lamivudine refractory/resistant \\
\hline$\geq 50$ & $0.5 \mathrm{mg} \mathrm{q} 24 \mathrm{~h}$ & $1 \mathrm{mg} \mathrm{q} 24 \mathrm{~h}$ \\
\hline $30-49$ & $0.25 \mathrm{mg} \mathrm{q} 24 \mathrm{~h}$ or $0.5 \mathrm{mg} \mathrm{q} 48 \mathrm{~h}$ & $0.5 \mathrm{mg} \mathrm{q} 24 \mathrm{~h}$ or $1 \mathrm{mg} \mathrm{q} 48 \mathrm{~h}$ \\
\hline $10-29$ & $0.15 \mathrm{mg} \mathrm{q} 24 \mathrm{~h}$ or $0.5 \mathrm{mg} \mathrm{q} 72 \mathrm{~h}$ & $0.3 \mathrm{mg} \mathrm{q} 24 \mathrm{~h}$ or $1 \mathrm{mg} \mathrm{q} 72 \mathrm{~h}$ \\
\hline $\begin{array}{l}<10 \text { or hemodialysis }{ }^{\text {b }} \text { or continuous } \\
\text { ambulatory peritoneal dialysis }\end{array}$ & $0.05 \mathrm{mg} \mathrm{q} 24$ h or $0.5 \mathrm{mg} \mathrm{q} 7$ days & $0.1 \mathrm{mg} \mathrm{q} 24 \mathrm{~h}$ or $1 \mathrm{mg} \mathrm{q} 7$ days \\
\hline \multicolumn{3}{|l|}{ Nucleotide analogues } \\
\hline \multicolumn{3}{|l|}{ Adefovir } \\
\hline$\geq 50$ & \multicolumn{2}{|l|}{$10 \mathrm{mg} \mathrm{q} 24 \mathrm{~h}$} \\
\hline $20-49$ & \multicolumn{2}{|l|}{$10 \mathrm{mg} \mathrm{q} 48 \mathrm{~h}$} \\
\hline $10-19$ & \multicolumn{2}{|l|}{$10 \mathrm{mg} \mathrm{q} 72 \mathrm{~h}$} \\
\hline$<10$ & \multicolumn{2}{|l|}{ No recommendation } \\
\hline Hemodialysis $^{b}$ & \multicolumn{2}{|l|}{10 mg q 7 days following dialysis } \\
\hline \multicolumn{3}{|l|}{ Tenofovir } \\
\hline$\geq 50$ & \multicolumn{2}{|l|}{$300 \mathrm{mg} \mathrm{q} 24 \mathrm{~h}$} \\
\hline $30-49$ & \multicolumn{2}{|l|}{$300 \mathrm{mg} \mathrm{q} 48 \mathrm{~h}$} \\
\hline $10-29$ & \multicolumn{2}{|l|}{300 mg q 72-96 h } \\
\hline$<10$ with dialysis ${ }^{c}$ & \multicolumn{2}{|c|}{300 mg q 7 days or after a total of approximately $12 \mathrm{~h}$ of dialysis } \\
\hline$<10$ without dialysis & \multicolumn{2}{|l|}{ No recommendation } \\
\hline
\end{tabular}

${ }^{\mathrm{a}}$ Calculated using ideal (lean) body weight.

${ }^{\mathrm{b}}$ Administer after hemodialysis.

'Generally once weekly assuming three hemodialysis sessions per week of approximately $4 \mathrm{~h}$ duration. Administer following completion of dialysis.

Peginterferon therapy resulted in a more significant reduction in qHBsAg levels than NA therapy. ${ }^{211,212}$ However, a low pretreatment qHBsAg level and greater qHBsAg decline were reported to be positive predictors of a sustained virologic response. ${ }^{213,214}$ In CHB patients receiving 10 years of NA therapy, low baseline qHBsAg levels $(<1,000 \mathrm{IU} / \mathrm{mL})$ and a greater rate of HBsAg reduction ( $>0.166 \log _{10} \mathrm{IU} / \mathrm{mL} /$ year) were predictive of $\mathrm{qHBsAg}$ seroclear- ance, strengthening the prognostic role of HBsAg measurements during NA therapy. ${ }^{203}$ Compliance and antiviral-resistance mutations should be monitored in patients who develop virologic breakthrough while receiving NA, and an appropriate rescue therapy should be initiated if necessary. ${ }^{215-219}$

Most NAs are excreted through the kidney, and hence dose adjustment is required in patients with renal insufficiency (Table 4), ${ }^{35}$ 
and regular monitoring of renal function should be performed in patients receiving adefovir or tenofovir. Several reports have associated tenofovir with bone loss in patients with HIV, although there was no consistent report during tenofovir monotherapy. ${ }^{220-222}$

Studies of entecavir-related carcinogenicity are in progress. There have been few reports on telbivudine-related myositis; however, monitoring of the serum creatine kinase (CK) level is recommended due to the possibility of CK elevation. ${ }^{223-226}$ For clevudine prescription, serum CK level and related symptoms should be monitored due to clevudine-related myositis and CK elevation. $^{227-229}$

\section{Peginterferon- $a$}

The serum CBC and ALT level of patients receiving peginterferon- $\alpha$ should be tested monthly. Serum HBV DNA should be measured after 3-6 months of treatment to verify the primary response. For response prediction, qHBsAg assay can be used before the treatment and at 12 and 24 weeks of treatment. All patients treated with peginterferon- $\alpha$ should be checked for the known adverse effects of interferon at every visit.

\section{HBeAg-positive CHB}

Patients should be tested for HBeAg and anti-HBe at 6 and 12 months during the treatment, and at 6 months post treatment. After cessation of treatment, patients should be monitored for 6-12 months to check if additional treatment is required. There is a high probability of HBsAg loss if serum HBV DNA becomes undetectable during treatment. HBeAg-positive patients who achieve $\mathrm{HBeAg}$ seroconversion with peginterferon- $\alpha$ require a long followup due to the possibility of $\mathrm{HBeAg}$ reversion or development of HBeAg-negative CHB. HBsAg loss should be checked at 6-month intervals after HBeAg seroconversion if serum HBV DNA is undetectable. The qHBsAg assay assists in predicting the treatment response. ${ }^{230,231}$ In case of a primary non-response (failure to achieve a $1 \log _{10}$ reduction in serum HBV DNA from baseline after 3 months of peginterferon- $\alpha$ treatment), peginterferon- $\alpha$ treatment should be stopped and replaced by a NA. Several studies recommend that peginterferon- $\alpha$ treatment should be stopped if qHBsAg does not decrease below 20,000 IU/mL after 24 weeks of treatment, which is predictive of non-response. ${ }^{230,231}$

\section{HBeAg-negative CHB}

HBeAg-negative patients should be monitored similarly to
HBeAg-positive patients during 48 weeks of treatment. A virologic response with a serum HBV DNA level of $<2,000 \mathrm{IU} / \mathrm{mL}$ is generally associated with remission of the liver disease. ${ }^{231}$ Undetectable serum HBV DNA by real-time PCR is the ideal off-treatment sustained response, with a high probability of HBsAg loss in the longer term. HBsAg should be checked at 6-month intervals if HBV DNA is not detectable. qHBsAg levels after 12 and 24 weeks of treatment as well as serum HBV DNA levels can be major predictive factors of a treatment response..$^{210,232,233}$ Several studies recommend treatment interruption when qHBsAg after 12 weeks of treatment does not decrease, together with $a<2 \log _{10}$ serum HBV DNA level. ${ }^{234,235}$

\section{[Recommendations]}

1. During treatment with NAs, liver function should be tested and serum HBV DNA should be measured by real-time PCR every 1-3 months, plus $\mathrm{HBeAg}$ status (HBeAg and antiHBeAg) should be checked every 3-6 months. (C1) qHBsAg assay may assist prediction of the treatment response and identification of cases in which discontinuation of antiviral therapy may be attempted. (C1)

2. During treatment with peginterferon- $\alpha, C B C$ and ALT level should be measured monthly. Serum HBV DNA should be measured by real-time PCR at 1- to 3-month intervals, plus $\mathrm{HBeAg}$ and anti-HBe should be checked at 6 and 12 months during the treatment and at 6 months post-treatment. (C1) qHBsAg assay should be performed before, at 12 and 24 weeks during the treatment and at the end of treatment. (B1)

3. After identification of a complete virologic response, serum HBV DNA should be measured by real-time PCR after 3-6 months and then retesting should be performed at 2-3 months after $\mathrm{HBeAg}$ seroclearance is achieved. (C1)

4. Patients who develop virologic breakthrough while receiving a NA should be monitored for compliance and antiviralresistance mutations. (A1)

5. During antiviral therapy, close monitoring for side effects of each drug is mandatory. (A1)

\section{Monitoring after antiviral treatment}

The response to antiviral treatment persists in some patients, while others relapse. Non-responders should prepare for the deterioration of liver function. Therefore, regular monitoring is needed to check for the durability of the treatment response, relapse, and liver function. 


\section{[Recommendations]}

1. During the first year after the cessation of antiviral treatment, liver function should be monitored and serum HBV DNA should be measured by real-time PCR every 1-3 months, plus $\mathrm{HBeAg}$ and anti-HBe should be checked at 3to 6-month intervals. Beyond 1 year after the cessation of antiviral treatment, liver function and serum HBV DNA by real-time PCR should be tested every 3-6 months to detect viral relapse. (C1)

2. For early detection of HCC, ultrasound and serum a-fetoprotein measurement should be performed regularly. (A1)

\section{CESSATION OF TREATMENT}

\section{HBeAg-positive CHB}

Although the ideal goal of treatment is to achieve HBsAg loss, the primary endpoint when treating patients with $\mathrm{HBeAg}$-positive hepatitis is to achieve HBeAg seroconversion. Undetectable serum HBV DNA by real-time PCR and HBeAg seroconversion are strongly correlated with favorable biochemical and histologic responses. NA can be stopped when HBeAg seroconversion is achieved and antiviral treatment has been maintained at least for 12 months. ${ }^{236}$ However, cessation should be decided carefully since $40-90 \%$ of patients developed reactivation of $\mathrm{HBeAg}$-positive or -negative hepatitis after HBeAg seroconversion induced by NA treatment. ${ }^{237-240} \mathrm{HBsAg}$ should be tested at 6-month intervals after $\mathrm{HBeAg}$ seroconversion. HBsAg loss is rarely observed after NA therapy; however, low baseline qHBsAg levels and greater rate of $\mathrm{HBsAg}$ reduction were highly predictive of $\mathrm{HBsAg}$ seroclearance. ${ }^{203}$ Peginterferon- $\alpha$ is generally administered for 48 weeks, and its efficacy was confirmed in a recent double-blind, randomized controlled study. ${ }^{241,242}$

\section{HBeAg-negative CHB}

The recommended duration of peginterferon- $\alpha$ treatment in patients with HBeAg-negative hepatitis is 48 weeks, but the optimal treatment duration for NA is unknown, and cessation of treatment should be individually decided according to the clinical treatment response and the baseline severity of the liver disease. Treatment with NA should be continued until the loss of HBsAg.
Treatment discontinuation can be considered if undetectable serum HBV DNA has been documented on three separate occasions 6 months apart. ${ }^{163}$ However, close follow up is required due to the high probability of reactivation (29.7-91.0\%) after treatment discontinuation. ${ }^{239,243-245}$ Peginterferon- $\alpha$ administration for 48 weeks is recommended.

\section{Liver cirrhosis}

Long-term treatment is required in patients with cirrhosis. In HBeAg-positive patients with compensated cirrhosis, treatment discontinuation can be considered when NA is administered for at least a further 12 months after HBeAg seroconversion. Treatment discontinuation can be considered after achievement of HBsAg loss in HBeAg-negative patients. Monitoring for viral relapse and acute exacerbation of disease is mandatory after discontinuation. Longterm treatment should be planned in patients with decompensated cirrhosis, including the possibility of liver transplantation.

\section{[Recommendations]}

\section{1. $\mathrm{HBeAg}$-positive $\mathrm{CHB}$}

1) The optimal duration of treatment with a NA is unclear, although the ideal goal is HBsAg loss, and alternative goals are $\mathrm{HBeAg}$ loss and seroconversion. NAs should be administered at least 12 months after serum HBV DNA is undetectable and $\mathrm{HBeAg}$ seroclearance or seroconversion is attained. (B1)

2) Peginterferon should be administered for 48 weeks. (A1)

\section{HBeAg-negative CHB}

1) Although the optimal duration of treatment with NA is unclear, discontinuation of NA treatment may be considered when HBsAg loss is demonstrated. (A1)

2) Peginterferon- $a$ should be administered for at least 48 weeks. (B1)

3. Liver cirrhosis

Patients require long-term treatment. (B1)

\section{DEFINITIONS OF RESPONSE AND PREDIC- TORS OF RESPONSE}

\section{Definitions of treatment responses (Table 5)}

The definitions of responses to antiviral therapy vary according 
to the type of therapy.

\section{NA}

A primary non-response to NA is defined as a decrease of less than $2 \log _{10} \mathrm{IU} / \mathrm{mL}$ in serum HBV DNA from baseline after 6 months of therapy. A complete virologic response is defined as undetectable serum HBV DNA by real-time PCR. A partial virologic response is defined as a decrease in serum HBV DNA of more than $1 \log _{10} \mathrm{IU} / \mathrm{mL}$ but with serum HBV DNA still being detectable by real-time $P C R \cdot{ }^{246} \mathrm{~A}$ partial virologic response should be assessed to determine whether to modify the current therapy after 24 weeks of treatment for moderately potent drugs or drugs with a low genetic barrier to resistance (lamivudine and telbivudine), and after 48 weeks of treatment for highly potent drugs, drugs with a high genetic barrier to resistance, and drugs with late emergence of resistance (e.g., entecavir, adefovir, and tenofovir).

Virologic breakthrough is defined as a confirmed increase in serum HBV DNA of more than $1 \log _{10} \mathrm{IU} / \mathrm{mL}$ relative to the nadir serum HBV DNA during therapy. This usually precedes a biochemical breakthrough, which is characterized by an increase in ALT level after an initial normalization. If a virologic breakthrough develops in a compliant patient, antiviral-resistant mutations should be tested for.

Genotypic resistance is defined as the presence of HBV mutations in serum that confers resistance to the antiviral agent, and phenotypic resistance is defined as the presence of HBV mutations that decrease susceptibility to antiviral drugs in an in vitro test. Cross- resistance is defined as an HBV mutation induced by one antiviral agent that confers resistance to other antiviral agents.

HBV resistance to NAs is characterized by the presence of HBV variants with amino-acid substitutions that confer reduced susceptibility to the administered NA. Such resistance may result in primary treatment failure or virologic breakthrough during therapy.

\section{Peginterferon- $a$}

A primary non-response to peginterferon- $\alpha$ is defined as a decrease of less than $1 \log _{10} \mathrm{IU} / \mathrm{mL}$ in serum HBV DNA from baseline after 3 months of therapy. A virologic response is defined as an HBV DNA level of less than 2,000 IU/mL after 6 months of therapy. A serologic response is defined by HBeAg seroconversion in patients with $\mathrm{HBeAg}$-positive CHB.

\section{Predictors of treatment responses}

Certain baseline and on-treatment predictors of the subsequent treatment response have been identified. The predictors of the responses to existing antiviral therapies at various time points vary according to the agent.

\section{NAs}

Pretreatment factors predictive of HBeAg seroconversion are a low viral load (serum HBV DNA of $<10^{7} \mathrm{IU} / \mathrm{mL}$ ), high ALT level $(<3$ ULN), and high inflammatory activity score in a liver biopsy (at least $A 2)^{247} \mathrm{~A}$ high pretreatment ALT level is the most important

Table 5. Definitions of responses to antiviral therapy of CHB patients

\begin{tabular}{ll}
\hline Category of response & \\
\hline Nucleos(t)ide analogues & Decrease in serum HBV DNA $<2 \log _{10} \mathrm{IU} / \mathrm{mL}$ after 6 months of therapy \\
\hline Primary non-response & Decrease in serum HBV DNA of more than $2 \log _{10} \mathrm{IU} / \mathrm{mL}$ but detectable HBV DNA by real-time PCR assay \\
\hline $\begin{array}{l}\text { Partial virologic response } \\
\text { Complete virologic response }\end{array}$ & Decrease in serum HBV DNA to an undetectable level by real-time PCR assay \\
\hline $\begin{array}{l}\text { Virologic breakthrough } \\
\text { Biochemical breakthrough }\end{array}$ & Increase in serum HBV DNA of more than $1 \log _{10} \mathrm{IU} / \mathrm{mL}$ compared to nadir (lowest value) \\
\hline Genotypic resistance & Detection of HBV mutations known to confer antiviral resistance during antiviral therapy \\
\hline Phenotypic resistance & Decreased susceptibility (in vitro testing) to inhibition by antiviral drugs associated with genotypic \\
\hline Cross resistance & resistance \\
\hline Peginterferon alpha & HBV mutation selected by one antiviral agent that also confers resistance to other antiviral agents \\
\hline Primary non-response & Decrease in serum HBV DNA <1 log $1 \mathrm{IU} / \mathrm{mL}$ after 3 months of peginterferon alpha therapy \\
\hline Virologic response & Decrease in serum HBV DNA of less than 2,000 IU/mL after 6 months of peginterferon alpha therapy \\
\hline Serologic response & HBeAg seroconversion in patients with HBeAg-positive chronic hepatitis B \\
\hline
\end{tabular}


predictor of the outcome of treatment with lamivudine, adefovir, or telbivudine. ${ }^{118}$ During treatment with lamivudine, adefovir, or telbivudine, a virologic response at 24 or 48 weeks (undetectable serum HBV DNA by a real-time PCR assay) is associated with lower incidences of antiviral resistance (i.e., higher probability of a sustained virologic response) and $\mathrm{HBeAg}$ seroconversion in $\mathrm{HBeAg}$ positive patients. ${ }^{156,225,248}$ HBV genotype does not influence the response to any NA. In a study of the ability of qHBsAg assay to predict a treatment response, both $\mathrm{HBsAg} \leq 2 \log \mathrm{IU} / \mathrm{mL}$ and reduction by $>1 \log$ from baseline at the end of treatment had a $78 \%$ positive predictive value and $96 \%$ negative predictive value for a 12-month sustained post-treatment response (HBV DNA $\leq 200 \mathrm{lU} /$ $\mathrm{mL}$ ) to lamivudine in HBeAg-negative patients. ${ }^{249}$ During telbivudine treatment, a decline in serum HBsAg levels $\left(\geq 1 \log _{10} \mathrm{IU} / \mathrm{mL}\right.$ ) in the first year was related to a greater likelihood of achieving HBsAg clearance at year 3. ${ }^{202}$ Serum HBsAg levels $\leq 2 \mathrm{log} \mathrm{IU} / \mathrm{mL}$ at treatment week 104 are highly predictive of sustained virologic response to telbivudine at 2 years off-treatment. ${ }^{250}$

\section{Peginterferon- $a$}

Pretreatment factors predictive of $\mathrm{HBeAg}$ seroconversion in HBeAg-positive patients are a high ALT level, low viral load, a high inflammatory activity score in a liver biopsy, and HBV genotype. ${ }^{183,251}$ There is no consensus among previous reports for patients with $\mathrm{HBeAg}$-negative hepatitis, but generally a pretreatment high ALT level, young age, and female gender are reported to be associated with a favorable treatment response. ${ }^{124,252}$

A decrease in serum HBV DNA to less than 20,000 IU/mL after 12 weeks of treatment is associated with a $50 \%$ probability of $\mathrm{HBeAg}$ seroconversion in HBeAg-positive patients and with a $50 \%$ probability of a sustained response in HBeAg-negative patients. ${ }^{124,253} \mathrm{~A}$ decrease in $\mathrm{HBeAg}$ at week 24 may predict $\mathrm{HBeAg}$ seroconversion. ${ }^{118,253}$ In HBeAg-positive patients, HBsAg levels $<1,500 \mathrm{IU} / \mathrm{mL}$ at week 12 during peginterferon alfa-2a therapy were associated with high rates of posttreatment response, but treatment discontinuation is indicated in all patients with $\mathrm{HBsAg}$ $>20,000 \mathrm{IU} / \mathrm{mL}$ at week $24 .{ }^{230,231} \mathrm{In} \mathrm{HBeAg}$-negative patients, at week 12 of peginterferon- $\alpha$ treatment, the combination of a decline in serum HBV DNA $<2 \log _{10}$ copies $/ \mathrm{mL}$ and absence of a decrease in HBsAg levels is predictive of a poor response. ${ }^{234,235} \mathrm{HBV}$ genotypes $A$ and $B$ are associated with a better response to interferon- $\alpha$ than genotype $C$, in terms of $H B e A g$ seroconversion and HBsAg loss. ${ }^{254-257}$ However, knowledge of the HBV genotype has a poor predictive value in individual cases, and currently genotype alone should not determine the choice of treatment.

\section{ANTIVIRAL RESISTANCE}

Both entecavir and tenofovir are highly potent antivirals with an excellent resistance profile, and to which antiviral resistance develops rarely. Nonetheless, the development of antiviral resistance is one of the most important factors predicting the success or failure of CHB treatment. The emergence of antiviral resistance results in resumption of active viral replication that had been suppressed after the initiation of antiviral therapy, and can impair biochemical or histologic improvement. ${ }^{258}$ Therefore, the prevention, early diagnosis, and management of antiviral resistance may significantly affect the long-term prognosis of CHB patients undergoing antiviral therapy. ${ }^{141}$

\section{Mechanism of antiviral resistance and definitions}

It is estimated that more than $10^{11}$ new virions are produced daily in a human body with active HBV replication. ${ }^{259}$ Some of the HBV mutants that emerge naturally during active replication are selected by the selection pressure exerted by the human immune system or antiviral therapy. Those mutants with maximal replication become predominant during antiviral therapy. Primary antiviral-resistant mutants usually have a low replication capacity, but recover to the level of the wild-type virus when compensatory mutations appear. ${ }^{260}$ In addition, a higher fold resistance to antiviral therapy allows increased replication of the mutant virus. A genetic barrier is defined as the number of genetic mutations needed to develop antiviral resistance, with a higher genetic barrier indicating a lower risk of resistance. ${ }^{261}$ The antiviral potency of drugs also influences the development of resistance. Drugs with a lower antiviral potency or potent antiviral activity have lower risks of antiviral resistance, because the former is associated with a lower selection pressure and the latter with complete suppression of the virus. However, drugs with intermediate potency have an increased risk of resistance because residual viremia during treatment may result in selection of mutants with good replication fitness. ${ }^{262}$ Clinically, the HBV DNA level, history of prior antiviral treatment, duration of treatment, serum drug concentration (peak and trough), and patient compliance are the most important factors influencing the development of resistance. Definitions of terms associated with antiviral resistance are provided in Table 5.

\section{Mutations conferring resistance to antiviral agents}

Antiviral agents for the treatment of HBV infection are classified 
Table 6. Cumulative incidences of development of antiviral resistance according to representative studies.

\begin{tabular}{|c|c|c|c|c|c|c|c|c|}
\hline \multirow{2}{*}{ Antiviral agent } & \multicolumn{8}{|c|}{ Resistance rate (\%) } \\
\hline & Year 1 & Year 2 & Year 3 & Year 4 & Year 5 & Year 6 & Year 7 & Year 8 \\
\hline Lamivudine $^{\mathrm{a}}$ & 24 & 42 & 53 & 70 & $\geq 65$ & & & \\
\hline \multicolumn{9}{|l|}{ Adefovir } \\
\hline in treatment-naïve patients ${ }^{*}$ & 0 & 3 & 11 & 18 & 29 & & & \\
\hline in lamivudine-resistant patients ${ }^{c}$ & $4.4-18$ & $18.4-25$ & 34.3 & 52.3 & 65.6 & & & \\
\hline \multicolumn{9}{|l|}{ Adefovir + lamivudine } \\
\hline in lamivudine-resistant patients ${ }^{d}$ & 1 & 2 & 4 & 4 & & & & \\
\hline \multicolumn{9}{|l|}{ Entecavir } \\
\hline in treatment-naïve patients ${ }^{\mathrm{e}}$ & 0.2 & 0.5 & 1.2 & 1.2 & 1.2 & 1.2 & & \\
\hline in lamivudine-refractory patients ${ }^{f}$ & 6 & 15 & 36 & 47 & 51 & & & \\
\hline Tenofovir $^{\text {tg }}$ & 0 & 0 & 0 & 0 & 0 & 0 & 0 & 0 \\
\hline Telbivudine $^{\text {h }}$ & $2.7-4.4$ & $10.8-25.1$ & & & & & & \\
\hline Clevudine ${ }^{i}$ & 2.3 & 24.4 & & & & & & \\
\hline
\end{tabular}

${ }^{*} \mathrm{HBeAg}$-negative patients.

${ }^{\dagger}$ Emtricitabine was added in patients with detectable HBV DNA after 72 weeks of treatment.

${ }^{a}$ Modified and updated from Lai et al. Clin Infect Dis $2003^{265}$ and Lok et al. Gastroenterology 2003. ${ }^{266}$

${ }^{\text {b}}$ From Hadziyannis et al. Gastroenterology 2006. ${ }^{157}$

'From Lee et al. Hepatology $2006^{280}$, Yeon et al. Gut $2006^{281}$, and Lee et al. Antivir Ther 2010. ${ }^{216}$

${ }^{d}$ From Lampertico et al. Gastroenterology 2007. ${ }^{277}$

${ }^{e 8 f}$ Tenney et al. Hepatology 2009. ${ }^{274}$

${ }^{9}$ Lampertico P et al. J Hepatol 2015. ${ }^{283}$

hFrom Lai et al. N Engl J Med $2007^{225}$ and Liaw et al. Gastroenterology 2009. ${ }^{226}$

'Yoon et al. J Clin Gastroenterol 2011. ${ }^{270}$

into two groups: NAs and nucleotide analogues. Cyclopentenes (entecavir) and L-nucleoside analogues (lamivudine, telbivudine, and clevudine) are NAs, while acyclic phosphonates (adefovir and tenofovir) are nucleotide analogues. ${ }^{263}$ The incidences of resistance to individual antiviral drugs are shown in Table 6.

\section{Nucleoside analogues}

1) L-nucleoside analogues (lamivudine, telbivudine, and clevudine) Mutations at rtM204 are the primary resistance mutations to lamivudine, telbivudine, and clevudine. ${ }^{264-267}$ The rtM204V and rtM204I mutations involve the substitution of methionine with valine and isoleucine, respectively, at codon 204 of the reverse transcriptase gene. Originally these were termed YMDD mutations, but that terminology is no longer recommended. ${ }^{268} \mathrm{rt}$ M204V emerges during lamivudine treatment, but rtM204I can develop during the administration of lamivudine, telbivudine, or clevudine. ${ }^{225,226,269,270}$

An rtM204V mutant may commonly accompany rtL180M but not rtM204I. ${ }^{271}$ These mutants are sensitive to adefovir and teno- fovir, but they exhibit cross-resistance to entecavir and show an eightfold decrease in sensitivity. The rtA181T mutation has been detected in $5 \%$ of lamivudine-resistant patients. ${ }^{272}$ The mutants exhibit cross-resistance to adefovir but remain sensitive to entecavir. $^{272}$

\section{2) Cyclopentene (entecavir)}

Resistance to entecavir develops via a two-hit mechanism. rtL180M and rtM204V first develop as background mutations, and then additional mutations such as rtT184L/F/A/M/S///C/G, rtS202G///C, or rtM250V/I/L develop as primary resistance mutations to entecavir, resulting in a marked decrease in drug susceptibility ${ }^{261,273}$ rtl169T is a compensatory mutation that increases the fold resistance of rtT184, rtS202, and rtM250 mutants. Since multiple genetic mutations are needed to develop high-level resistance to entecavir (high genetic barrier), the resistance rate in treatment-naïve subjects is very low. However, a resistance rate as high as $51 \%$ has been reported after 5 years of treatment in lamivudine-refractory subjects. ${ }^{274}$ 


\section{Nucleotide analogues}

1) Adefovir

rtN236T and rtA181V/T are the primary resistance mutations to adefovir. $^{157,275}$ The levels of resistance of rtN236T and rtA181T to adefovir are 7- to 10-fold and 2.5- to 5-fold, respectively, compared to the wild-type virus. ${ }^{263,272}$ rtA181T can be detected in subjects receiving lamivudine monotherapy or combination therapy comprising adefovir plus lamivudine. ${ }^{276,277}$

\section{2) Tenofovir}

Clinically significant resistance mutations to tenofovir have not been reported in patients with HBV monoinfection. However, rtA194T can decrease the susceptibility to tenofovir 10-fold in the presence of rtL180M+rtM204V, according to a case study of a patient with HBV and HIV coinfection. ${ }^{278}$

\section{Management of antiviral resistance}

Prior antiviral resistance predisposes individuals to subsequent viral mutations and limits the choice of rescue therapies due to the presence of cross-resistance. ${ }^{263,279}$ Although antiviral agents without cross-resistance may be selected, the resistance to the rescue therapy is greater than that of treatment-naïve subjects. ${ }^{279-281}$

It is therefore critical to initially choose the antiviral agent with the lowest resistance rate.

Appropriate monitoring during treatment is needed to detect virologic and biochemical breakthroughs as early as possible. Antiviral resistance testing is required when a virologic or biochemical breakthrough is detected in subjects with good compliance. If genotypic resistance is confirmed, rescue therapy should be initiated before the clinical situation deteriorates. ${ }^{282}$

\section{[Recommendations]}

General principles of antiviral resistance management:

1. An antiviral resistance test should be performed when virologic breakthrough occurs, especially in cases with good compliance. (A1)

2. Rescue antiviral therapy should be started as soon as possible upon emergence of resistant variants, especially when viral breakthrough is detected and genotypic resistance is confirmed. (A1)

\section{MANAGEMENT OF ANTIVIRAL-RESISTANT CHB}

\section{Management of lamivudine resistance}

\section{Tenofovir}

Tenofovir shows potent antiviral activity against lamivudine-resistant HBV. ${ }^{284-287}$ In a retrospective study that compared a tenofovir monotherapy group with a tenofovir-plus-lamivudine combination-therapy group for 197 patients (105 naïve patients and 92 patients resistant to lamivudine), the HBV undetectable rate (HBV DNA $<20 \mathrm{IU} / \mathrm{mL}$ ) was not different significantly in the HBeAgnegative group (94\% vs. $96 \%$, respectively) and HBeAg-positive group ( $67 \%$ vs. $83 \%$, respectively). ${ }^{285}$ One comparative study involving lamivudine-resistant CHB patients coinfected with HIV found that the HBV DNA level after 48 weeks was $<10^{5} \mathrm{cpm}$ in $100 \%$ of patients in the tenofovir group but in only $44 \%$ of patients in the adefovir group, with the difference being statistically significant. ${ }^{284}$ In a study that compared a tenofovir monotherapy group with a tenofovir-plus-emtricitabine combination-therapy group including 280 patients with lamivudine-resistant HBV, the HBV undetectable rate $(69 \mathrm{IU} / \mathrm{mL})$ was not significantly different (85.8\% vs. $83.5 \%$, respectively) and tenofovir-resistant HBV was not detected in either group after 96 weeks. ${ }^{287}$ No prospective study has compared tenofovir monotherapy with tenofovir-pluslamivudine combination-therapy. However, in a retrospective study that compared a tenofovir monotherapy group $(n=71)$ with a tenofovir-plus-lamivudine combination-therapy group $(n=54)$ among 125 patients with a history of antiviral treatment, the cumulative HBV undetectable rate $(<20 \mathrm{IU} / \mathrm{mL})$ differed significantly after 3 years $\left(90.7 \%\right.$ vs. $96.0 \%$, respectively). ${ }^{286}$

\section{Adefovir}

Adefovir has shown antiviral activity against lamivudine-resistant HBV. The development of resistance to adefovir was significantly less frequent in the adefovir-plus-lamivudine combinationtherapy group than in the adefovir-monotherapy group in longterm studies. ${ }^{288,289}$ No comparative study of tenofovir monotherapy and adefovir plus NA combination therapy has been performed. However, combination therapy with lamivudine plus adefovir results in a higher adefovir resistance rate (2.2-13.3\%) compared to tenofovir (0\%). ${ }^{290-293}$ Few studies of combination therapy with adefovir plus other NAs such as entecavir, telbivudine, and clevudine instead of lamivudine are available; moreover, the studies reported to date have involved small populations. One retrospective study 
involving 91 lamivudine-resistant CHB patients consisted of adefovir monotherapy $(n=29)$, adefovir and lamivudine combination therapy ( $n=30$ ), adefovir and entecavir $1 \mathrm{mg}$ combination therapy $(\mathrm{n}=32)$ found that the HBV DNA undetectable rate $(<60 \mathrm{IU} / \mathrm{mL})$ was not significantly different ( $48.2 \%$ vs. $76.7 \%$ vs. $87.5 \%$, respectively) but the adefovir resistance rate differed significantly (27.6\% vs. $13.3 \%$ vs. $0 \%$, respectively) after 24 months. ${ }^{292}$ In a small prospective study that compared an adefovir-plus-telbivudine combination-therapy group $(n=21)$ with an adefovir-monotherapy group ( $n=21)$, the HBV undetectable rate ( $<300$ copies/ $\mathrm{mL}$ ) was $38.5 \%$ and $0 \%$, respectively, and adefovir resistant virus was detected in $9.6 \%$ of patients in the adefovir-monotherapy group after 96 weeks. ${ }^{294}$ Two small prospective studies revealed that the reduction in HBV load was greater in the adefovir-plustelbivudine combination-therapy group than the adefovir-plus-lamivudine combination-therapy group. ${ }^{295,296}$

\section{Entecavir}

Entecavir at a dose of $1.0 \mathrm{mg}$ exhibits antiviral activity in lamivudine-resistant CHB patients. ${ }^{297,298}$ In a study of monotherapy with $1.0 \mathrm{mg}$ entecavir compared with adefovir-plus-lamivudine combination therapy in patients with lamivudine resistance, monotherapy showed a significantly higher viral breakthrough rate (17.6\% vs. $2.0 \%$ ) but comparable antiviral efficacy. ${ }^{291,299-301}$ Two retrospective studies of combination treatment with adefovir and entecavir $1 \mathrm{mg}$ in patients with lamivudine resistance revealed a significantly lower viral breakthrough rate (0-2.6\%) than adefovir combination therapy with another NA or entecavir $1 \mathrm{mg}$ monotherapy. ${ }^{202,302}$

\section{Peginterferon alpha}

In a study that compared a group receiving peginterferon alpha group for 48 weeks $(n=155)$ with a group receiving adefovir for 72 weeks $(n=80)$ among patients with compensated liver disease, the HBV DNA undetectable rate $(<80 \mathrm{IU} / \mathrm{mL})$ was lower $(10.6 \%$ vs. $22.5 \%)$, but the HBeAg seroconversion rate was higher $(14.8 \%$ vs. $3.8 \%$ ) significantly in the peginterferon alpha group. ${ }^{303}$ There was no significant difference in the HBeAg seroconversion rate and $\mathrm{HBV}$ undetectable rate in another study that compared the efficacy of peginterferon alpha between patients with wild-type virus and lamivudine-resistant virus. ${ }^{304}$

\section{[Recommendations]}

\section{Switch to tenofovir or combine tenofovir with a nucleoside}

analogue. (A1)

2. Consider combination of adefovir and a nucleoside analogue if use of tenofovir is contraindicated. (B1)

3. Stop lamivudine and consider treatment with peginterferon- $a$ if the patient has compensated liver function. (B2)

\section{Management of telbivudine resistance}

Few data related to telbivudine resistance are available. In a study in which telbivudine- resistant patients or viral breakthrough patients without resistance $(n=68)$ were treated with adefovir, over $70 \%$ of patients had an HBV level of $\leq 300$ copies $/ \mathrm{mL}$ after 12 months. ${ }^{305}$ Treatment based on tenofovir could be a therapeutic option, but comparative data for telbivudine and lamivudine are insufficient. The general principles of management of telbivudine resistance are similar to those for the management of lamivudine resistance.

\section{[Recommendation]}

\section{Follow the recommendations for the management of lami-} vudine-resistant CHB. (B2)

\section{Management of clevudine resistance}

Few data related to clevudine resistance are extant. The general principles of treatment of patients with clevudine resistance are similar to those of lamivudine resistance.

\section{[Recommendation]}

1. Follow the recommendations for the management of lamivudine-resistant CHB. (B2)

\section{Management of adefovir resistance}

The HBV mutations rtN236T and rtA181V/T result in primary resistance to adefovir. ${ }^{157,275}$ rtA181T can also be detected in subjects receiving lamivudine monotherapy or combination therapy of adefovir plus lamivudine. ${ }^{272,275-27,306} \mathrm{rtN236T}$ and rtA181T result in 7to 10 -fold and 2.5- to 5 -fold, respectively, greater resistance to adefovir relative to the wild-type virus. ${ }^{263,272}$ The double mutation (rtA181T/V and rtN236T) results in a 5.2- to 18-fold reduction in sensitivity to adefovir. ${ }^{272}$ Patients with persistent drug-resistant HBV viremia are more likely to suffer hepatitis flares, disease progression, and death than those without drug-resistant $\mathrm{HBV}^{307}$ 
The rate of adefovir-resistance is $20 \%$ and $29 \%$ after 5 years of adefovir treatment in $\mathrm{HBeAg}$-positive and $\mathrm{HBeAg}$-negative treatment naïve patients, respectively. ${ }^{157,308}$ The risk of genotypic resistance to adefovir increases in patients resistant to lamivudine compared to treatment-naïve patients. After 48 weeks of adefovir treatment, the rate of resistance was $18 \%$ and $0 \%$ in lamivudineresistant and treatment-naïve patients, respectively. ${ }^{280}$ Moreover, the rate of adefovir resistance can reach $22-25 \%$ after 2 years of treatment in lamivudine-resistant patients. ${ }^{281,309}$

\section{Lamivudine}

In vitro studies showed that the rtN236T mutant remained sensitive to lamivudine, while the rtA181/V mutant exhibited reduced susceptibility to lamivudine. ${ }^{272}$

In adefovir-resistant patients without prior exposure to lamivudine, ${ }^{310}$ the combination of telbivudine/adefovir and monotherapy with entecavir was associated with virologic response rates of $73.3 \%$ and $57.1 \%$, respectively, and $\mathrm{HBeAg}$ seroconversion rates of only $20 \%$ and $0 \%$, respectively.

In patients who developed adefovir resistance in the presence of lamivudine resistance, the combination of lamivudine/adefovir resulted in a virologic breakthrough rate of $7.3 \%$ and primary nonresponse rate of $51.2 \%$ at 1 year, and a very low virologic response rate (HBV DNA $<60 \mathrm{IU} / \mathrm{mL}$ ) of $12.2 \%{ }^{311}$

\section{Entecavir}

In vitro studies have shown that HBV with adefovir-mono-resistant mutations may be susceptible to entecavir. ${ }^{272}$ However, HBV with lamivudine-resistance mutations have cross-resistance to entecavir. Thus, in patients resistant to both adefovir and lamivudine, entecavir monotherapy was associated with a suboptimal virologic response (42\%) and high rate of additional resistance to entecavir (17\%) at 1 year. In these patients, even the combination of entecavir/adefovir resulted in a very low virologic response rate of $31.1 \%$ and $44.7 \%$ at 1 and 2 years, respectively. ${ }^{302,312,313}$

\section{Tenofovir}

Tenofovir has about 30-fold higher antiviral efficacy than adefovir. ${ }^{314-316}$ However, in vitro studies show that HBV strains expressing the adefovir resistance-associated substitutions, rtA181T/V and/or rtN236T, demonstrate reduced susceptibility to tenofovir, ranging from 2.9 - to 10 -fold that of the wild-type virus. ${ }^{276,317-319}$ Nonetheless, several studies have suggested that tenofovir disoproxil fumarate (TDF) monotherapy is efficacious in patients with lamivudine-resistant, entecavir-resistant, adefovir-refractory, and adefovir-resistant HBV. ${ }^{287,315,316,320,321}$ An European trial comparing TDF and emtricitabine (FTC) plus TDF in patients with adefovir-refractory CHB demonstrated that the rate of virologic response did not differ between TDF and FTC/TDF therapies; $82 \%$ vs. $84 \%$ at 3.5 years. ${ }^{315,316}$ A randomized trial comparing TDF monotherapy and TDF/entecavir combination therapy in patients with adefovirresistant HBV showed a similar virologic response rate of $62 \%$ and $63.5 \%$, respectively, at 48 weeks. ${ }^{322}$ However, in a subgroup of patients who had double adefovir-resistance mutations; i.e., both rtA181T/V and rtN236T, the decrease in serum HBV DNA levels tended to be less in the TDF group than in the TDF/entecavir group (-3.03 $\log _{10} \mathrm{IU} / \mathrm{mL}$ vs. $-3.31 \log _{10} \mathrm{IU} / \mathrm{mL}, P=0.38$ )

\section{[Recommendations]}

1. Switch to tenofovir or combine tenofovir with entecavir. (B1)

2. Combination therapy with tenofovir and a nucleoside analogue other than entecavir. (B2)

3. Consider combination of adefovir and a nucleoside analogue if use of tenofovir is contraindicated. (B2)

\section{Management of entecavir resistance}

In patients with lamivudine-resistant HBV, the rate of entecavir resistance increases to $51 \%$ after 5 years of entecavir treatment, in contrast to a $1.2 \%$ resistance rate in NA-naïve patients. ${ }^{273,274}$ The difference is because the entecavir resistance barrier is lowered by the initial selection of the lamivudine-resistance HBV mutation, rtM204V/I. ${ }^{323}$ In vitro studies have shown that susceptibility to entecavir is decreased by $10-250$-fold when one of the entecavir resistance-associated substitutions at rtT184, rtS202, or rtM250 is present in combination with rtM204V/I, and by $>500$ fold when two or more of these mutations are present. ${ }^{273,323}$

In vitro studies suggest that entecavir-resistant HBV mutants are susceptible to adefovir and TDF. ${ }^{324,325}$ A few cohort studies have reported the efficacy of adefovir or TDF in patients with entecavir-resistant HBV. ${ }^{326-329}$

\section{Adefovir}

No randomized trial of adefovir treatment in patients with entecavir resistance has been performed. Adding adefovir to entecavir would be more reasonable for reducing adefovir resistance and improving the antiviral efficacy. ${ }^{330}$ Combination therapy of adefovir plus lamivudine could also be considered. ${ }^{331}$ However, small retrospective cohort studies demonstrated that the virologic re- 
sponse rate was $24-51 \%$ at 1 or 2 years of treatment with the combination of adefovir and entecavir or lamivudine. ${ }^{326-328,332}$

\section{Tenofovir}

Tenofovir does not show cross-resistance to entecavir in vitro and has excellent potency. ${ }^{333}$ A Korean multicenter randomized trial was performed in HBV patients with entecavir resistance-associated mutations comparing TDF monotherapy and TDF and entecavir combination therapy for 48 weeks. ${ }^{334}$ All patients had at least one entecavir-resistance mutation: $r t T 184 \mathrm{~A} / \mathrm{C} / \mathrm{F} / \mathrm{G} / \mathrm{I} / \mathrm{L} / \mathrm{S}$, rtS202G, and rtM250L/V, in addition to rtM204V/l. At week 48, the proportion of patients with HBV DNA $<15 \mathrm{IU} / \mathrm{mL}$, the primary efficacy endpoint, was not significantly different between the TDF and TDF+entecavir groups (71\% vs. 73\%; $P=0.81)$. Virologic breakthrough occurred in one patient on TDF, which was attributed to poor drug adherence. At week 48, six and three patients in the TDF and TDF+entecavir groups, respectively, retained their baseline resistance mutations $(P>0.99)$. None developed additional resistance mutations. Safety profiles were comparable in the two groups.

\section{[Recommendations]}

1. Switch to tenofovir or combine tenofovir with entecavir. (B1)

2. Consider combination of adefovir and a nucleoside analogue if use of tenofovir is contraindicated. (B2)

\section{Management of tenofovir-resistance}

No tenofovir-resistant patients have been reported to date. $A$ prospective study found no HBV strain resistant to TDF after up to 8 years of treatment. ${ }^{335} \mathrm{An}$ in vitro study reported that A194T in combination with lamivudine resistance mutations, rtL180M and rtM204V, might account for TDF resistance in HBV. ${ }^{278}$ However, other in vitro studies have reported inconsistent results. ${ }^{336,337}$

\section{Management of multiple drug resistance}

Multidrug resistance is defined as resistance to two or more groups of antiviral drugs; i.e., L-nucleoside (lamivudine, telbivudine, clevudine), cyclopentane (entecavir), or nucleotide analogue (adefovir and tenofovir). ${ }^{279,318}$

Interferon has not been used for the management of patients with multidrug-resistant HBV. However, there is also no suggestion that such patients have decreased susceptibility to interferon.
In vitro clonal analyses showed that multidrug-resistance mutations usually reside in the same viral genome, ${ }^{279,318}$ and replicating clones with lamivudine- and adefovir- associated mutations had $>50$-fold reduced susceptibility to combination of lamivudine and adefovir. $^{338,339}$ In fact, a cohort study demonstrated that in patients with HBV resistant to lamivudine and adefovir, combination therapy with these two drugs was not effective and indeed was inferior to entecavir monotherapy in terms of suppressing HBV DNA. ${ }^{311}$ However, the response to entecavir monotherapy was not optimal. Entecavir was markedly less effective in patients refractory to both lamivudine and adefovir than in those with lamivudine monoresistance, ${ }^{313}$ or treatment-naïve patients. ${ }^{273}$

In patients with multidrug-resistant $\mathrm{HBV}$, a combination of the two most potent drugs, TDF and entecavir, would likely prevent the emergence of resistance to TDF. ${ }^{340}$ However, two randomized trials in patients with resistance to entecavir and/or adefovir in addition to lamivudine resistance showed no difference in virologic response between TDF monotherapy and TDF and entecavir combination therapy, and no emergence of additional resistance mutations. ${ }^{322,334}$ Based on their comparable antiviral efficacy, extremely low risk of TDF resistance, lower cost, and potentially better safety profile, TDF monotherapy would be a reasonable option for the treatment of entecavir-resistant patients.

\section{[Recommendations]}

1. Switch to tenofovir or combine tenofovir with entecavir. (B1)

2. Consider combining adefovir with a nucleoside analogue if use of tenofovir is contraindicated. (B2)

\section{RESPONSE-GUIDED THERAPY DURING ORAL ANTIVIRAL DRUG TREATMENT FOR CHB}

Once antiviral-resistant HBV mutants have been selected, they are persistently archived (retained in the virus population) in cccDNA in the nucleus of infected cells, even if treatment is stopped, which can limit future therapeutic options. ${ }^{341,342}$ Preventing the development of resistance is important to ensure long-term therapeutic efficacy. Persistence of viral replication during antiviral treatment is associated with the emergence of drug resistance. ${ }^{225,343,344}$ Therefore, evaluation of the treatment response using sensitive PCR assays to measure serum HBV DNA levels every 3-6 months is recommended.

The response patterns of oral antivirals during treatment are 
classified as complete response, partial response and primary non-response. Complete response is defined as undetectable serum HBV DNA by PCR during treatment. Partial virologic response is defined as detectable serum HBV DNA with a more than $2 \log _{10}$ $\mathrm{IU} / \mathrm{mL}$ reduction in HBV DNA level from baseline. ${ }^{345}$ A primary non-response is defined as a reduction in the serum HBV DNA level of less than $2 \log _{10} \mathrm{IU} / \mathrm{mL}$ at week $24 .{ }^{35}$ Virologic breakthrough is defined as an increase in serum HBV DNA level of more than $1 \log _{10} \mathrm{IU} / \mathrm{mL}$ from nadir. Although virologic breakthrough is generally associated with emergence of resistance mutations, up to $30 \%$ of the cases of virologic breakthrough in clinical trials are related to medication noncompliance. ${ }^{346}$ Therefore, compliance should be checked in all patients with a sub-optimal response.

In patients with a complete virologic response, treatment should be continued until the endpoint is achieved, which should be evaluated by measuring the serum HBV DNA level every 3-6 months. ${ }^{117,347}$ Primary non-response is very rare in oral antiviral therapy, with the exception of adefovir. Therefore, few studies of primary non-response patients have been performed. In patients with primary non-response with good compliance, switching to a drug with a high genetic barrier is indicated if the patient is taking a drug with a low genetic barrier, due to the possibility of immanent resistance. ${ }^{117,347}$ However, a recent study of entecavir for treatment-naïve $\mathrm{CHB}$ reported a primary non-response rate of 1.3$1.7 \%$, and all patients achieved a virologic response after continuing entecavir therapy during follow up..$^{348,349}$ Therefore, if the patient is taking a drug with a high genetic barrier, such as entecavir or tenofovir, treatment could either be switched to another highgenetic-barrier drug or be continued using the same high genetic barrier drug with monitoring for virologic response at 3-6-month intervals in patients with primary non-response.

The rate of emergence of lamivudine or telbivudine-resistant HBV was directly proportional to the HBV DNA level after 24 weeks of treatment. ${ }^{225,343,344}$ Yuen and colleagues found that these rates were $8 \%, 13 \%, 32 \%$, and $64 \%$ for patients with 24 week HBV DNA levels of $<200,3 \log _{10}, 4 \log _{10}$, and $4 \log _{10}$ or higher, respectively, after a median follow-up of 29 months. ${ }^{344} \mathrm{Al}$ though few studies on this issue have been conducted, a partial response should be evaluated at 6 months after therapy and switching to a drug with a higher genetic barrier should be considered if lamivudine or telbivudine is used. ${ }^{117,347} \mathrm{~A}$ prospective study of switching to entecavir $1 \mathrm{mg}$ in patients with a partial response to lamivudine reported a virologic response rate of $67.6 \%$ and a resistance rate of $3 \%$ at 96 weeks. ${ }^{350}$ However, a history of exposure to lamivudine is associated with a high rate of emer- gence of entecavir resistance during entecavir therapy. ${ }^{351}$ Therefore, switching to entecavir should be considered carefully. The response to tenofovir monotherapy was influenced by neither a previous history of lamivudine treatment nor resistance. ${ }^{287,333,352-354}$ The incidences of adefovir resistance at 114 weeks of adefovir therapy in patients with an HBV DNA level of less than 1,000 copies $/ \mathrm{mL}, 10^{3}-10^{6}$ copies $/ \mathrm{mL}$ or more than $10^{6}$ copies $/ \mathrm{mL}$ at 48 weeks of adefovir therapy were $4 \%, 26 \%$ and $67 \%$, respectively. ${ }^{355} \mathrm{~A}$ partial virologic response to adefovir should be evaluated at 12 months after adefovir therapy and switching or adding antivirals is recommended for patients with a partial virologic response. ${ }^{345}$ Although a prospective controlled study reported that the virologic response rates were $81 \%$ and $88 \%$ after 12 months of therapy with adding lamivudine or telbivudine in patients with a partial virologic response to adefovir at 48 weeks, ${ }^{356}$ these combination therapies have a substantial risk of emergence of resistance during long-term treatment. ${ }^{293}$ Switching to entecavir 1.0 mg needs to be done with upmost caution since the incidence of entecavir resistance was as high as $25.7 \%$ in patients with adefovir resistance. ${ }^{357}$ In a prospective controlled study of treatmentnaive CHB patients, the virologic response rate during adefovir therapy at 48 weeks was $63 \%$ but increased to $90 \%$ after switching to tenofovir for a further 48 weeks. ${ }^{314}$ Tenofovir is an effective alternative for patients with a suboptimal response to adefovir and adefovir resistance mutations, ${ }^{316}$ and no report of tenofovir resistance has been published.

Partial virologic response to entecavir and tenofovir (which have a high genetic barrier) should be evaluated at 12 months after therapy due to the high potency and low incidence of resistance. ${ }^{345}$ Although some studies suggested that a partial virologic response to entecavir could be defined as a serum HBV DNA level of $1,000 \mathrm{IU} / \mathrm{mL}$ or $35 \mathrm{IU} / \mathrm{mL}$ at 12 months after therapy, ${ }_{1}^{24,358}$ it is generally defined as detectability of HBV DNA by PCR. The incidence of a partial virologic response to entecavir therapy has been reported to be $10 \%$ to $28 \%$ and that of a virologic response to maintenance entecavir therapy after a partial virologic response have been reported to be $45 \%$ to $95 \% .{ }^{349,358-361}$ Although switching therapy to tenofovir in 14 patients with a decline in HBV DNA level of less than $1 \log _{10}$ during more than 6 months of entecavir therapy achieved a virologic response in all patients during a mean of 50 weeks of tenofovir therapy, ${ }^{362}$ further studies are needed to determine the optimal treatment strategy for patients with a partial virologic response to entecavir. Although a partial virologic response has been found in patients with a high genetic barrier, continuing the antiviral agent, especially in cases with a continuous decrease 
in HBV DNA level, could be recommended as the incidence of resistance during long-term treatment is low. ${ }^{345}$ However, switching to another high genetic barrier antiviral is another option.

\section{[Recommendation]}

1. In patients with a complete virologic response, treatment should be continued until the treatment endpoint is achieved, and monitored by measuring the serum HBV DNA level every 3-6 months. (B1)

2. Drug compliance should be checked thoroughly in patients with a partial virologic response or primary non-response. For patients treated with a drug with a low genetic barrier, treatment should be switched to a drug with a higher genetic barrier. (B1) For patients treated with a drug with a high genetic barrier, treatment could either be switched to another drug with a high genetic barrier or be continued with monitoring for a virologic response at 3-6-months intervals. (C1)

3. In the event of viral breakthrough, rescue therapy should be implemented according to the genotypic resistance profile. (A1)

4. The treatment strategy should follow the recommendations for treating drug-resistant HBV when genotypic resistant mutations are identified. (A1)

\section{TREATMENT OF SPECIAL POPULATIONS}

\section{Acute hepatitis B}

Acute hepatitis B resolves spontaneously and does not progress to the chronic stage in more than $95 \%$ of patients, so antiviral therapy is generally not recommended. ${ }^{363,364}$ Early initiation of antiviral therapy has been reported to interfere with the normal protective immune response and suppresses production of neutralizing antibodies against hepatitis virus, increasing the risk of chronic hepatitis. ${ }^{365}$ However, acute hepatitis B infection seldom progresses to serious hepatitis and may lead to hepatic failure. ${ }^{364}$ According to a randomized controlled trial in 71 patients with severe acute hepatitis $B$, HBV DNA levels were significantly lower in the lamivudine-treated group ( $\mathrm{n}=31,3.7 \log _{10}$ copies $/ \mathrm{mL}$ ) compared with the control group ( $n=40,4.2 \log _{10}$ copies $/ \mathrm{mL}$ ) after 4 weeks. However, the rate of HBsAg loss after 12 months was similar in the two groups (93.5\% in the lamivudine group and $96.7 \%$ in the placebo group). ${ }^{366}$ In this study, the rate of development of protective anti-HBs after 1 year was $67.7 \%$ in the lamivudine group and $85 \%$ in the placebo group; the difference was not significant. A recent, small, prospective, controlled study also reported no significant benefit of lamivudine in severe acute hepatitis $B{ }^{367}$ In contrast, Tillman et al. reported that lamivudine is safe in patients with severe acute or fulminant hepatitis $B$, leading to rapid recovery with the potential to prevent liver failure and liver transplantation when administered sufficiently early. ${ }^{368}$ However, only a few case reports of antiviral agents as treatment for acute hepatitis B other than lamivudine have been published to date. ${ }^{369-371}$

\section{[Recommendation]}

1. For patients with acute hepatitis $B$, oral antiviral therapy might be considered in cases of persistent serious hepatitis or acute liver failure. (C1)

\section{Liver transplant patients}

In the past, severe liver damage and a low survival rate due to HBV recurrence after liver transplantation in HBV-related liver disorder patients were major problems. ${ }^{372-379}$ However, in an extensive cohort study of 372 patients who received liver transplants in the early 1990s and were positive for $\mathrm{HBsAg}$, the study group treated with HBIG therapy for more than 6 months showed a significantly lower rate of hepatitis $B$ recurrence than the group treated with HBIG therapy for less than 6 months or those who were not treated. The study group also had a higher long-term survival rate than the other groups. ${ }^{380}$ Since then, several studies have reported hepatitis $B$ recurrence rates ranging from $16 \%$ to $35 \%$ after liver transplantation in groups receiving high-dose HBIG (10,000 IU) therapy. ${ }^{381-383}$

Lamivudine and $\mathrm{HBIG}$ combination therapy reduces the rate of HBV recurrence to less than $10 \%$ after $1-2$ years and is superior to high-dose HBIG therapy with respect to cost and effectiveness. ${ }^{384-387}$ In a meta-analysis of six independent studies, lamivudine and HBIG combination therapy was found to reduce the rates of HBV recurrence and death 12-fold compared with HBIG therapy alone. ${ }^{388,389}$ A meta-analysis of 46 studies in which 2,161 HBV-infected patients received liver transplants found that adefovir and HBIG combination therapy significantly reduced the rate of hepatitis $B$ recurrence to $2 \%$ compared to $6 \%$ with lamivudine and HBIG combination therapy. ${ }^{390}$

In patients who received lamivudine monotherapy without 
HBIG, the hepatitis B recurrence rate after 4 years of liver transplantation was $\sim 40 \% .391,392$ In contrast, a study of lamivudine and adefovir combination therapy reported no recurrence in $\mathrm{CHB}$ patients during the 22-month observation period. ${ }^{393}$ In patients who received entecavir monotherapy without $\mathrm{HBIG}^{394,395}$ the rate of HBsAg loss was $88-91 \%$ and negative viremia was maintained in more than $98 \%$ during a $26-53$-month follow up; moreover, the rate of HBV recurrence was lower than that with lamivudine monotherapy. ${ }^{395}$

In a meta-analysis of 19 studies, lamivudine or adefovir with HBIG significantly reduced HBV recurrence compared to monotherapy with either lamivudine or adefovir. ${ }^{396}$ However, in a metaanalysis of 17 studies with 519 patients, those treated with lamivudine and HBIG (6.1\%) combination therapy showed a rate of HBV recurrence comparable to that of those treated with either entecavir or tenofovir monotherapy $(3.9 \%, P=0.52)$, and significantly higher than that of those treated with the combination of HBIG and either entecavir or tenofovir therapy $(1 \%, P<0.001){ }^{397}$ To date, few studies regarding entecavir or tenofovir monotherapy for the prevention of HBV recurrence after liver transplantation have been reported. Therefore, the combination of an antiviral and HBIG is recommended to prevent HBV recurrence after liver transplantation.

To reduce the cost of HBIG, studies of low-dose HBIG in combination with an antiviral or conversion to antiviral monotherapy after short-term HBIG combination therapy have been performed. In a study of 147 patients who received liver transplants, Gane et al. showed that lamivudine and low-dose HBIG (400-800 IU) combination therapy effectively suppressed the recurrence of hepatitis $B$ at a moderate cost, as the 5 -year recurrence rate of hepatitis $B$ was $4 \% .{ }^{398}$ Furthermore, patients with HBV DNA levels of less than $2.5 \mathrm{pg} / \mathrm{mL}$ before liver transplant and treated with lamivudine and HBIG (2,000 IU) combination therapy for 1 month after liver transplant were randomly assigned to either a combination therapy maintaining group or lamivudine monotherapy group. The rates of HBV recurrence and patient survival did not differ between the two groups. ${ }^{399}$ Two other retrospective studies reported no recurrence of HBV when lamivudine and HBIG combination therapy or HBIG therapy alone for 2 years after liver transplantation was replaced with lamivudine monotherapy. ${ }^{400,401}$ In a recent study by Angus et al., lamivudine and low-dose HBIG (800 IU) combination therapy was continued for at least 12 months after liver transplantation. The group in which HBIG was replaced by adefovir and the group in which HBIG was continuously administered showed similar rates of hepatitis $B$ recurrence. ${ }^{402}$ Lamivudine and adefovir combination therapy with initial short-term low-dose HBIG (400-800 IU) did not show HBV recurrence during the 57-month follow-up period. ${ }^{393}$

Few studies with a small number of patients have evaluated entecavir- or tenofovir-based therapy to reduce HBIG usage. The HBV recurrence rate was reported to be $10 \%(1 / 10)^{403}$ and $0 \%(0 / 11)^{404}$ when combination entecavir and HBIG therapy was converted to entecavir monotherapy; there was no HBV recurrence after converting to tenofovir monotherapy in 9 patients ${ }^{403}$ and 17 patients. ${ }^{404}$ The rates of recurrence were $5.9 \%(1 / 17)^{405}$ and $4.8 \%(1 / 21)^{406}$ in a study of conversion to tenofovir and emtricitabine (Truvada ${ }^{\circledR}$ ); however, HBIG withdrawal had an economic benefit. Although these studies suggested the possibility of reducing the dose and duration of HBIG treatment, further work is needed to determine the optimal duration, amount and type of antiviral treatment.

If hepatitis B recurs after preventive HBIG therapy following liver transplantation, lamivudine therapy could effectively inhibit the virus. However, it has been reported that long-term lamivudine therapy is associated with a resistance rate of $>50 \%$ after 3 years. ${ }^{407-409}$ Such lamivudine resistance causes inflammatory changes and hepatic fibrosis in the transplanted liver; indeed, death following hepatic failure is possible in severe cases. ${ }^{408,410,411}$

A few studies have reported the effects of tenofovir and entecavir on hepatitis B recurrence after liver transplantation; however, further research is required. ${ }^{412}$ Several studies have reported relatively good efficacy of lamivudine and adefovir in patients with recurrent hepatitis $B$ who exhibit lamivudine resistance after liver transplantation. The most extensive study administered the combination therapy to 241 patients with recurrent hepatitis B. The rate of reduction in HBV DNA was $65 \%$, whereas the rate of lamivudine resistance at 96 weeks after the initiation of therapy was $2 \%{ }^{413}$ Although these studies were conducted for a short period in small groups, it was recently reported that tenofovir is effective against mutants with lamivudine resistance. ${ }^{411,414}$ However, a high rate of emergence of entecavir resistance has been reported when entecavir is administered as a rescue therapy to patients with lamivudine resistance. ${ }^{274}$ Therefore, entecavir is not recommended in patients with lamivudine resistance after liver transplantation.

If $\mathrm{HBsAg}$ seronegative patients receive liver transplants from positive anti-HBC donors, $~ 50 \%$ will develop new hepatitis B. ${ }^{415}$ When HBIG therapy was administered to these patients after liver transplantation, hepatitis B occurred in $>20 \%$. However, when lamivudine therapy was applied, hepatitis B developed only in $2-3 \%$ of patients. Nevertheless, lamivudine and HBIG combination therapy had no additional preventive effects compared to la- 
mivudine therapy alone. ${ }^{415-417}$ The protective effect against HBV recurrence was similar between lamivudine and entecavir or tenofovir. ${ }^{418}$ Lamivudine was more cost-effective than entecavir or tenofovir according to a Markov model. ${ }^{419}$

\section{[Recommendation]}

1. Pre-transplant therapy with a NA is recommended for all $\mathrm{HBsAg}$-positive patients undergoing liver transplantation to achieve the lowest possible level of HBV DNA before transplantation. (A1)

2. Antiviral therapy before liver transplantation should comply with the guidelines for chronic hepatitis B therapy. (B1)

3. Therapy with a NA and HBIG should be administered for the lifetime of the patient to prevent recurrence of hepatitis $B$ after liver transplantation, until more evidence regarding alternative treatment regimens is accumulated. (B1) If serum HBV DNA becomes negative before the liver transplant, withdrawal of HBIG may be considered in certain patients after long-term monitoring. (B1)

4. In case of HBV recurrence after liver transplantation, a potent NA with a high barrier to resistance is recommended. (B1) Upon emergence of drug-resistant variants, the CHB treatment guidelines should be followed. (B1)

5. When an $\mathrm{HBsAg}$-negative recipient receives an $\mathrm{HBsAg-neg-}$ ative but anti-HBc-positive graft, the recipient should take oral antivirals indefinitely. (B1)

\section{Immunosuppression and chemotherapy}

The clinical course of individual patients with chronic hepatitis $B$ is affected by the interaction between the virus and the host immune system. Impaired host immunity due to chemotherapy or immunosuppressive treatment increases the risk of HBV reactivation. ${ }^{420}$ Previously, HBV reactivation referred to the reappearance of necroinflammatory disorders in patients with either inactive CHB or with resolved hepatitis, ${ }^{421}$ and was commonly defined as an increase in the serum HBV DNA of $>10$-fold the baseline level or an absolute level of $>10^{8} \mathrm{IU} / \mathrm{mL}$ together with elevated serum ALT (higher than $3 \times$ ULN or an absolute increase of $>100 \mathrm{IU} /$ L). ${ }^{422,423}$ However, most studies of HBV reactivation used their own definition of HBV reactivation, and so the exact incidence of HBV reactivation during immunosuppressive therapy or chemotherapy was unclear. In addition, several terms such as "preventive", "prophylactic" and "preemptive" were used but not clearly defined, which resulted in confusion in scientific communications. In this guideline, "prophylactic" therapy means starting antiviral therapy simultaneously with initiation of immunosuppressive therapy or chemotherapy. Meanwhile, "preemptive" therapy means deferring antiviral therapy until the HBV DNA level increases. We prefer the term "preventive" therapy, which means not only starting antiviral therapy upon initiation of immunosuppressive therapy or chemotherapy but also deferring antiviral therapy until the HBV DNA level increases.

Two definitions of HBV reactivation are in use. ${ }^{424}$ One is exacerbation of chronic HBV infection, and the other is relapse of past HBV infection. Exacerbation of chronic HBV infection is defined $\geq 2 \log _{10}$ increase of HBV DNA level from the baseline level or a new appearance of HBV DNA to a level of $\geq 100 \mathrm{lU} / \mathrm{mL}$. Relapse of past HBV infection is defined among HBsAg negative, IgG anti$\mathrm{HBC}$ positive and HBV DNA negative patients as reappearance of HBsAg or detectable HBV DNA. The diagnosis of HBV reactivation requires the exclusion of other conditions such as chemotherapyrelated hepatic injury, hepatic metastases, and other types of viral hepatitis. The reactivation rate has been reported to be $20-50 \%$, although the ranges varied among studies. Many patients with HBV reactivation are asymptomatic, but the clinical course varies widely from jaundice to decompensation or even death. ${ }^{422,425-427}$ In typical cases, HBV DNA appears in the serum during immunosuppressive treatment, followed by elevation of ALT after treatment cessation. If HBV reactivation occurs during chemotherapy, treatment disruption or premature termination may adversely affect the outcome of chemotherapy. ${ }^{428-430}$ Predictive factors for HBV reactivation include the pretreatment HBV DNA level, HBeAg positivity, cccDNA in hepatocytes and PC/BCP mutation as viral factors, type of malignancy, male and young age as host factors, and type or intensity of immunosuppression or chemotherapy and hematopoietic stem cell or organ transplantation as environmental therapeutic factors. ${ }^{431}$

The reported reactivation rate in lymphoma patients ranges from $24 \%$ to $67 \%$, possibly due to intense chemotherapeutic regimens against lymphoma and higher HBsAg positivity rates in these patients. ${ }^{46,432-434}$ Rituximab, which is commonly administered with corticosteroid for lymphoma, further increases the risk of $\mathrm{HBV}$ reactivation. ${ }^{435,436}$ One retrospective study reported a 27.8\% (45/162) HBV reactivation rate among HBsAg-positive lymphoma patients, with a lower rate of HBV reactivation in the preventive antiviral therapy group compared to the non-preventive antiviral therapy group (22.9\% [32/140] vs. 59.1\% [13/22]; $P<0.001) .{ }^{437}$ In this study, entecavir reduced the rate of HBV reac- 
tivation to a greater degree than lamivudine $(6.3 \%$ vs. $39.3 \%$; $P<0.05)$. In HBsAg negative/anti-HBC positive patients, the rate of HBV reactivation was $2.4 \%$ in this retrospective study. Another prospective study of HBsAg negative/anti-HBc-positive lymphoma patients reported a higher rate of HBV reactivation and hepatitis aggravation (10.4 and 6.4 per 100 person-years, respectively) during rituximab plus cyclophosphamide, doxorubicin, vincristine, and prednisone (R-CHOP) chemotherapy. ${ }^{438}$ In this study, close monitoring of HBsAg and HBV DNA with immediate antiviral therapy usually overcame the complications of HBV reactivation; however, some cases showed marked aggravation and progression of severe hepatitis, which was associated with reappearance of HBsAg compared to reappearance of HBV DNA without HBsAg $(100 \%$ vs. $28 \%)$. A rituximab-containing regimen increased the risk of HBV reactivation among HBsAg-positive and HBsAg-negative/anti-HBc-positive lymphoma patients (relative risk 2.14, 95\% Cl 1.42-3.22, $P=0.0003$ ), especially in HBsAg-negative/anti-HBCpositive lymphoma patients (relative risk 5.52). ${ }^{439}$ Preventive antiviral therapy in lymphoma reduced the rate of HBV reactivation significantly compared to a non-preventive group (13.3\% vs. $60 \%){ }^{440}$ Pretreatment screening for HBsAg and anti-HBc before R-CHOP chemotherapy in lymphoma and preventive antiviral therapy enhanced survival and cost-effectiveness by reducing the rate of $\mathrm{HBV}$ reactivation. ${ }^{441}$

The risk of reactivation is also elevated when high-intensity chemotherapy is applied prior to hematopoietic stem-cell transplantation in hematologic malignancies. ${ }^{442,443}$ Similarly, preventive antiviral therapy with lamivudine or entecavir reduced the rate of HBV reactivation. ${ }^{444}$ Although the reactivation rate was $14-21 \%$ in solid tumors, higher rates of $41-70 \%$ were reported in breast cancer, possibly related to the use of high-dose chemotherapy with anthracycline agents and steroids. ${ }^{430,44,446}$ The rate of HBV reactivation during transcatheter arterial chemoembolization (TACE) as a therapeutic option for HCC was 4-40\%. ${ }^{447-450}$ Preventive lamivudine therapy compared to non-preventive group reduced the rates of HBV reactivation (2.8\% vs. $40.5 \%$ ), hepatitis aggravation ( $2.8 \%$ vs. $29.7 \%)$ and hepatic failure (0\% vs. $8.1 \%$ ) significantly. ${ }^{448}$ Preventive antiviral therapy can be considered in cases undergoing TACE for HCC treatment to reduce HBV reactivation; however, the rates of HBV reactivation during TACE differed according to procedure method, interval, frequency and the TACE agents. ${ }^{447,448,451}$ Therefore, further studies are required to elucidate the criteria for preventive antiviral therapy in TACE. Sorafenib, which was approved for advanced HCC, seems not to cause HBV reactivation ${ }^{452}$ but this should be confirmed in further investiga- tions. Steroids can suppress the host immune system but also induce HBV replication directly, which increases the risk of HBV reactivation. Other risk factors for reactivation include the use of anti-TNF agents for inflammatory bowel diseases or rheumatologic diseases (e.g., infliximab, etanercept, and adalimumab), the HBV genotype or specific mutations in the HBV genome, and recovery from neutropenia. ${ }^{453-462}$ The rate of HBV reactivation was $12.3 \%$ among $\mathrm{HBsAg}$-positive patients receiving an anti-TNF $\alpha$ antibody or disease-modifying antirheumatic drug (DMARD), which are used in rheumatologic diseases. ${ }^{463}$ Other study reported a rate of HBV reactivation of $39 \%$ among $\mathrm{HBsAg}$-positive patients and $5 \%$ among isolated anti-HBc-positive patients receiving antiTNF $\alpha$ antibody therapy. Preventive antiviral therapy decreased the rate of HBV reactivation significantly (23\% vs. $62 \%, P=0.003) .{ }^{464}$

Because HBV reactivation is associated with the risk of hepatic failure and death, prevention is of utmost importance. This necessitates screening for HBsAg and IgG anti-HBC. Vaccination should be considered if there is no evidence of (past) HBV infection (i.e., negative for both $\mathrm{HBsAg}$ and $\lg \mathrm{G}$ anti-HBc). Preventive antiviral therapy is recommended in $\mathrm{HBsAg}$-positive patients regardless of the serum HBV DNA level. ${ }^{455}$ Preventive lamivudine therapy has significantly reduced the rates of HBV reactivation, hepatic failure, and mortality in randomized controlled studies of lymphoma patients in Hong Kong and Taiwan. ${ }^{433,443,465,466}$ Therefore, it is recommended that preventive antiviral therapy be started simultaneously with the initiation of chemotherapy rather than deferring until the HBV DNA level increases, and should be maintained for certain period after the termination of chemotherapy (e.g., at least 6 months). ${ }^{46,467}$ However, evidence that can be used to determine the duration of preventive antiviral therapy remains limited. Elevated risk of reactivation was reported with cessation of preventive lamivudine therapy at 3 months following the termination of chemotherapy, especially in cases with a high HBV DNA level before chemotherapy $(\geq 2,000 \mathrm{IU} / \mathrm{mL}){ }^{468}$ Therefore, the duration of preventive antiviral therapy could be determined based upon treatment guidelines for CHB if the pre-treatment HBV DNA level is high. In contrast, attention should be paid to reports of reactivation after more than 6 months irrespective of the pre-treatment HBV DNA level. Although there is limited information about the efficacy of preventive treatment with other antiviral agents—such as adefovir, telbivudine, clevudine, entecavir, and tenofovirthese agents could be administered for preventive purpose considering their mechanisms of action and therapeutic results. Since resistance was reported in preventive lamivudine therapy, other antiviral agents with lower resistance rates should be considered 
in cases with prolonged treatment (e.g., $>1$ year). ${ }^{433} \mathrm{~A}$ retrospective study reported that the risks of hepatitis and chemotherapy disruption due to HBV reactivation in lymphoma patients were lower for entecavir than for lamivudine. ${ }^{469}$ However, data on the relative efficacy and cost-effectiveness of antiviral agents are scarce. Prospective studies to determine the appropriate antiviral agents and optimal treatment duration in various types of malignancy are needed, as most previous studies involved only lymphoma patients. If cost is ignored, entecavir and tenofovir are appropriate choices based on their potency and resistance rate. Interferon- $\alpha$ is contraindicated for preventive use due to its bone marrow suppression and exacerbation of underlying hepatitis.

In some cases, HBV reactivation occurs not only in HBsAg-positive patients but also in IgG anti-HBc-positive patients without HBsAg. ${ }^{470}$ The latter cases correspond to either occult HBV infection in which HBV DNA is detected in the hepatocytes or even in the serum, or reverse seroconversion (seroreversion) of HBsAg in which HBV replication resumes after immunosuppression with reappearance of HBsAg. ${ }^{422,471,472}$ The rate of HBV reactivation is higher in patients with isolated anti-HBc than in patients with both anti$\mathrm{HBC}$ and anti-HBs. ${ }^{473} \mathrm{IgG}$ anti-HBc-positive patients (HBsAgnegative) have a risk of $\mathrm{HBV}$ reactivation irrespective of anti-HBs, but a uniform treatment recommendation cannot be provided because the effects of the type of malignancy or immunosuppressive/ chemotherapeutic agents used on the reactivation risk are unclear. However, preventive therapy should be started if serum HBV DNA is positive in high-risk groups such as patients with lymphoma under a rituximab-containing regimen or those with leukemia who undergo hematopoietic stem cell transplantation; preventive treatment may be started together with immunosuppressive/chemotherapy or determined with periodic monitoring (e.g., every 1-2 months) of the HBV DNA level in patients with no detectable serum HBV DNA at baseline.

\section{[Recommendation]}

1. It is recommended to screen for $\mathrm{HBsAg}$ and IgG anti-HBc prior to initiation of immunosuppressive treatment or chemotherapy. If either is positive, serum HBV DNA should be tested. (A1)

2. Patients without evidence of $\mathrm{HBV}$ infection should be vaccinated. (B1)

3. Consider preventive antiviral therapy simultaneously with the initiation of immunosuppressive treatment/chemotherapy if HBsAg or HBV DNA is positive. (A1) Although selec- tion of a NA requires consideration of the serum HBV DNA level, the intensity and duration of immunosuppressive treatment/chemotherapy and the cost, entecavir or tenofovir can be preferentially considered if the baseline HBV DNA level is high or long-term treatment is anticipated. (C1)

4. If IgG anti-HBC is positive without $\mathrm{HBsAg}$ or HBV DNA, irrespective of anti-HBs, serum HBV and HBsAg should be tested regularly and preventive antiviral therapy should be considered if either reappears during immunosuppressive treatment/chemotherapy. (A1) Preventive antiviral therapy in patients with isolated anti-HBc can be initiated in highrisk groups such as patients with lymphoma under a rituximab-containing regimen or those with leukemia who undergo hematopoietic stem cell transplantation. (B2)

5. Serum HBV DNA should be monitored periodically during and after preventive antiviral therapy. (A1)

6. Preventive antiviral therapy should be maintained for at least 6 months after the termination of immunosuppressive treatment/chemotherapy. (C1)

\section{Patients with chronic kidney disease and under dialysis}

Patients under dialysis are relatively prone to being exposed to HBV infection, which might exert a negative influence on their long-term prognosis. Exacerbation of hepatitis $B$ is of particular importance for immunosuppression after renal transplantation. ${ }^{474}$ Fortunately, the incidence of HBV infection in dialysis patients has decreased due to surveillance of blood products, enhanced infection control, and widespread use of erythropoietin. The prevalence of HBV infection based on HBsAg positivity in this population is $0-6.6 \%$ in Western countries, and $\sim 5 \%$ in Korea in recent reports. ${ }^{475-477}$ The prevalence of occult HBV infection was higher than the HBsAg-positivity rate in one report, ${ }^{478}$ but this was not the case in Korea. ${ }^{479}$ The standard precautions to avoid nosocomial transmission are of the highest priority for preventing new HBV infections in dialysis patients. ${ }^{480}$ Vaccination against HBV is widely recommended in these patients; the efficacy is higher with earlier vaccination because the antibody production rate is $50-60 \%$ compared with $\sim 90 \%$ in the general population, and decreases as residual renal function declines. ${ }^{481-483}$ Data on antiviral treatment in dialysis patients are insufficient. Although a randomized controlled study of interferon- $\alpha$ in HBV-infected patients with glomerulonephritis has been performed, ${ }^{484}$ it is difficult to recommend its use due to the increased adverse events in this popula- 
The Korean Association for the Study of the Liver (KASL) Treatment guideline for hepatitis $B$

tion due to pharmacodynamic changes. ${ }^{485,486}$ Several small studies have reported the effectiveness of lamivudine. ${ }^{487-489}$ Resistance to lamivudine was $39 \%$ at 16.5 months of treatment, which was similar to the rate in patients with normal renal function. ${ }^{490}$ Entecavir or tenofovir may be preferentially used, given their potency and resistance profile in patients with normal renal function. ${ }^{35}$ Careful dose adjustment is required for adefovir and tenofovir due to their potential nephrotoxicity in patients with residual renal function. ${ }^{491-494}$ Tenofovir is less nephrotoxic than adefovir. Two of 426 patients with chronic hepatitis B who underwent tenofovir therapy for 144 weeks showed elevation of serum creatinine to $>0.5 \mathrm{mg} / \mathrm{dL}$ compared to baseline with no reduction in glomerular filtration rate to $<50 \mathrm{~mL} / \mathrm{min}^{495}$

\section{[Recommendation]}

1. Vaccination is recommended for patients under dialysis negative for $\mathrm{HBsAg}$ and anti-HBs. (A1)

2. Oral NAs such as entecavir and tenofovir are preferable to interferon therapy in patients under dialysis. (B1) NAs should be dose-adjusted according to residual renal function. (A1)

\section{CO-INFECTION WITH OTHER VIRUSES}

\section{HCV Co-infection}

In patients with CHB the anti-HCV antibody positivity rate varies from $0.1 \%$ to $22 \%$, depending on the region ${ }^{496-499}$ with it being very low in Korea (0.1\%). ${ }^{497}$ Patients with HBV/HCV co-infection have an increased risk of severe or fulminant infection, and high incidences of cirrhosis and HCC. ${ }^{500-503}$ The scarcity of data makes it impossible to recommend a treatment for HBV/HCV coinfection. ${ }^{504-506}$ However, it is necessary to determine which virus is dominant by means of serologic or virology tests. If HCV RNA is positive with a low or undetectable serum HBV DNA level, HCV infection should be considered dominant and the patient treated as for HCV monoinfection. Combination therapy of pegIFN- $\alpha-2 a$ plus ribavirin is equally effective in patients with HCV monoinfection and HBV/HCV co-infection. ${ }^{507,508}$ HBV treatment should be added when HBV reactivates, which can reportedly occur during or after combination therapy of pegIFN- $\alpha$ plus ribavirin for $\mathrm{HCV}^{509}$

The role of direct-acting agents (DAAs) in HBV/HCV co-infection needs to be elucidated.

\section{[Recommendations]}

1. After confirming the dominant cause of liver disease in $\mathrm{HBV} / \mathrm{HCV}$ coinfection, treatment following the same strategy as that for the dominant virus is recommended. (B1)

2. HBV treatment should be initiated when HBV proliferation is identified during or after treatment for HCV. (B1)

\section{HDV Co-infection}

It is estimated that $\sim 20$ million people are infected with HDV worldwide. ${ }^{510}$ HDV infection is prevalent in Mediterranean countries, the Middle East, central Africa, and South America. ${ }^{511}$ The HDV co-infection rate in CHB patients has been reported to be $0-3.6 \%$ in Korea. ${ }^{512-514}$ The incidences of cirrhosis and HCC are higher in patients with HBV/HDV coinfection than in those with HBV monoinfection. ${ }^{515,516}$

HDV infection can be diagnosed by detecting anti-HDV antibody or HDV RNA in the serum or by detecting HDV antigen in liver tissue by immunohistochemistry. The treatment goals are to inhibit HDV replication, normalize ALT, and improve histology findings. IFN- $\alpha$ (conventional or pegylated) is the only drug that can inhibit HDV replication. ${ }^{517-521}$ The biochemical, virologic, and histologic responses to high-dose IFN- $\alpha$ therapy ( $9 \mathrm{MU}$, three times per week) were better than those to the conventional dose of IFN- $\alpha$ (3 $\mathrm{MU}$, three times per week), with the high-dose therapy producing an HDV RNA negativity rate of $43 \%$ at 6 months after the end of 48 weeks of treatment. ${ }^{520}$ PeglFN- $\alpha$ showed HDV RNA negativity rates of $17-43 \%$ at 6 months after the end of 48 or 72 weeks of treatment. ${ }^{517,521,522}$ No head-to-head comparison trial between high-dose IFN- $\alpha$ and pegIFN- $\alpha$ therapies has been performed and hence either pegIFN- $\alpha$ or high-dose IFN- $\alpha$ therapy for longer than 1 year is recommended for patients with HBV/HDV co-infection. ${ }^{523}$ The treatment response can be evaluated by measuring the serum HDV RNA level at week 24. Both lamivudine and adefovir were found to be ineffective in terms of inhibiting HDV replication. ${ }^{524,525}$ Combination therapy of lamivudine plus IFN- $\alpha$ was not superior to IFN- $\alpha$ monotherapy, ${ }^{526}$ and adefovir plus pegIFN- $\alpha$ therapy did not improve the response rate compared to pegIFN- $\alpha$ monotherapy. ${ }^{525}$ In addition, the rates of HDV DNA negativity at 24 weeks after therapy with the combination of adefovir plus pegIFN- $\alpha$ or pegIFN- $\alpha$ monotherapy for 48 weeks were superior to those following adefovir monotherapy for 48 weeks (26\%, 31\% and 0\%, respectively). ${ }^{527}$ 


\section{[Recommendation]}

1. CHB patients with HDV co-infection should be treated with peginterferon- $a$ or high dose interferon-a $(9 \mathrm{MU}$, three times per week) for $>1$ year. (B1)

\section{HIV Co-infection}

The incidences of cirrhosis and HCC are reportedly higher in patients with HBV/HIV coinfection than in those with HBV monoinfection. ${ }^{528,529}$ HBV should be treated in HBV/HIV-coinfected patients who exhibit ALT elevation due to HBV. Before such treatment it is necessary to determine whether treatment for HIV is also required. ${ }^{530}$ Patients who are not indicated for HAART should receive the standard treatment for CHB. In such cases antiviral agents (e.g., IFN, adefovir, or telbivudine) that do not affect HIV proliferation should be selected, to prevent the future development of HIV cross-resistance. Entecavir or tenofovir monotherapy should not be used in patients with HBV/HIV co-infection due to the development of resistant HIV. Patients who need treatment for both HIV and HBV should be treated with antiviral agents that are effective against both viruses, such as tenofovir/emtricitabine, tenofovir or lamivudine, as highly active anti-retroviral therapy (HAART). ${ }^{531-533}$ When HAART regimens are altered, antiviral agents that are effective against HBV should be included to avoid HBV reactivation, except in patients who meet the criteria for discontinuation of anti-HBV treatment.

\section{[Recommendation]}

1. HBV/HIV-coinfected patients who exhibit ALT elevation due to HBV should be considered for HBV treatment. (B1)

2. Patients who are not indicated for HAART at present or in the near future should receive the standard treatment for CHB. In such cases, NAs that do not affect HIV proliferation should be used to prevent the future development of HIV cross-resistance. (B1)

3. Patients who need treatment for both HIV and HBV should be treated with HAART agents effective against both viruses; e.g., tenofovir/emtricitabine or tenofovir plus lamivudine. (B1)

\section{Female patients of childbearing age}

\section{Treatment before pregnancy}

When planning treatment for females of child-bearing age, spe- cial considerations for the fetus and the duration of treatment are needed in addition to the aforementioned general considerations. For example, IFN preparations are preferred in female patients who are planning pregnancy as the period of treatment is more clearly defined. However, the IFN side effect of fetal malformations makes it contraindicated during pregnancy, and so it must be recommended in combination with contraception during the therapy and until 6 month after cessation of therapy. Females who want to be pregnant should be treated with antiviral agents that belong to pregnancy category B drugs (which, according to the results of animal studies, carry no teratogenic or embryogenic risk and for which there have been no controlled human studies or for which animal studies may indicate a risk, but controlled human studies refute the findings). Tenofovir and telbivudine belong to pregnancy category B, while entecavir, adefovir and lamivudine belong to pregnancy category $\mathrm{C}$ drugs (drugs that exert teratogenic or embryocidal effects in animals and for which there are no controlled studies in humans). ${ }^{15}$

\section{Treatment during pregnancy}

Pregnant females with chronic HBV infection are usually in the immune-tolerance phase, ${ }^{534}$ and changes in the maternal immune system during pregnancy, such as a shift in the Th1-Th2 balance toward a Th2 response, lead to an increase in the HBV DNA level and a reduction in the ALT level. ${ }^{535}$ These immune responses are restored after delivery, thereby causing a reduction in the HBV DNA level and ALT elevation, and so careful monitoring is needed. ${ }^{535-537}$

The optimal antiviral treatment strategy during pregnancy is based on the aforementioned general principles for the treatment of CHB. However, all decisions regarding the timing and duration of treatment in pregnancy should include an analysis of the risks and benefits for both the mother and fetus. In addition, pregnant females often experience worsening of liver disease unrelated to HBV infection (e.g., acute fatty liver of pregnancy), which is difficult to discriminate from an HBV flare-up. Thus, antiviral treatment should be considered when liver disease is present (e.g., jaundice or prolongation of PT), and the HBV DNA level meets the general criteria for antiviral treatment.

When starting antiviral therapy during pregnancy, category B drugs are recommended. Safety data of antiviral agents during pregnancy can be found at the Antiretroviral Pregnancy Registry (APR; http://www.apregistry.com). The APR is an international, voluntary, prospective registry that reports the rate of birth defects of newborns born to mothers receiving antiretroviral therapy, 
and it contains a considerable amount of data on lamivudine and tenofovir. According to the APR, the rates of birth defects among females exposed to lamivudine and tenofovir in the first trimester (3.1\% and $2.4 \%$ of live births, respectively) are similar to that in the general population (2.7\%), as reported by the CDC birth defect surveillance system. Few cases related to other drugs such as telbivudine and entecavir have been reported. However, since the APR is designed to report only defects identified at birth, it may not contain accurate data on developmental anomalies (e.g., cardiac or neurologic defects).

Oral antiviral agents may cause mitochondrial toxicity by inhibiting mitochondrial DNA replication. It is difficult to estimate their effects on the fetus, especially in the developmental stages. ${ }^{224}$ Thus, based on considerations of fetal safety oral antiviral agents should not be administered, especially in the first trimester of pregnancy. However, the decision about whether to discontinue drugs in patients receiving treatment with oral antiviral agents should be individualized. One retrospective study showed that $\sim 14 \%$ of pregnant females with active chronic hepatitis B without antiviral therapy can progress to hepatic failure and have a risk of maternal or fetal death, so appropriate antiviral therapy should be considered in pregnant females in the active phase of chronic hepatitis $B^{538}$

In childbearing females who require treatment with an oral antiviral agent against HBV, pregnancy category B drugs such as tenofovir can be considered if the patient wants to become pregnant. In females already receiving antiviral therapy with a category $C$ drug who want to become pregnant, the category $C$ drug should be changed to a category B drug, such as tenofovir.

In the first trimester of pregnancy, pregnant females with mild chronic hepatitis B and undetectable HBV DNA ( $<60 \mathrm{IU} / \mathrm{mL})$ may be considered for temporary drug discontinuation with careful monitoring for HBV reactivation. Meanwhile, females who become pregnant while on category $C$ drugs should change to category B drugs if continuous antiviral therapy is needed. ${ }^{539}$

As little about whether or not antiviral agents are secreted into breast milk is known, and the effects on babies of antiviral agents in breast milk is unclear, breast-feeding is not currently recommended.

\section{Prevention of vertical transmission with antiviral drugs}

A high maternal HBV DNA level is associated with a high rate of failure of neonatal passive-active immunoprophylaxis..$^{500-543}$ In a double-blind, randomized controlled trial, pregnant females with high serum HBV DNA levels (>103 Meq/mL $\left[\sim 10^{9} \mathrm{cpm}\right]$ ) were given lamivudine from week 32 of gestation to week 4 postpartum in addition to neonatal passive-active immunoprophylaxis. HBsAg positivity was present in $18 \%$ and $39 \%$ of 1 -year-old infants from lamivudine- and placebo-treated mothers, respectively $(P=0.014)^{544}$ No safety concerns were noted in the lamivudine-treated mothers and their newborns. However, these data should be interpreted with caution due to the high dropout rates, especially in the placebo group (13\% in the lamivudine group and 31\% in the placebo group). A prospective study included pregnant females with HBeAg-positive and high serum HBV DNA levels ( $>10^{7}$ copies $/ \mathrm{mL}$ ) who were treated with lamivudine from week 24 to week 32 in addition to neonatal passive-active immunoprophylaxis as the treatment group. The HBsAg-positivity rates of infants at 1 year after birth were significantly different: $0 \%(0 / 94)$ in the treatment group and $7.7 \%(7 / 91)$ in the placebo group. ${ }^{545}$ Another prospective study included pregnant females with high serum HBV DNA levels ( $>10^{6}$ copies $/ \mathrm{mL}$ ) treated with telbivudine from week 12-30 to birth in addition to neonatal passive-active immunoprophylaxis as the treatment group. The HBsAg-positivity rates of infants at 6 months after birth were significantly different: $0 \%(0 / 54)$ in the treatment group and $8.6 \%(3 / 35)$ in the placebo group. ${ }^{546}$ Another prospective controlled study included pregnant females with high serum HBV DNA levels ( $>10^{7}$ copies $/ \mathrm{mL}$ ) treated with telbivudine from weeks 20 to 32 of gestation to week 4 postpartum in addition to neonatal passive-active immunoprophylaxis. $\mathrm{HBsAg}$ positivity was present in none (0/132) of the 6 -month-old infants from telbivudine-treated mothers, whereas it was present in $8 \%$ (7/88) of those from placebo-treated mothers. ${ }^{547}$ Another prospective study included pregnant females with high serum HBV DNA levels ( $>10^{7}$ copies $/ \mathrm{mL}$ ) treated with tenofovir or lamivudine from week 32 to week 4-12 postpartum in addition to neonatal passive-active immunoprophylaxis as the treatment group. The HBsAg-positivity rates of infants at 9 months after birth were significantly different: $1 \%(1 / 87)$ in the treatment group and 20\% $(2 / 10)$ in the placebo group. ${ }^{548}$ The prevalence of safety issues did not differ significantly between the two groups. These studies imply that antiviral medication in the late stage of pregnancy is likely to reduce the rate of vertical transmission. However, the decision about whether or not to treat should be individualized in patients not indicated for the treatment of HBV, based on the treatment duration, stopping point, possible appearance of drug-resistant strains, and the patient's preferences. 


\section{[Recommendations]}

1. Peginterferon- $a$ has an advantage in female patients who are planning pregnancy due to its finite treatment duration. (C1) However, the side effects pertaining to fetal malformations make peginterferon- $a$ treatment contraindicated during pregnancy, and it should be recommended in combination with contraception. (A1)

2. When antiviral treatment is needed during pregnancy, pregnancy category B NAs are recommended. (B1)

3. The antiviral treatment strategy during pregnancy is based on the general principles of CHB treatment; however, decisions should be based on analysis of the risks and benefits for both the mother and fetus. (C1)

4. Breastfeeding is not recommended in females receiving treatment with NAs. (C1)

\section{Children and adolescents}

Providing HBIG and HBV vaccine to newborns of $\mathrm{HBsAg}$-positive mothers within $12 \mathrm{~h}$ of birth can prevent $90-95 \%$ of cases of perinatal infection. Ninety percent of infants infected as a neonates progress to chronic infection. Most children remain in the immune-tolerant phase until late childhood or adolescence. However, some children progress to the immune-reactive phase. The spontaneous HBeAg seroconversion rate in immune-tolerant Korean children was $4.6 \%, 7.1 \%$, and $28.0 \%$ for patients aged $<6$, $6-12,>12$ years, respectively. ${ }^{549} \mathrm{~A}$ Taiwanese study reported annual spontaneous $\mathrm{HBeAg}$ seroconversion rates of $2 \%$ and $4-5 \%$ in children younger than 3 years and older than 3 years, respectively. ${ }^{50}$ Children who are in the immune-reactive phase-with increased ALT levels and histologic findings of liver inflammation and fibrosis - are usually asymptomatic. Long-term treatment in children with CHB is expected, and a prudent decision should be made based on the adverse effects of the drugs and the potential for viral resistance to affect future therapies. The treatment window should not be missed because cirrhosis can occur in their 20s and HCC later in life. The goals of therapy are to suppress viral replication, reduce liver inflammation, reverse liver fibrosis, and prevent cirrhosis and HCC.

Treating children in the immune-tolerant phase is not beneficial, and there is a high risk of development of drug resistance, which would limit treatment options in later life. Children with a persistent elevated serum ALT level should be evaluated for viral active replication, including measurement of HBV DNA levels. HBeAg- positive children should be considered for treatment when their serum ALT levels are above 2 ULN for at least 6 months and their HBV DNA levels are above 20,000 IU/mL. ${ }^{551}$ Acute elevation of liver enzymes with an ALT level of $>5$ ULN may be followed by spontaneous HBeAg seroconversion. It is therefore reasonable to delay treatment for an observation period of at least 3 months if there is no concern regarding hepatic decompensation. Children with moderate-to-severe necroinflammation or periportal fibrosis in a liver biopsy are recommended for treatment. The decision to treat is based on factors such as age, liver biopsy findings, and family history of HBV-associated cirrhosis or HCC. In obese children it is important to remember that ALT elevations may be due to fatty liver disease. ${ }^{552}$ The responses to interferon- $\alpha$ and lamivudine are better in children with higher activity scores in a liver biopsy. ${ }^{553,554}$

A randomized controlled trial of interferon- $\alpha$ therapy involving children aged 1 to 17 years found that $36 \%$ of those with a baseline ALT level of at least 2 ULN became negative for HBeAg at the end of treatment. HBsAg seroconversion occurred in $10 \%$ of the treated children. ${ }^{553}$ Factors predictive of a positive response among children are being younger than 5 years, ${ }^{555}$ having a low serum HBV DNA level, and having active inflammation in a liver biopsy. ${ }^{553}$ After 5 years of observation, the rate of HBeAg seroconversion did not differ between the treatment and control groups. However, loss of HBsAg occurred in $25 \%$ of children who responded to treatment, but in none of the children in the nonresponse and control groups. ${ }^{556}$ The recommended treatment regimen for interferon- $\alpha$ is $6 \mathrm{MU} / \mathrm{m}^{2}$ three times per week by subcutaneous injection for 6 months. Interferon- $\alpha$ is approved in children older than 12 months, and its advantages include the finite duration of treatment and no development of viral resistance. The adverse effects include fever, flu-like symptoms, bone marrow suppression, depression, and transient growth suppression. Interferon- $\alpha$ is contraindicated in children with decompensated cirrhosis and autoimmune disease. Clinical trials of peginterferon in children with CHB are ongoing. The efficacy and safety of peginterferon were demonstrated in children with chronic hepatitis $C$, and an update of the Swedish national recommendations for the treatment of CHB recommends the use of peginterferon (100 $\mu \mathrm{g} / \mathrm{m}^{2}$ weekly) in children. ${ }^{557}$

A randomized controlled study of lamivudine involving children aged 2-17 years found that loss of HBeAg at 52 weeks of treatment occurred in $34 \%$ of those with a baseline ALT level of at least 2 ULN, and that the resistance rate was $18 \% .{ }^{558}$ The HBeAg seroconversion rate after 2 years of therapy was $54 \%$ in children 
The Korean Association for the Study of the Liver (KASL) Treatment guideline for hepatitis $B$

without lamivudine-resistant virus. The resistance rate was $64 \%$ in children who received lamivudine for 3 years. Lamivudine treatment for $>3$ years did not significantly increase seroconversion rates and increased the incidence of viral resistance. ${ }^{559}$ Studies of Korean children found that the $\mathrm{HBeAg}$ seroconversion rates after 2 and 3 years of treatment were $65 \%$ and $70 \%$, respectively. ${ }^{560,561}$ Loss of HBsAg was observed in $20 \%$ of children after 2 years of lamivudine treatment, and the resistance rates at 1 and 2 years of treatment were $10 \%$ and $23 \%$, respectively. Factors associated with a response were elevated baseline ALT, high baseline histology-activity-index score, ${ }^{554}$ and being younger than 7 years. ${ }^{560}$ Long-term durability of $\mathrm{HBeAg}$ seroconversion was observed in more than $90 \%$ of the subjects after they had taken lamivudine for at least 2 years. ${ }^{562}$ Lamivudine is orally administered at a dose of $3 \mathrm{mg} / \mathrm{kg} / \mathrm{day}$, with a maximum of $100 \mathrm{mg} /$ day. ${ }^{552}$ Lamivudine treatment should be continued for at least 1 year, and it is desirable to continue treatment for 1 year after HBeAg seroconversion. If lamivudine resistance develops, it should be treated in accordance with the guidelines for antiviral resistance management in adults

A randomized controlled study of $173 \mathrm{HBeAg}$-positive children aged 2-17 years showed undetectable HBV DNA and a normal ALT level after 48 weeks of adefovir treatment in $23 \%$ of 12 - to 17-year-old subjects, but there was no significant difference between adefovir and placebo in those aged 2-11 years. The HBeAg seroconversion rate in the adefovir group and placebo group was $16 \%$ and $5 \%$, respectively $(P=0.051)$. No subject developed adefovir resistance. ${ }^{563}$ Continuation of adefovir treatment for a further 4 years was safe. Resistance to adefovir was observed in one child. ${ }^{564}$

Entecavir and tenofovir are potent HBV inhibitors with a high barrier to resistance. Entecavir is considered the first-line therapy in children older than 2 years and tenofovir in those older than 12 years. A randomized controlled trial of tenofovir in adolescents aged 12 to 17 years reported that the rate of a virologic response (HBV DNA $<400$ copies $/ \mathrm{mL}$ ) at week 72 was significantly higher in patients $(n=52)$ who received tenofovir than those $(n=54)$ who received placebo ( $89 \%$ vs. $0 \%) .{ }^{565}$ No resistance to tenofovir developed through week 72 . The rate of grade $3 / 4$ adverse events was higher among patients treated with placebo (24\%) than those treated with tenofovir (10\%). In a randomized controlled study involving 180 children aged 2 to 17 years with $\mathrm{HBeAg}$-positive CHB, the $\mathrm{HBeAg}$ seroconversion and $\mathrm{HBV}$ DNA $<50 \mathrm{IU} / \mathrm{mL}$ rates at week 48 were significantly higher with entecavir than placebo (24.2\% versus $3.3 \%$ ). The cumulative probability of entecavir resistance at 1 and 2 years was $0.6 \%$ and $2.6 \%$, respectively. Ente- cavir showed no difference in safety compared with placebo. ${ }^{566}$

\section{[Recommendations]}

1. HBeAg-positive CHB children with an HBV DNA level $>20,000 \mathrm{IU} / \mathrm{mL}$ and $\mathrm{HBeAg}$-negative $\mathrm{CHB}$ children with an HBV DNA level $>2,000 \mathrm{IU} / \mathrm{mL}$ should be considered for treatment when the AST or ALT level is > 2 ULN for at least 6 months, or moderate-to-severe necroinflammation or periportal fibrosis is evident in a liver biopsy. (A1)

2. Tenofovir, entecavir or interferon- $a$ is the first-line therapy in children with CHB. (B1) Data on peginterferon are currently scarce, but its use in children can be based on the results of studies involving adults. (C1)

3. If antiviral resistance develops, it should be treated in accordance with the guidelines for antiviral resistance management in adults. (B1)

\section{Conflicts of Interest}

Potential conflicts of interests are as the followings.

Kwan Sik Lee: Consulted Gilead

Si Hyun Bae: Consulted BMS, Yuhan, Bayer and received honorarium from MSD.

Won Hyeok Choe: Nothing to disclose

Moon Seok Choi: Received honoraria from Roche, BMS, GSK, MSD, Gilead and consulted Gilead.

Woo Jin Chung: Received grants from MSD, BMS, Roche, Bukwang and received honoraria from BMS, Yuhan.

Chang Wook Kim: Received honoraria or grant and consulted BMS, Gilead, Yuhan, Handok, Daewoong, PharmaKing, Pharmicell, KT\&G, Roche, Dong-A, Hanmi

Hyung Joon Kim: Consulted BMS, Gilead, Dong-A, Hanmi, and received grants from BMS, Gilead, Roche, Samil, PharmaKing, MSD and received honoraria from BMS, Yuhan, Gilead, Dong-A, Roche, Chongkundang, Handok, MSD.

Ja Kyung Kim: Received grants from MSD, Pharmicell, Bayer, JW Pharmaceutical

Ji Hoon Kim: Received honoraria and consulted BMS, Bayer, Gilead, Bukwang, GSK, Hanmi, Dong-A, Daewoong, Samil.

Suk Bae Kim: Received grants or honoraria from BMS, Gilead, Daewoong.

Yoon Jun Kim: Consulted or received grants/ honoraria from JW creagene, Ildong, Daewoong, Roche, LG, Bayer, PharmaKing, Gilead, MSD, BMS, Samil, Yuhan. 
Jae Sung Ko: Nothing to disclose.

Byung Seok Lee: Received honoraria from BMS, Boryung, Roche, MSD, Taejoon, and received grants from Gilead, Yuhan, Boryung, Roche, MSD, BMS, Pharmicell, Ildong, Samil, Bukwang, Dong-A, Handok, Bayer, Chongkundang.

Jung II Lee: Received grants from MSD, BMS, Gilead, Bayer, Roche, KOWA, Eisai, Novotech, EPS, Eli Lilly, Ildong, Pharmicell, Medigen, received honoraria from BMS, Gilead, and consulted Gilead.

Young-Suk Lim: Received grants from GSK, BMS, Roche, received honoraria from Bayer, BMS, MSD and consulted Roche.

Won Young Tak: Consulted Bayer, Gilead, JW creagene and received grants from Samil

Jong Eun Yeon: Received a grant from Yuhan.

Ki Tae Yoon: Received grants from BMS, Gilead, Bayer, received honoraria and consulted BMS, Gilead, GSK, Roche, Handok.

\section{REFERENCES}

1. Park CH, Lee SM, Kim TO, Kim DU, Jung WJ, Kim GH, et al. Treatment of solitary extramedullary plasmacytoma of the stomach with endoscopic submucosal dissection. Gut Liver 2009;3:334-337.

2. Song IS, Kim CY. Seasonal and annual variations on occurrence of HBsAg and acquisition of anti-HBs in Korea. Korean J Intern Med 1979;22:1007-1015.

3. Ahn YO. A review study on descriptive epidemiology of $\mathrm{HBs}$ antigen positivity in Korea. Korean J Epidemiol 1982;4:35-45.

4. Sim JG, Seo JK, Suh SJ. Prevalence and its changes of hepatitis B viral markers from 1988 to 1993 in Korean children. J Korean Pediatr 1995;38:1535-1539.

5. Korea Centers for Disease Control and Prevention. 2006 Disease Control White Paper. Korea Centers for Disease Control and Prevention 2007:144.

6. Lee BS, Cho YK, Jeong SH, Lee JH, Lee D, Park NH, et al. Nationwide seroepidemiology of hepatitis $B$ virus infection in South Korea in 2009 emphasizes the coexistence of HBsAg and anti-HBs. J Med Virol 2013;85:1327-1333.

7. Ministry of Helalth \& Welfare KCfDCaP. The Fourth Korea National Health and Nutrition Examination Survey (KNHANES IV), 2010. Health Examination. Ministry of Helalth \& Welfare 2012.

8. Chae HB, Kim JH, Kim JK, Yim HJ. Current status of liver diseases in Korea: hepatitis B. Korean J Hepatol 2009;15(Suppl 6):S13-S24.

9. Cheon JH, Park JW, Park KW, Kim YI, Kim SH, Lee WJ, et al. The clinical report of 1,078 cases of hepatocellular carcinomas: National Cancer Center experience. Korean J Hepatol 2004;10:288-297.

10. Kim SR, Kudo M, Hino O, Han KH, Chung YH, Lee HS. Epidemiology of hepatocellular carcinoma in Japan and Korea. Oncology 2008;75:13-16.
11. Bae SH, Yoon SK, Jang JW, Kim CW, Nam SW, Choi JY, et al. Hepatitis $B$ virus genotype $C$ prevails among chronic carriers of the virus in Korea. J Korean Med Sci 2005;20:816-820.

12. Kim H, Jee YM, Song B-C, Shin JW, Yang SH, Mun HS, et al. Molecular epidemiology of hepatitis B virus (HBV) genotypes and serotypes in patients with chronic HBV infection in Korea. Intervirology 2007;50:52-57.

13. Lee JM, Ahn SH, Chang HY, Shin JE, Kim DY, Sim MK, et al. Reappraisal of HBV genotypes and clinical significance in Koreans using MALDI-TOF mass spectrometry. Korean J Hepatol 2004;10:260-270.

14. Lok AS, McMahon BJ. Chronic hepatitis B. Hepatology 2007;45:507539.

15. Hoofnagle JH, Doo E, Liang TJ, Fleischer R, Lok AS. Management of hepatitis $B$ : summary of a clinical research workshop. Hepatology 2007:45:1056-1075.

16. Tran TT. Immune tolerant hepatitis B: a clinical dilemma. Gastroenterol Hepatol (NY) 2011;7:511.

17. Lok AS, Lai CL. A longitudinal follow-up of asymptomatic hepatitis $B$ surface antigen-positive chinese children. Hepatology 1988:8:1130-1133.

18. Chang MH, Hsu HY, Hsu HC, Ni YH, Chen JS, Chen DS. The significance of spontaneous hepatitis $\mathrm{B}$ e antigen seroconversion in childhood: with special emphasis on the clearance of hepatitis B e antigen before 3 years of age. Hepatology 1995;22:1387-1392.

19. Hui CK, Leung N, Yuen ST, Zhang HY, Leung KW, Lu L, et al. Natural history and disease progression in Chinese chronic hepatitis B patients in immune-tolerant phase. Hepatology 2007;46:395-401.

20. Livingston SE, Simonetti JP, Bulkow LR, Homan CE, Snowball MM, Cagle $\mathrm{HH}$, et al. Clearance of hepatitis $B$ e antigen in patients with chronic hepatitis B and genotypes A, B, C, D, and F. Gastroenterology 2007;133:1452-1457.

21. Vierling JM. The immunology of hepatitis B. Clin Liver Dis 2007;11:727-759.

22. Lee PI, Chang MH, Lee CY, Hsu HY, Chen JS, Chen PJ, et al. Changes of serum hepatitis $B$ virus DNA and aminotransferase levels during the course of chronic hepatitis $B$ virus infection in children. Hepatology 1990;12:657-660.

23. Lok AS, Lai C-L. Acute exacerbations in Chinese patients with chronic hepatitis B virus (HBV) infection: incidence, predisposing factors and etiology. J Hepatol 1990;10:29-34.

24. McMahon BJ, Holck P, Bulkow L, Snowball M. Serologic and clinical outcomes of 1536 Alaska Natives chronically infected with hepatitis B virus. Ann Intern Med 2001;135:759-768.

25. Tsai SL, Chen PJ, Lai MY, Yang PM, Sung JL, Huang JH, et al. Acute exacerbations of chronic type $B$ hepatitis are accompanied by increased $T$ cell responses to hepatitis $B$ core and e antigens. Implications for hepatitis B e antigen seroconversion. J Clin Invest 1992;89:87-96.

26. Hsu YS, Chien RN, Yeh CT, Sheen IS, Chiou HY, Chu CM, et al. Long- 
term outcome after spontaneous HBeAg seroconversion in patients with chronic hepatitis B. Hepatology 2002;35:1522-1527.

27. Bortolotti F, Guido M, Bartolacci S, Cadrobbi P, Crivellaro C, No-

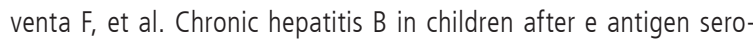
clearance: final report of a 29-year longitudinal study. Hepatology 2006;43:556-562.

28. Yim HJ, Lok AS. Natural history of chronic hepatitis B virus infection: what we knew in 1981 and what we know in 2005. Hepatology 2006;43:S173-181.

29. Lok AS, Lai CL, Wu PC, Leung EK, Lam TS. Spontaneous hepatitis $\mathrm{B}$ e antigen to antibody seroconversion and reversion in Chinese patients with chronic hepatitis B virus infection. Gastroenterology 1987;92:1839-1843.

30. Sheen IS, Liaw YF, Tai DI, Chu CM. Hepatic decompensation associated with hepatitis $B$ e antigen clearance in chronic type $B$ hepatitis. Gastroenterology 1985;89:732-735.

31. Martinot-Peignoux $M$, Boyer $N$, Colombat $M$, Akremi R, Pham BN, Ollivier $S$, et al. Serum hepatitis B virus DNA levels and liver histology in inactive HBsAg carriers. J Hepatol 2002;36:543-546.

32. Zacharakis GH, Koskinas J, Kotsiou S, Papoutselis M, Tzara F, Vafeiadis N, et al. Natural history of chronic HBV infection: a cohort study with up to 12 years follow-up in North Greece (part of the Interreg I-II/EC-project). J Med Virol 2005;77:173-179.

33. de Franchis R, Meucci G, Vecchi M, Tatarella M, Colombo M, Del Ninno $E$, et al. The natural history of asymptomatic hepatitis B surface antigen carriers. Ann Intern Med 1993;118:191-194.

34. Chen YC, Sheen IS, Chu CM, Liaw YF. Prognosis following spontaneous HBsAg seroclearance in chronic hepatitis B patients with or without concurrent infection. Gastroenterology 2002;123:1084-1089.

35. Lok AS, McMahon BJ. Chronic hepatitis B: update 2009. Hepatology 2009;50:661-662.

36. Funk ML, Rosenberg DM, Lok AS. World-wide epidemiology of HBeAg-negative chronic hepatitis B and associated precore and core promoter variants. J Viral Hepat 2002;9:52-61.

37. Lok AS, Akarca $U$, Greene $S$. Mutations in the pre-core region of hepatitis $B$ virus serve to enhance the stability of the secondary structure of the pre-genome encapsidation signal. Proc Natl Acad Sci U S A 1994;91:4077-4081.

38. Okamoto H, Tsuda F, Akahane Y, Sugai Y, Yoshiba M, Moriyama K, et al. Hepatitis $B$ virus with mutations in the core promoter for an $e$ antigen-negative phenotype in carriers with antibody to e antigen. J Virol 1994;68:8102-8110.

39. Croagh CM, Bell SJ, Slavin J, Kong YX, Chen RY, Locarnini S, et al. Increasing hepatitis B viral load is associated with risk of significant liver fibrosis in $\mathrm{HBeAg}$-negative but not $\mathrm{HBeAg}$-positive chronic hepatitis B. Liver Int 2010;30:1115-1122.

40. Yoo BC, Park JW, Kim HJ, Lee DH, Cha YJ, Park SM. Precore and core promoter mutations of hepatitis $B$ virus and hepatitis $B$ e antigen- negative chronic hepatitis B in Korea. J Hepatol 2003;38:98-103.

41. Raimondo G, Allain JP, Brunetto MR, Buendia MA, Chen DS, Colombo $M$, et al. Statements from the Taormina expert meeting on occult hepatitis B virus infection. J Hepatol 2008;49:652-657.

42. Hadziyannis SJ, Vassilopoulos D. Hepatitis B e antigen-negative chronic hepatitis B. Hepatology 2001;34:617-624.

43. Chu CM, Liaw YF. HBsAg seroclearance in asymptomatic carriers of high endemic areas: appreciably high rates during a long-term follow-up. Hepatology 2007;45:1187-1192.

44. Liu J, Yang HI, Lee MH, Lu SN, Jen CL, Wang LY, et al. Incidence and determinants of spontaneous hepatitis $\mathrm{B}$ surface antigen seroclearance: a community-based follow-up study. Gastroenterology 2010;139:474-482.

45. Brunetto MR, Giarin MM, Oliveri F, Chiaberge E, Baldi M, Alfarano A, et al. Wild-type and e antigen-minus hepatitis $B$ viruses and course of chronic hepatitis. Proc Natl Acad Sci U S A 1991;88:4186-4190.

46. Liaw YF, Sheen IS, Chen TJ, Chu CM, Pao CC. Incidence, determinants and significance of delayed clearance of serum $\mathrm{HBsAg}$ in chronic hepatitis B virus infection: a prospective study. Hepatology 1991;13:627-631.

47. Nam SW, Jung JJ, Bae SH, Choi JY, Yoon SK, Cho SH, et al. Clinical outcomes of delayed clearance of serum HBSAG in patients with chronic HBV infection. Korean J Intern Med 2007;22:73-76.

48. Ahn SH, Park YN, Park JY, Chang HY, Lee JM, Shin JE, et al. Long-term clinical and histological outcomes in patients with spontaneous hepatitis B surface antigen seroclearance. J Hepatol 2005;42:188-194.

49. Simonetti J, Bulkow L, McMahon BJ, Homan C, Snowball M, Negus $S$, et al. Clearance of hepatitis B surface antigen and risk of hepatocellular carcinoma in a cohort chronically infected with hepatitis B virus. Hepatology 2010;51:1531-1537.

50. Huo TI, Wu JC, Lee PC, Chau GY, Lui WY, Tsay SH, et al. Seroclearance of hepatitis $B$ surface antigen in chronic carriers does not necessarily imply a good prognosis. Hepatology 1998;28:231-236.

51. Yuen MF, Wong DK, Fung J, Ip P, But D, Hung I, et al. HBsAg Seroclearance in chronic hepatitis $B$ in Asian patients: replicative level and risk of hepatocellular carcinoma. Gastroenterology 2008;135:11921199.

52. Fattovich G, Pantalena M, Zagni I, Realdi G, Schalm SW, Christensen E. Effect of hepatitis $B$ and $C$ virus infections on the natural history of compensated cirrhosis: a cohort study of 297 patients. Am J Gastroenterol 2002;97:2886-2895.

53. Niederau C, Heintges T, Lange S, Goldmann G, Niederau CM, Mohr L, et al. Long-term follow-up of HBeAg-positive patients treated with interferon alfa for chronic hepatitis B. N Engl J Med 1996;334:1422-1427.

54. Kim C, Kim J, Lee H, Yoon Y, Song I. Natural history and survival rate of chronic liver diseases in Korea: 20 years prospective analysis. Korean J Med 1994;46:168-180.

55. Lee KJ, Han KH, Chun JY, Moon YM, Lee SI, Park IS, et al. Natural 
history of chronic hepatitis type B throughout long-term follow-up. Korean J Gastroenterol 1997;29:343-351.

56. McMahon BJ. Natural history of chronic hepatitis B. Clin Liver Dis 2010;14:381-396.

57. Iloeje UH, Yang HI, Su J, Jen CL, You SL, Chen CJ. Predicting cirrhosis risk based on the level of circulating hepatitis B viral load. Gastroenterology 2006;130:678-686.

58. Huo T, Wu JC, Hwang SJ, Lai CR, Lee PC, Tsay SH, et al. Factors predictive of liver cirrhosis in patients with chronic hepatitis $\mathrm{B}$ : a multivariate analysis in a longitudinal study. Eur J Gastroenterol Hepatol 2000;12:687-693.

59. Chen CJ, Yang HI, Su J, Jen CL, You SL, Lu SN, et al. Risk of hepatocellular carcinoma across a biological gradient of serum hepatitis $B$ virus DNA level. JAMA 2006;295:65-73.

60. McMahon BJ, Bulkow L, Harpster A, Snowball M, Lanier A, Sacco $F$, et al. Screening for hepatocellular carcinoma in Alaska natives infected with chronic hepatitis B: a 16-year population-based study. Hepatology 2000;32:842-846.

61. Alberts SR, Lanier AP, McMahon BJ, Harpster A, Bulkow LR, Heyward WL, et al. Clustering of hepatocellular carcinoma in Alaska Native families. Genet Epidemiol 1991;8:127-139.

62. Hainaut $P$, Boyle P. Curbing the liver cancer epidemic in Africa. Lancet 2008;371:367-368.

63. Chen ZM, Liu BQ, Boreham J, Wu YP, Chen JS, Peto R. Smoking and liver cancer in China: case-control comparison of 36,000 liver cancer deaths vs. 17,000 cirrhosis deaths. Int J Cancer 2003;107:106-112.

64. Wang CS, Yao WJ, Chang TT, Wang ST, Chou P. The impact of type 2 diabetes on the development of hepatocellular carcinoma in different viral hepatitis statuses. Cancer Epidemiol Biomarkers Prev 2009;18:2054-2060.

65. Peng D, Han Y, Ding H, Wei L. Hepatic steatosis in chronic hepatitis $B$ patients is associated with metabolic factors more than viral factors. J Gastroenterol Hepatol 2008;23:1082-1088.

66. Yun JW, Cho YK, Park JH, Kim HJ, Park DI, Sohn Cl, et al. Hepatic steatosis and fibrosis in young men with treatment-naive chronic hepatitis B. Liver Int 2009;29:878-883.

67. Minakari M, Molaei M, Shalmani HM, Mohammad Alizadeh AH, Jazi $\mathrm{AH}$, Naderi $\mathrm{N}$, et al. Liver steatosis in patients with chronic hepatitis B infection: host and viral risk factors. Eur J Gastroenterol Hepatol 2009;21:512-516.

68. Freedman ND, Everhart JE, Lindsay KL, Ghany MG, Curto TM, Shiffman ML, et al. Coffee intake is associated with lower rates of liver disease progression in chronic hepatitis C. Hepatology 2009;50:1360-1369.

69. La Vecchia C. Coffee, liver enzymes, cirrhosis and liver cancer. J Hepatol 2005;42:444-446.

70. Tanaka K, Hara M, Sakamoto T, Higaki Y, Mizuta T, Eguchi Y, et al. Inverse association between coffee drinking and the risk of he- patocellular carcinoma: a case-control study in Japan. Cancer Sci 2007:98:214-218.

71. Cadden IS, Partovi N, Yoshida EM. Review article: possible beneficial effects of coffee on liver disease and function. Aliment Pharmacol Ther 2007;26:1-8.

72. Masterton GS, Hayes PC. Coffee and the liver: a potential treatment for liver disease? Eur J Gastroenterol Hepatol 2010;22:1277-1283.

73. Harris RA, Chen G, Lin WY, Shen FM, London WT, Evans AA. Spontaneous clearance of high-titer serum HBV DNA and risk of hepatocellular carcinoma in a Chinese population. Cancer Causes Control 2003;14:995-1000.

74. Yang HI, Lu SN, Liaw YF, You SL, Sun CA, Wang LY, et al. Hepatitis $\mathrm{B}$ e antigen and the risk of hepatocellular carcinoma. N Engl J Med 2002;347:168-174.

75. Yu MW, Yeh SH, Chen PJ, Liaw YF, Lin CL, Liu CJ, et al. Hepatitis B virus genotype and DNA level and hepatocellular carcinoma: a prospective study in men. J Natl Cancer Inst 2005;97:265-272.

76. McMahon BJ. The influence of hepatitis B virus genotype and subgenotype on the natural history of chronic hepatitis B. Hepatol Int 2009;3:334-342.

77. Chu CJ, Keeffe EB, Han SH, Perrillo RP, Min AD, Soldevila-Pico C, et al. Hepatitis $B$ virus genotypes in the United States: results of a nationwide study. Gastroenterology 2003;125:444-451.

78. Kim JK, Chang HY, Lee JM, Baatarkhuu O, Yoon YJ, Park JY, et al. Specific mutations in the enhancer II/core promoter/precore regions of hepatitis B virus subgenotype C2 in Korean patients with hepatocellular carcinoma. J Med Virol 2009;81:1002-1008.

79. Choi JW, Ahn SH, Park JY, Chang HY, Kim JK, Baatarkhuu O, et al. Hepatitis $B$ e antigen-negative mutations in the precore and core promoter regions in Korean patients. J Med Virol 2009;81:594-601.

80. Yang HI, Yeh SH, Chen PJ, Iloeje UH, Jen CL, Su J, et al. Associations between hepatitis $\mathrm{B}$ virus genotype and mutants and the risk of hepatocellular carcinoma. J Natl Cancer Inst 2008;100:1134-1143.

81. Grandjacques C, Pradat P, Stuyver L, Chevallier M, Chevallier P, Pichoud $C$, et al. Rapid detection of genotypes and mutations in the pre-core promoter and the pre-core region of hepatitis $B$ virus genome: correlation with viral persistence and disease severity. J Hepatol 2000;33:430-439.

82. Naoumov NV, Schneider R, Grotzinger T, Jung MC, Miska S, Pape $G R$, et al. Precore mutant hepatitis $B$ virus infection and liver disease. Gastroenterology 1992;102:538-543.

83. Ohnishi K, Terabayashi H, Unuma T, Takahashi A, Okuda K. Effects of habitual alcohol intake and cigarette smoking on the development of hepatocellular carcinoma. Alcohol Clin Exp Res 1987;11:45-48.

84. Chevillotte G, Durbec JP, Gerolami A, Berthezene P, Bidart JM, Camatte R. Interaction between hepatitis $b$ virus and alcohol consumption in liver cirrhosis. An epidemiologic study. Gastroenterology 1983;85:141-145. 
85. Villa E, Rubbiani L, Barchi T, Ferretti I, Grisendi A, De Palma M, et al. Susceptibility of chronic symptomless HBsAg carriers to ethanolinduced hepatic damage. Lancet 1982;2:1243-1244.

86. Morgan TR, Mandayam S, Jamal MM. Alcohol and hepatocellular carcinoma. Gastroenterology 2004;127(5 Suppl 1):S87-S96.

87. Donato F, Tagger A, Gelatti U, Parrinello G, Boffetta P, Albertini A, et al. Alcohol and hepatocellular carcinoma: the effect of lifetime intake and hepatitis virus infections in men and women. Am J Epidemiol 2002;155:323-331.

88. Bellentani S, Saccoccio G, Costa G, Tiribelli C, Manenti F, Sodde M, et al. Drinking habits as cofactors of risk for alcohol induced liver damage. The Dionysos Study Group. Gut 1997;41:845-850.

89. Becker U, Deis A, Sorensen TI, Gronbaek M, Borch-Johnsen K, Muller $\mathrm{CF}$, et al. Prediction of risk of liver disease by alcohol intake, sex, and age: a prospective population study. Hepatology 1996;23:1025-1029.

90. Loomba R, Yang HI, Su J, Brenner D, lloeje U, Chen CJ. Obesity and alcohol synergize to increase the risk of incident hepatocellular carcinoma in men. Clin Gastroenterol Hepatol 2010;8:891-898, 898 e1-2.

91. Kim JH, Kim JS, Lee JJ, Kim JH, Kim SY, Jung YK, et al. Survey of perinatal hepatitis B virus transmission after Korean National Prevention Program in a tertiary hospital. Korean J Intern Med 2014;29:307-314.

92. Mast EE, Weinbaum CM, Fiore AE, Alter MJ, Bell BP, Finelli L, et al. A comprehensive immunization strategy to eliminate transmission of hepatitis B virus infection in the United States: recommendations of the Advisory Committee on Immunization Practices (ACIP) Part II: immunization of adults. MMWR Recomm Rep 2006;55:1-33; quiz CE31-34.

93. Mast EE, Margolis HS, Fiore AE, Brink EW, Goldstein ST, Wang SA, et al. A comprehensive immunization strategy to eliminate transmission of hepatitis B virus infection in the United States: recommendations of the Advisory Committee on Immunization Practices (ACIP) part 1: immunization of infants, children, and adolescents. MMWR Recomm Rep 2005;54:1-31.

94. Beasley RP, Hwang LY, Lee GC, Lan CC, Roan CH, Huang FY, et al. Prevention of perinatally transmitted hepatitis $B$ virus infections with hepatitis $B$ immune globulin and hepatitis $B$ vaccine. Lancet 1983;2:1099-1102.

95. Hill JB, Sheffield JS, Kim MJ, Alexander JM, Sercely B, Wendel GD. Risk of hepatitis $B$ transmission in breast-fed infants of chronic hepatitis B carriers. Obstet Gynecol 2002;99:1049-1052.

96. Nordenfelt E, Dahlquist E. HBsAg positive adopted children as a cause of intrafamilial spread of hepatitis B. Scand J Infect Dis 1978;10:161-163.

97. Steinberg SC, Alter HJ, Leventhal BG. The risk of hepatitis transmission to family contacts of leukemia patients. J Pediatr 1975;87:753756.

98. Updated U.S. Public Health Service Guidelines for the Management of Occupational Exposures to HBV, HCV, and HIV and Recommendations for Postexposure Prophylaxis. MMWR Recomm Rep 2001;50:1-52.
99. Keeffe EB. Hepatitis A and B superimposed on chronic liver disease: vaccine-preventable diseases. Trans Am Clin Climatol Assoc 2006;117:227-237; discussion 237-228.

100. Craig AS, Schaffner W. Prevention of hepatitis A with the hepatitis A vaccine. N Engl J Med 2004;350:476-481

101. Lemon SM, Gates NL, Simms TE, Bancroft WH. IgM antibody to hepatitis $B$ core antigen as a diagnostic parameter of acute infection with hepatitis B virus. J Infect Dis 1981;143:803-809.

102. Lai CL, Lau JY, Yeoh EK, Chang WK, Lin HJ. Significance of isolated anti-HBC seropositivity by ELISA: implications and the role of radioimmunoassay. J Med Virol 1992;36:180-183.

103. Sanchez-Quijano A, Jauregui J, Leal M, Pineda JA, Castilla A, Abad MA, et al. Hepatitis $B$ virus occult infection in subjects with persistent isolated anti-HBc reactivity. J Hepatol 1993;17:288-293.

104. Raimondo G, Navarra G, Mondello S, Costantino L, Colloredo G, Cucinotta $E$, et al. Occult hepatitis $B$ virus in liver tissue of individuals without hepatic disease. J Hepatol 2008;48:743-746.

105. Said ZN. An overview of occult hepatitis B virus infection. World J Gastroenterol 2011;17:1927-1938.

106. Jacobsen KH, Koopman JS. Declining hepatitis A seroprevalence: a global review and analysis. Epidemiol Infect 2004;132:1005-1022.

107. Moon HW, Cho JH, Hur M, Yun YM, Choe WH, Kwon SY, et al. Laboratory characteristics of recent hepatitis $A$ in Korea: ongoing epidemiological shift. World J Gastroenterol 2010;16:1115-1118.

108. Song HJ, Kim TH, Song JH, Oh HJ, Ryu KH, Yeom HJ, et al. Emerging need for vaccination against hepatitis $A$ virus in patients with chronic liver disease in Korea. J Korean Med Sci 2007;22:218-222.

109. Pawlotsky JM. Hepatitis B virus (HBV) DNA assays (methods and practical use) and viral kinetics. J Hepatol 2003;39 Suppl 1:S31-35.

110. Lindh $M$, Hannoun C. Dynamic range and reproducibility of hepatitis $B$ virus (HBV) DNA detection and quantification by Cobas Taqman HBV, a real-time semiautomated assay. J Clin Microbiol 2005;43:4251-4254.

111.Chu CM, Liaw YF. Genotype C hepatitis B virus infection is associated with a higher risk of reactivation of hepatitis $B$ and progression to cirrhosis than genotype B: a longitudinal study of hepatitis $B$ e antigen-positive patients with normal aminotransferase levels at baseline. J Hepatol 2005;43:411-417.

112. Sumi H, Yokosuka O, Seki N, Arai M, Imazeki F, Kurihara T, et al. Influence of hepatitis $B$ virus genotypes on the progression of chronic type B liver disease. Hepatology 2003;37:19-26.

113. Chu CM, Liaw YF. Predictive factors for reactivation of hepatitis $B$ following hepatitis B e antigen seroconversion in chronic hepatitis B. Gastroenterology 2007;133:1458-1465.

114. Chan HL, Hui AY, Wong ML, Tse AM, Hung LC, Wong VW, et al. Genotype C hepatitis B virus infection is associated with an increased risk of hepatocellular carcinoma. Gut 2004;53:1494-1498.

115. Kao JH, Chen DS. Clinical relevance of hepatitis B virus genotypes 
Ba and Bj in Taiwan. Gastroenterology 2003;125:1916-1917; author reply 1917-1918.

116. Kao JH, Wu NH, Chen PJ, Lai MY, Chen DS. Hepatitis B genotypes and the response to interferon therapy. J Hepatol 2000;33:9981002.

117. Keeffe EB, Dieterich DT, Han SH, Jacobson IM, Martin P, Schiff ER, et al. A treatment algorithm for the management of chronic hepatitis $B$ virus infection in the United States: 2008 update. Clin Gastroenterol Hepatol 2008;6:1315-1341; quiz 1286.

118. Perrillo RP, Lai CL, Liaw YF, Dienstag JL, Schiff ER, Schalm SW, et al. Predictors of $\mathrm{HBeAg}$ loss after lamivudine treatment for chronic hepatitis B. Hepatology 2002;36:186-194.

119. Prati D, Taioli E, Zanella A, Della Torre E, Butelli S, Del Vecchio E, et al. Updated definitions of healthy ranges for serum alanine aminotransferase levels. Ann Intern Med 2002;137:1-10.

120. Kariv R, Leshno M, Beth-Or A, Strul H, Blendis L, Kokia E, et al. Reevaluation of serum alanine aminotransferase upper normal limit and its modulating factors in a large-scale population study. Liver Int 2006;26:445-450.

121. Kim HC, Nam CM, Jee SH, Han KH, Oh DK, Suh I. Normal serum aminotransferase concentration and risk of mortality from liver diseases: prospective cohort study. BMJ 2004;328:983.

122. Lee JK, Shim JH, Lee HC, Lee SH, Kim KM, Lim YS, et al. Estimation of the healthy upper limits for serum alanine aminotransferase in Asian populations with normal liver histology. Hepatology 2010;51:1577-1583.

123. Bedossa $P$, Dargere $D$, Paradis V. Sampling variability of liver fibrosis in chronic hepatitis C. Hepatology 2003;38:1449-1457.

124. Bonino F, Marcellin P, Lau GK, Hadziyannis S, Jin R, Piratvisuth T, et al. Predicting response to peginterferon alpha-2a, lamivudine and the two combined for HBeAg-negative chronic hepatitis B. Gut 2007:56:699-705

125. Lai M, Hyatt BJ, Nasser I, Curry M, Afdhal NH. The clinical significance of persistently normal ALT in chronic hepatitis B infection. J Hepatol 2007;47:760-767.

126. Cho SW, Cheong JY. Clinical Application of Non-invasive Diagnosis for Hepatic Fibrosis. Korean J Hepatol 2007;13:129-137.

127. Kim BK, Kim SA, Park YN, Cheong JY, Kim HS, Park JY, et al. Noninvasive models to predict liver cirrhosis in patients with chronic hepatitis B. Liver Int 2007;27:969-976.

128. Wong GL. Update of liver fibrosis and steatosis with transient elastography (Fibroscan). Gastroenterol Rep (Oxf) 2013;1:19-26.

129. Lucidarme D, Foucher J, Le Bail B, Vergniol J, Castera L, Duburque $C$, et al. Factors of accuracy of transient elastography (fibroscan) for the diagnosis of liver fibrosis in chronic hepatitis C. Hepatology 2009:49:1083-1089.

130. Myers RP, Crotty P, Pomier-Layrargues G, Ma M, Urbanski SJ, Elkashab M. Prevalence, risk factors and causes of discordance in fibrosis staging by transient elastography and liver biopsy. Liver Int 2010;30:1471-1480.

131. Castera L, Forns X, Alberti A. Non-invasive evaluation of liver fibrosis using transient elastography. J Hepatol 2008;48:835-847.

132. Sandrin L, Fourquet B, Hasquenoph JM, Yon S, Fournier C, Mal F, et al. Transient elastography: a new noninvasive method for assessment of hepatic fibrosis. Ultrasound Med Biol 2003;29:1705-1713.

133. Castera L, Pinzani M. Biopsy and non-invasive methods for the diagnosis of liver fibrosis: does it take two to tango? Gut 2010;59:861-866.

134. Castera L. Noninvasive methods to assess liver disease in patients with hepatitis B or C. Gastroenterology 2012;142:1293-1302 e4.

135. Zhu X, Wang LC, Chen EQ, Chen XB, Chen LY, Liu L, et al. Prospective evaluation of FibroScan for the diagnosis of hepatic fibrosis compared with liver biopsy/AST platelet ratio index and FIB-4 in patients with chronic HBV infection. Dig Dis Sci 2011;56:27422749.

136. Kim do Y, Kim SU, Ahn SH, Park JY, Lee JM, Park YN, et al. Usefulness of FibroScan for detection of early compensated liver cirrhosis in chronic hepatitis B. Dig Dis Sci 2009;54:1758-1763.

137. Seo YS, Kim MY, Kim SU, Hyun BS, Jang JY, Lee JW, et al. Accuracy of transient elastography in assessing liver fibrosis in chronic viral hepatitis: A multicentre, retrospective study. Liver Int 2015.

138. Practice guidelines for management of hepatocellular carcinoma 2009. Korean J Hepatol 2009;15:391-423.

139. Committee NCC-NCSGR. National Cancer Screening Guideline Revision web site $<$ http://www.cancer.go.kr > National Cancer Center-National Cancer Screening Guideline Revision Accessed 2015.

140. Liaw YF. Impact of therapy on the outcome of chronic hepatitis B. Liver Int 2013;33(Suppl 1):111-115.

141. Liaw YF, Sung JJ, Chow WC, Farrell G, Lee CZ, Yuen H, et al. Lamivudine for patients with chronic hepatitis $B$ and advanced liver disease. N Engl J Med 2004;351:1521-1531.

142. Shim JH, Lee HC, Kim KM, Lim YS, Chung YH, Lee YS, et al. Efficacy of entecavir in treatment-naive patients with hepatitis $B$ virusrelated decompensated cirrhosis. J Hepatol 2010;52:176-182.

143. Liaw YF, Sheen IS, Lee CM, Akarca US, Papatheodoridis GV, SuetHing Wong $F$, et al. Tenofovir disoproxil fumarate (TDF), emtricitabine/TDF, and entecavir in patients with decompensated chronic hepatitis B liver disease. Hepatology 2011;53:62-72.

144. Matsumoto A, Tanaka E, Rokuhara A, Kiyosawa K, Kumada H, Omata $M$, et al. Efficacy of lamivudine for preventing hepatocellular carcinoma in chronic hepatitis B: A multicenter retrospective study of 2795 patients. Hepatol Res 2005;32:173-184.

145. Yuen MF, Seto WK, Chow DH, Tsui K, Wong DK, Ngai VW, et al. Long-term lamivudine therapy reduces the risk of long-term complications of chronic hepatitis B infection even in patients without 
advanced disease. Antivir Ther 2007;12:1295-1303.

146. Calvaruso V, Craxi A. Fibrosis in chronic viral hepatitis. Best Pract Res Clin Gastroenterol 2011;25:219-230.

147. Yapali S, Talaat N, Lok AS. Management of hepatitis B: our practice and how it relates to the guidelines. Clin Gastroenterol Hepatol 2014;12:16-26.

148. Papatheodoridis GV, Cholongitas E, Archimandritis AJ, Burroughs AK. Current management of hepatitis B virus infection before and after liver transplantation. Liver Int 2009;29:1294-1305.

149. Chu CM, Hung SJ, Lin J, Tai DI, Liaw YF. Natural history of hepatitis $\mathrm{B}$ e antigen to antibody seroconversion in patients with normal serum aminotransferase levels. Am J Med 2004;116:829-834.

150. Lin SM, Yu ML, Lee CM, Chien RN, Sheen IS, Chu CM, et al. Interferon therapy in $\mathrm{HBeAg}$ positive chronic hepatitis reduces progression to cirrhosis and hepatocellular carcinoma. J Hepatol 2007:46:45-52.

151. Mommeja-Marin H, Mondou E, Blum MR, Rousseau F. Serum HBV DNA as a marker of efficacy during therapy for chronic HBV infection: analysis and review of the literature. Hepatology 2003;37:1309-1319.

152. Schiff ER, Lee SS, Chao YC, Kew Yoon S, Bessone F, Wu SS, et al. Long-term treatment with entecavir induces reversal of advanced fibrosis or cirrhosis in patients with chronic hepatitis B. Clin Gastroenterol Hepatol 2011;9:274-276.

153. Yuan HJ, Yuen MF, Ka-Ho Wong D, Sablon E, Lai CL. The relationship between HBV-DNA levels and cirrhosis-related complications in Chinese with chronic hepatitis B. J Viral Hepat 2005;12:373-379.

154. Chang TT, Gish RG, de Man R, Gadano A, Sollano J, Chao YC, et al. A comparison of entecavir and lamivudine for $\mathrm{HBeAg}$-positive chronic hepatitis B. N Engl J Med 2006;354:1001-1010.

155. Chang TT, Liaw YF, Wu SS, Schiff E, Han KH, Lai CL, et al. Longterm entecavir therapy results in the reversal of fibrosis/cirrhosis and continued histological improvement in patients with chronic hepatitis B. Hepatology 2010;52:886-893.

156. Hadziyannis SJ, Tassopoulos NC, Heathcote EJ, Chang TT, Kitis $\mathrm{G}$, Rizzetto $\mathrm{M}$, et al. Long-term therapy with adefovir dipivoxil for HBeAg-negative chronic hepatitis B. N Engl J Med 2005;352:26732681.

157. Hadziyannis SJ, Tassopoulos NC, Heathcote EJ, Chang TT, Kitis $G$, Rizzetto $M$, et al. Long-term therapy with adefovir dipivoxil for $\mathrm{HBeAg-negative} \mathrm{chronic} \mathrm{hepatitis} \mathrm{B} \mathrm{for} \mathrm{up} \mathrm{to} 5$ years. Gastroenterology 2006;131:1743-1751.

158. Lai CL, Shouval D, Lok AS, Chang TT, Cheinquer H, Goodman Z, et al. Entecavir versus lamivudine for patients with $\mathrm{HBeAg}$-negative chronic hepatitis B. N Engl J Med 2006;354:1011-1020.

159. Andreani T, Serfaty L, Mohand D, Dernaika S, Wendum D, Chazouilleres 0 , et al. Chronic hepatitis B virus carriers in the immunotolerant phase of infection: histologic findings and outcome.
Clin Gastroenterol Hepatol 2007;5:636-641.

160. Consensus statements on the prevention and management of hepatitis B and hepatitis C in the Asia-Pacific region. Core Working Party for Asia-Pacific Consensus on Hepatitis B and C. J Gastroenterol Hepatol 2000;15:825-841.

161. Lok AS, McMahon BJ; Practice Guidelines Committee, American Association for the Study of Liver Diseases. Hepatology 2001;34:1225-1241.

162. Lee KS, Kim DJ. [Management of Chronic Hepatitis B]. Korean J Hepatol 2007;13:447-488.

163. Liaw YF, Leung N, Kao JH, Piratvisuth T, Gane E, Han KH, et al. Asian-Pacific consensus statement on the management of chronic hepatitis B: a 2008 update. Hepatol Int 2008;2:263-283.

164. Chu CJ, Hussain M, Lok AS. Quantitative serum HBV DNA levels during different stages of chronic hepatitis B infection. Hepatology 2002;36:1408-1415.

165. Yuen MF, Tanaka Y, Fong DY, Fung J, Wong DK, Yuen JC, et al. Independent risk factors and predictive score for the development of hepatocellular carcinoma in chronic hepatitis B. J Hepatol 2009;50:80-88.

166. Lok AS, Heathcote EJ, Hoofnagle JH. Management of hepatitis B: 2000--summary of a workshop. Gastroenterology 2001;120:18281853.

167. Yuen MF, Yuan HJ, Wong DK, Yuen JC, Wong WM, Chan AO, et al. Prognostic determinants for chronic hepatitis B in Asians: therapeutic implications. Gut 2005;54:1610-1614.

168. Park JY, Park YN, Kim DY, Paik YH, Lee KS, Moon BS, et al. High prevalence of significant histology in asymptomatic chronic hepatitis B patients with genotype C and high serum HBV DNA levels. J Viral Hepat 2008;15:615-621.

169. Kumar M, Sarin SK, Hissar S, Pande C, Sakhuja P, Sharma BC, et al. Virologic and histologic features of chronic hepatitis $B$ virusinfected asymptomatic patients with persistently normal ALT. Gastroenterology 2008;134:1376-1384.

170. Tong MJ, Hsien C, Hsu L, Sun HE, Blatt LM. Treatment recommendations for chronic hepatitis B: an evaluation of current guidelines based on a natural history study in the United States. Hepatology 2008:48:1070-1078.

171. Tong MJ, Hsu L, Chang PW, Blatt LM. Evaluation of current treatment recommendations for chronic hepatitis B: a 2011 update. J Gastroenterol Hepatol 2011;26:829-835.

172. Rockey DC, Caldwell SH, Goodman ZD, Nelson RC, Smith AD. Liver biopsy. Hepatology 2009;49:1017-1044.

173. Zeuzem S, Gane E, Liaw YF, Lim SG, DiBisceglie A, Buti M, et al. Baseline characteristics and early on-treatment response predict the outcomes of 2 years of telbivudine treatment of chronic hepatitis B. J Hepatol 2009;51:11-20.

174. Center TKAftSoL-LCCR. Clinical Practice Guideline for Liver Cirrho- 
sis, Update. 2011.

175. Papatheodoridis GV, Dimou E, Dimakopoulos K, Manolakopoulos $S$, Rapti I, Kitis $G$, et al. Outcome of hepatitis B e antigen-negative chronic hepatitis $B$ on long-term nucleos(t)ide analog therapy starting with lamivudine. Hepatology 2005;42:121-129.

176. Eun JR, Lee HJ, Kim TN, Lee KS. Risk assessment for the development of hepatocellular carcinoma: according to on-treatment viral response during long-term lamivudine therapy in hepatitis B virusrelated liver disease. J Hepatol 2010;53:118-125.

177. Sung JJ, Tsoi KK, Wong VW, Li KC, Chan HL. Meta-analysis: Treatment of hepatitis $B$ infection reduces risk of hepatocellular carcinoma. Aliment Pharmacol Ther 2008;28:1067-1077.

178. Zhang QQ, An X, Liu YH, Li SY, Zhong Q, Wang J, et al. Long-Term Nucleos(t)ide Analogues Therapy for Adults With Chronic Hepatitis $B$ reduces the Risk of Long-Term Complications: a meta-analysis. Virol J 2011;8:72.

179. Sinn DH, Lee J, Goo J, Kim K, Gwak GY, Paik YH, et al. Hepatocellular carcinoma risk in chronic hepatitis B virus-infected compensated cirrhosis patients with low viral load. Hepatology 2015;62:694701.

180. EASL Clinical Practice Guidelines: management of chronic hepatitis B. J Hepatol 2009;50:227-242.

181. Fattovich G, Giustina G, Realdi G, Corrocher R, Schalm SW. Longterm outcome of hepatitis $B$ e antigen-positive patients with compensated cirrhosis treated with interferon alfa. European Concerted Action on Viral Hepatitis (EUROHEP). Hepatology 1997;26:13381342.

182. Peters M, Davis GL, Dooley JS, Hoofnagle JH. The interferon system in acute and chronic viral hepatitis. Prog Liver Dis 1986;8:453-467.

183. Buster EH, Hansen BE, Buti M, Delwaide J, Niederau C, Michielsen $P P$, et al. Peginterferon alpha-2b is safe and effective in $\mathrm{HBeAg}$ positive chronic hepatitis B patients with advanced fibrosis. Hepatology 2007;46:388-394.

184. Schiff E, Simsek H, Lee WM, Chao YC, Sette H, Jr., Janssen HL, et al. Efficacy and safety of entecavir in patients with chronic hepatitis B and advanced hepatic fibrosis or cirrhosis. Am J Gastroenterol 2008;103:2776-2783.

185. Liang J, Han T, Xiao SX. [Telbivudine treatment on cirrhosis resulting from chronic hepatitis B]. Zhonghua Gan Zang Bing Za Zhi 2009;17:24-27.

186. Kim JH, Yim HJ, Jung ES, Jung YK, Seo YS, Yeon JE, et al. Virologic and biochemical responses to clevudine in patients with chronic HBV infection-associated cirrhosis: data at week 48. J Viral Hepat 2011;18:287-293.

187. Marcellin P, Gane E, Buti M, Afdhal N, Sievert W, Jacobson IM, et al. Regression of cirrhosis during treatment with tenofovir disoproxil fumarate for chronic hepatitis B: a 5-year open-label followup study. Lancet 2013;381:468-475.
188. Yao FY, Terrault NA, Freise C, Maslow L, Bass NM. Lamivudine treatment is beneficial in patients with severely decompensated cirrhosis and actively replicating hepatitis B infection awaiting liver transplantation: a comparative study using a matched, untreated cohort. Hepatology 2001;34:411-416.

189. Perrillo R, Tamburro C, Regenstein F, Balart L, Bodenheimer $H$, Silva $M$, et al. Low-dose, titratable interferon alfa in decompensated liver disease caused by chronic infection with hepatitis B virus. Gastroenterology 1995;109:908-916.

190. Villeneuve JP, Condreay LD, Willems B, Pomier-Layrargues G, Fenyves $D$, Bilodeau $M$, et al. Lamivudine treatment for decompensated cirrhosis resulting from chronic hepatitis B. Hepatology 2000;31:207-210.

191. Chien RN, Lin CH, Liaw YF. The effect of lamivudine therapy in hepatic decompensation during acute exacerbation of chronic hepatitis B. J Hepatol 2003;38:322-327.

192. Fontana RJ, Hann HW, Perrillo RP, Vierling JM, Wright T, Rakela J, et al. Determinants of early mortality in patients with decompensated chronic hepatitis B treated with antiviral therapy. Gastroenterology 2002;123:719-727.

193. Chan HLY, Hsu C-W, Sarin S, Suh DJ, Piravisuth T, Gane E, et al. Efficacy and safety of telbivudine versus lamivudine in the treatment of decompensated chronic hepatitis B for 2 years[Abstract]. Hepatol Int 2010;4:146.

194. Moon W, Choi MS, Moon YM, Paik SW, Lee JH, Koh KC, et al. [Efficacy and safety of adefovir dipivoxil in patients with decompensated liver cirrhosis with Lamivudine resistance compared to patients with compensated liver disease]. Korean J Hepatol 2005;11:125134.

195. Liaw YF, Raptopoulou-Gigi M, Cheinquer H, Sarin SK, Tanwandee $T$, Leung $N$, et al. Efficacy and safety of entecavir versus adefovir in chronic hepatitis B patients with hepatic decompensation: A randomized, open-label study. Hepatology 2011;54:91-100.

196. Afdhal NH, Lok AS, Di Bisceglie AM. Clinical decisions. Management of incidental hepatitis C virus infection. N Engl J Med 2009;360:1902-1906.

197. Chevaliez S, Bouvier Alias M, Laperche S, Pawlotsky J. Performance of the Cobas AmpliPrep/Cobas TaqMan real-time PCR assay for hepatitis B virus DNA quantification. J Clin Microbiol 2008:46:1716-1723.

198. Ahn SH, Yuen L, Revill P. Clarification required for the definition of hepatitis B virus subgenotypes $\mathrm{C} 1$ and $\mathrm{C} 2$. Intervirology 2009;52:321-322.

199. Ahn SH, Chan HL, Chen PJ, Cheng J, Goenka MK, Hou J, et al. Chronic hepatitis B: whom to treat and for how long? Propositions, challenges, and future directions. Hepatol Int 2010;4:386-395.

200. Lee JM, Ahn SH. Quantification of HBsAg: basic virology for clinical practice. World I Gastroenterol 2011;17:283-289. 
201. Lee JM, Ahn SH, Kim HS, Park H, Chang HY, Kim DY, et al. Quantitative hepatitis B surface antigen and hepatitis B e antigen titers in prediction of treatment response to entecavir. Hepatology 2011;53:1486-1493.

202. Wursthorn K, Jung M, Riva A, Goodman ZD, Lopez P, Bao W, et al. Kinetics of hepatitis $B$ surface antigen decline during 3 years of telbivudine treatment in hepatitis B e antigen-positive patients. Hepatology 2010;52:1611-1620.

203. Seto WK, Wong DK, Fung J, Huang FY, Lai CL, Yuen MF. Reduction of hepatitis B surface antigen levels and hepatitis B surface antigen seroclearance in chronic hepatitis $B$ patients receiving 10 years of nucleoside analogue therapy. Hepatology 2013;58:923-931.

204. Liaw YF. Clinical utility of hepatitis B surface antigen quantitation in patients with chronic hepatitis B: a review. Hepatology 2011;54:E1-9.

205. Chan HL, Thompson A, Martinot-Peignoux M, Piratvisuth T, Cornberg $M$, Brunetto $M R$, et al. Hepatitis $B$ surface antigen quantification: why and how to use it in 2011 - a core group report. J Hepatol 2011;55:1121-1131

206. Nguyen T, Thompson AJ, Bowden S, Croagh C, Bell S, Desmond PV, et al. Hepatitis B surface antigen levels during the natural history of chronic hepatitis B: a perspective on Asia. J Hepatol 2010;52:508 513.

207. Jaroszewicz J, Calle Serrano B, Wursthorn K, Deterding K, Schlue $J$, Raupach $R$, et al. Hepatitis B surface antigen (HBsAg) levels in the natural history of hepatitis B virus (HBV)-infection: a European perspective. J Hepatol 2010;52:514-522.

208. Chan HL, Wong VW, Wong GL, Tse CH, Chan HY, Sung JJ. A longitudinal study on the natural history of serum hepatitis $B$ surface antigen changes in chronic hepatitis B. Hepatology 2010;52:12321241.

209. Jung YK, Kim JH, Lee YS, Lee HJ, Yoon E, Jung ES, et al. Change in serum hepatitis $B$ surface antigen level and its clinical significance in treatment-naive, hepatitis B e antigen-positive patients receiving entecavir. J Clin Gastroenterol 2010;44:653-657.

210. Brunetto MR, Moriconi F, Bonino F, Lau GK, Farci P, Yurdaydin C, et al. Hepatitis $B$ virus surface antigen levels: a guide to sustained response to peginterferon alfa-2a in $\mathrm{HBeAg-negative} \mathrm{chronic} \mathrm{hepa-}$ titis B. Hepatology 2009;49:1141-1150.

211. Manesis EK, Hadziyannis ES, Angelopoulou OP, Hadziyannis SJ. Prediction of treatment-related $\mathrm{HBsAg}$ loss in $\mathrm{HBeAg}$-negative chronic hepatitis B: a clue from serum HBsAg levels. Antivir Ther 2007;12:73-82.

212. Reijnders JG, Rijckborst V, Sonneveld MJ, Scherbeijn SM, Boucher $C A$, Hansen $B E$, et al. Kinetics of hepatitis B surface antigen differ between treatment with peginterferon and entecavir. J Hepatol 2011;54:449-454.

213. Gramenzi A, Loggi E, Micco L, Cursaro C, Fiorino S, Galli S, et al.
Serum hepatitis B surface antigen monitoring in long-term lamivudine-treated hepatitis B virus patients. J Viral Hepat 2011;18:e468474.

214. Zoulim F, Carosi G, Greenbloom S, Mazur W, Nguyen T, Jeffers L, et al. Quantification of HBsAg in nucleos(t)ide-naive patients treated for chronic hepatitis $B$ with entecavir with or without tenofovir in the BE-LOW study. J Hepatol 2015;62:56-63.

215. Kim DY, Ahn SH, Lee HW, Park JY, Kim SU, Paik YH, et al. Clinical course of virologic breakthrough after emergence of YMDD mutations in $\mathrm{HBeAg}$-positive chronic hepatitis B. Intervirology 2008;51:293-298.

216. Lee JM, Park JY, Kim do Y, Nguyen T, Hong SP, Kim SO, et al. Longterm adefovir dipivoxil monotherapy for up to 5 years in lamivudine-resistant chronic hepatitis B. Antivir Ther 2010;15:235-241.

217. Lee JM, Kim HJ, Park JY, Lee CK, Kim DY, Kim JK, et al. Rescue monotherapy in lamivudine-resistant hepatitis B e antigenpositive chronic hepatitis B: adefovir versus entecavir. Antivir Ther 2009;14:705-712.

218. Kim H, Han K, Ahn SH, Kim E, Chang H, Moon MS, et al. Evaluation of methods for monitoring drug resistance in chronic hepatitis $B$ patients during lamivudine therapy based on mass spectrometry and reverse hybridization. Antivir Ther 2005;10:441-449.

219. Han KH, Hong SP, Choi SH, Shin S, Cho SW, Ahn SH, et al. Comparison of multiplex restriction fragment mass polymorphism and sequencing analyses for detecting entecavir resistance in chronic hepatitis B. Antivir Ther 2011;16:77-87.

220. Buti M, Tsai N, Petersen J, Flisiak R, Gurel S, Krastev Z, et al. Seven-year efficacy and safety of treatment with tenofovir disoproxil fumarate for chronic hepatitis B virus infection. Dig Dis Sci 2015;60:1457-1464.

221. Gill US, Zissimopoulos A, Al-Shamma S, Burke K, McPhail MJ, Barr $D A$, et al. Assessment of bone mineral density in tenofovir-treated patients with chronic hepatitis $B$ : can the fracture risk assessment tool identify those at greatest risk? J Infect Dis 2015;211:374-382.

222. Tien C, Xu JJ, Chan LS, Chang M, Lim C, Lee S, et al. Long-Term Treatment with Tenofovir in Asian-American Chronic Hepatitis B Patients Is Associated with Abnormal Renal Phosphate Handling. Dig Dis Sci 2014.

223. Fleischer RD, Lok AS. Myopathy and neuropathy associated with nucleos(t)ide analog therapy for hepatitis B. J Hepatol 2009;51:787791.

224. Fontana RJ. Side effects of long-term oral antiviral therapy for hepatitis B. Hepatology 2009;49:S185-195.

225. Lai CL, Gane E, Liaw YF, Hsu CW, Thongsawat S, Wang Y, et al. Telbivudine versus lamivudine in patients with chronic hepatitis $B$. N Engl J Med 2007;357:2576-2588.

226. Liaw YF, Gane E, Leung N, Zeuzem S, Wang Y, Lai CL, et al. 2-Year GLOBE trial results: telbivudine Is superior to lamivudine in patients 
with chronic hepatitis B. Gastroenterology 2009;136:486-495.

227. Seok JI, Lee DK, Lee CH, Park MS, Kim SY, Kim HS, et al. Long-term therapy with clevudine for chronic hepatitis $B$ can be associated with myopathy characterized by depletion of mitochondrial DNA. Hepatology 2009;49:2080-2086.

228. Tak WY, Park SY, Cho CM, Jung MK, Jeon SW, Kweon YO, et al. Clinical, biochemical, and pathological characteristics of clevudineassociated myopathy. J Hepatol 2010;53:261-266.

229. Tak WY, Park SY, Jung MK, Jeon SW, Cho CM, Kweon YO, et al. Mitochondrial myopathy caused by clevudine therapy in chronic hepatitis B patients. Hepatol Res 2009;39:944-947.

230. Piratvisuth T, Marcellin P, Popescu M, Kapprell HP, Rothe V, Lu ZM. Hepatitis B surface antigen: association with sustained response to peginterferon alfa-2a in hepatitis $B$ e antigen-positive patients. Hepatol Int 2013;7:429-436.

231. Sonneveld MJ, Hansen BE, Piratvisuth T, Jia JD, Zeuzem S, Gane $E$, et al. Response-guided peginterferon therapy in hepatitis $B$ e antigen-positive chronic hepatitis B using serum hepatitis B surface antigen levels. Hepatology 2013;58:872-880.

232. Moucari R, Mackiewicz V, Lada O, Ripault MP, Castelnau C, Martinot-Peignoux $\mathrm{M}$, et al. Early serum HBsAg drop: a strong predictor of sustained virological response to pegylated interferon alfa-2a in HBeAg-negative patients. Hepatology 2009;49:1151-1157.

233. Marcellin P, Bonino F, Yurdaydin C, Hadziyannis S, Moucari R, Kapprell $\mathrm{HP}$, et al. Hepatitis $B$ surface antigen levels: association with 5 -year response to peginterferon alfa-2a in hepatitis B e-antigennegative patients. Hepatol Int 2013;7:88-97.

234. Rijckborst V, Hansen BE, Cakaloglu Y, Ferenci P, Tabak F, Akdogan $M$, et al. Early on-treatment prediction of response to peginterferon alfa-2a for HBeAg-negative chronic hepatitis B using $\mathrm{HBsAg}$ and HBV DNA levels. Hepatology 2010;52:454-461.

235. Rijckborst V, Hansen BE, Ferenci P, Brunetto MR, Tabak F, Cakaloglu $Y$, et al. Validation of a stopping rule at week 12 using HBsAg and HBV DNA for HBeAg-negative patients treated with peginterferon alfa-2a. J Hepatol 2012;56:1006-1011.

236. Lee HW, Lee HJ, Hwang JS, Sohn JH, Jang JY, Han KJ, et al. Lamivudine maintenance beyond one year after $\mathrm{HBeAg}$ seroconversion is a major factor for sustained virologic response in $\mathrm{HBeAg}$-positive chronic hepatitis B. Hepatology 2010;51:415-421.

237. Reijnders JG, Perquin MJ, Zhang N, Hansen BE, Janssen HL. Nucleos(t)ide analogues only induce temporary hepatitis B e antigen seroconversion in most patients with chronic hepatitis B. Gastroenterology 2010;139:491-498.

238. Song MJ, Song do S, Kim HY, Yoo SH, Bae SH, Choi JY, et al. Durability of viral response after off-treatment in $\mathrm{HBeAg}$ positive chronic hepatitis B. World J Gastroenterol 2012;18:6277-6283.

239. Hadziyannis SJ, Sevastianos V, Rapti I, Vassilopoulos D, Hadziyannis $\mathrm{E}$. Sustained responses and loss of HBsAg in HBeAg-negative patients with chronic hepatitis B who stop long-term treatment with adefovir. Gastroenterology 2012;143:629-636 e621.

240. Kuo LF, Lee CM, Hung CH, Wang JH, Hu TH, Lu SN, et al. High risk of hepatitis $B$ virus reactivation in nucleos(t)ide analogue-induced hepatitis B e antigen seroconverters older than 40 years. Dig Dis Sci 2014;59:2580-2587.

241. Liaw YF, Xie Q, Han KH, Gane EJ, Piratvusuth T, McCloud PI, et al. Shorter duration and lower dose of peginterferon alpha-2a therapy results in inferior $\mathrm{HBeAg}$ seroconversion rates compared with the duration and dose of 48 weeks and 180ug: Neptune study [Abstract]. Hepatology 2011;52(Suppl 1):112A.

242. Gane E, J. Jia, K. Han, T. Tanwandee, W.L. Chuang, P. Marcellin, et al. Neptune study: On-treatment HBsAg level analysis confirms prediction of response observed in phase 3 study of peginterferon alpha-2a in HBeAg-positive patients. J Hepatol 2011;54(Suppl 2):544.

243. Jeng WJ, Sheen IS, Chen YC, Hsu CW, Chien RN, Chu CM, et al. Off-therapy durability of response to entecavir therapy in hepatitis $\mathrm{B}$ e antigen-negative chronic hepatitis B patients. Hepatology 2013;58:1888-1896.

244. Kim YJ, Kim K, Hwang SH, Kim SS, Lee D, Cheong JY, et al. Durability after discontinuation of nucleos(t)ide therapy in chronic $\mathrm{HBeAg}$ negative hepatitis patients. Clin Mol Hepatol 2013;19:300-304.

245. Seto WK, Hui AJ, Wong VW, Wong GL, Liu KS, Lai CL, et al. Treatment cessation of entecavir in Asian patients with hepatitis $B$ e antigen negative chronic hepatitis B: a multicentre prospective study. Gut 2015;64:667-672.

246. Chon YE, Kim SU, Lee CK, Heo J, Kim JK, Yoon KT, et al. Partial virological response to entecavir in treatment-naive patients with chronic hepatitis B. Antivir Ther 2011;16:469-477.

247. Zoulim F, Perrillo R. Hepatitis B: reflections on the current approach to antiviral therapy. J Hepatol 2008;48 Suppl 1:S2-S19.

248. Yuen M, Fong DY, Wong DK, Yuen JC, Fung J, Lai C. Hepatitis B virus DNA levels at week 4 of lamivudine treatment predict the 5-year ideal response. Hepatology 2007;46:1695-1703.

249. Chan HL, Wong GL, Chim AM, Chan HY, Chu SH, Wong VW. Prediction of off-treatment response to lamivudine by serum hepatitis $B$ surface antigen quantification in hepatitis $B$ e antigen-negative patients. Antivir Ther 2011;16:1249-1257.

250. Cai W, Xie Q, An B, Wang H, Zhou X, Zhao G, et al. On-treatment serum $\mathrm{HBsAg}$ level is predictive of sustained off-treatment virologic response to telbivudine in $\mathrm{HBeAg}$-positive chronic hepatitis $\mathrm{B}$ patients. J Clin Virol 2010;48:22-26.

251. Lau GK, Piratvisuth T, Luo KX, Marcellin P, Thongsawat S, Cooksley $G$, et al. Peginterferon Alfa-2a, lamivudine, and the combination for HBeAg-positive chronic hepatitis B. N Engl J Med 2005;352:26822695.

252. Kau A, Vermehren J, Sarrazin C. Treatment predictors of a 
sustained virologic response in hepatitis B and C. J Hepatol 2008;49:634-651.

253. Fried MW, Piratvisuth T, Lau GK, Marcellin P, Chow W, Cooksley G, et al. HBeAg and hepatitis $B$ virus DNA as outcome predictors during therapy with peginterferon alfa-2a for HBeAg-positive chronic hepatitis B. Hepatology 2008;47:428-434.

254. Flink HJ, van Zonneveld M, Hansen BE, de Man RA, Schalm SW, Janssen HL. Treatment with Peg-interferon alpha-2b for HBeAgpositive chronic hepatitis B: HBsAg loss is associated with HBV genotype. Am J Gastroenterol 2006;101:297-303.

255. Janssen $\mathrm{HL}$, van Zonneveld M, Senturk $H$, Zeuzem S, Akarca US, Cakaloglu $Y$, et al. Pegylated interferon alfa-2b alone or in combination with lamivudine for $\mathrm{HBeAg-positive} \mathrm{chronic} \mathrm{hepatitis} \mathrm{B:} \mathrm{a}$ randomised trial. Lancet 2005;365:123-129.

256. Perrillo RP, Schiff ER, Davis GL, Bodenheimer HC, Jr., Lindsay K, Payne J, et al. A randomized, controlled trial of interferon alfa- $2 b$ alone and after prednisone withdrawal for the treatment of chronic hepatitis B. The Hepatitis Interventional Therapy Group. N Engl J Med 1990;323:295-301.

257. Lok AS, Wu PC, Lai CL, Lau JY, Leung EK, Wong LS, et al. A controlled trial of interferon with or without prednisone priming for chronic hepatitis B. Gastroenterology 1992;102:2091-2097.

258. Zoulim F, Durantel D, Deny P. Management and prevention of drug resistance in chronic hepatitis $B$. Liver Int 2009;29 Suppl 1:108-115.

259. Nowak MA, Bonhoeffer S, Hill AM, Boehme R, Thomas HC, MCDade $H$. Viral dynamics in hepatitis $B$ virus infection. Proc Natl Acad Sci U S A 1996;93:4398-4402.

260. Melegari M, Scaglioni PP, Wands JR. Hepatitis B virus mutants associated with 3TC and famciclovir administration are replication defective. Hepatology 1998;27:628-633.

261. Tenney DJ, Levine SM, Rose RE, Walsh AW, Weinheimer SP, Discotto $L$, et al. Clinical emergence of entecavir-resistant hepatitis $B$ virus requires additional substitutions in virus already resistant to Lamivudine. Antimicrob Agents Chemother 2004;48:3498-3507.

262. Richman DD. The impact of drug resistance on the effectiveness of chemotherapy for chronic hepatitis B. Hepatology 2000;32:866867.

263. Bartholomeusz A, Locarnini SA. Antiviral drug resistance: clinical consequences and molecular aspects. Semin Liver Dis 2006;26:162170.

264. Lok AS, Zoulim F, Locarnini S, Bartholomeusz A, Ghany MG, Pawlotsky JM, et al. Antiviral drug-resistant HBV: standardization of nomenclature and assays and recommendations for management. Hepatology 2007:46:254-265.

265. Lai CL, Dienstag J, Schiff E, Leung NW, Atkins M, Hunt C, et al. Prevalence and clinical correlates of YMDD variants during lamivudine therapy for patients with chronic hepatitis B. Clin Infect Dis 2003;36:687-696.
266. Lok AS, Lai CL, Leung N, Yao GB, Cui ZY, Schiff ER, et al. Longterm safety of lamivudine treatment in patients with chronic hepatitis B. Gastroenterology 2003;125:1714-1722.

267. Gish RG, Trinh H, Leung N, Chan FK, Fried MW, Wright TL, et al. Safety and antiviral activity of emtricitabine (FTC) for the treatment of chronic hepatitis B infection: a two-year study. J Hepatol 2005;43:60-66.

268. Stuyver LJ, Locarnini SA, Lok A, Richman DD, Carman WF, Dienstag $J \mathrm{~L}$, et al. Nomenclature for antiviral-resistant human hepatitis $B$ virus mutations in the polymerase region. Hepatology 2001;33:751757.

269. Koh KH, Kang CJ, Kim DH, Choi YW, Kim MJ, Cheong JY, et al. Development of clevudine resistance after switching from lamivudine in a patient with chronic hepatitis B. Korean J Gastroenterol 2008:52:325-328.

270. Yoon EL, Yim HJ, Lee HJ, Lee YS, Kim JH, Jung ES, et al. Comparison of Clevudine and Entecavir for Treatment-naive Patients With Chronic Hepatitis B Virus Infection: Two-Year Follow-up Data. J Clin Gastroenterol 2011;45:893-899.

271. Locarnini S. Molecular virology and the development of resistant mutants: implications for therapy. Semin Liver Dis 2005;25 Suppl 1:9-19.

272. Qi X, Xiong S, Yang H, Miller M, Delaney WEth. In vitro susceptibility of adefovir-associated hepatitis B virus polymerase mutations to other antiviral agents. Antivir Ther 2007;12:355-362.

273. Tenney DJ, Rose RE, Baldick CJ, Levine SM, Pokornowski KA, Walsh AW, et al. Two-year assessment of entecavir resistance in Lamivudine-refractory hepatitis B virus patients reveals different clinical outcomes depending on the resistance substitutions present. Antimicrob Agents Chemother 2007;51:902-911.

274. Tenney DJ, Rose RE, Baldick CJ, Pokornowski KA, Eggers BJ, Fang $J$, et al. Long-term monitoring shows hepatitis $B$ virus resistance to entecavir in nucleoside-naive patients is rare through 5 years of therapy. Hepatology 2009;49:1503-1514.

275. Villeneuve JP, Durantel D, Durantel S, Westland C, Xiong S, Brosgart $\mathrm{CL}$, et al. Selection of a hepatitis $B$ virus strain resistant to adefovir in a liver transplantation patient. J Hepatol 2003;39:10851089.

276. Villet S, Pichoud C, Billioud G, Barraud L, Durantel S, Trepo C, et al. Impact of hepatitis B virus rtA181V/T mutants on hepatitis B treatment failure. J Hepatol 2008;48:747-755.

277. Lampertico P, Vigano M, Manenti E, lavarone M, Sablon E, Colombo M. Low resistance to adefovir combined with lamivudine: a 3-year study of 145 lamivudine-resistant hepatitis B patients. Gastroenterology 2007;133:1445-1451.

278. Sheldon J, Camino N, Rodes B, Bartholomeusz A, Kuiper M, Tacke $F$, et al. Selection of hepatitis $B$ virus polymerase mutations in HIV-coinfected patients treated with tenofovir. Antivir Ther 
2005;10:727-734.

279. Yim HJ, Hussain M, Liu Y, Wong SN, Fung SK, Lok AS. Evolution of multi-drug resistant hepatitis $B$ virus during sequential therapy. Hepatology 2006;44:703-712.

280. Lee YS, Suh DJ, Lim YS, Jung SW, Kim KM, Lee HC, et al. Increased risk of adefovir resistance in patients with lamivudine-resistant chronic hepatitis B after 48 weeks of adefovir dipivoxil monotherapy. Hepatology 2006;43:1385-1391.

281. Yeon JE, Yoo W, Hong SP, Chang YJ, Yu SK, Kim JH, et al. Resistance to adefovir dipivoxil in lamivudine resistant chronic hepatitis B patients treated with adefovir dipivoxil. Gut 2006;55:1488-1495.

282. Yim HJ. Management of antiviral-resistant chronic hepatitis B virus infection. Korean J Gastroenterol 2008;51:346-359.

283. Lampertico P, Maini M, Papatheodoridis G. Optimal Management of Hepatitis B Virus Infection - EASL Special Conference. J Hepatol 2015.

284. van Bommel F, Wunsche T, Mauss S, Reinke P, Bergk A, Schurmann $D$, et al. Comparison of adefovir and tenofovir in the treatment of lamivudine-resistant hepatitis B virus infection. Hepatology 2004:40:1421-1425.

285. Baran B, Soyer OM, Ormeci AC, Gokturk S, Evirgen S, Bozbey HU, et al. Efficacy of tenofovir in patients with Lamivudine failure is not different from that in nucleoside/nucleotide analogue-naive patients with chronic hepatitis B. Antimicrob Agents Chemother 2013:57:1790-1796.

286. Seto WK, Liu K, Wong DK, Fung J, Huang FY, Hung IF, et al. Patterns of hepatitis $B$ surface antigen decline and HBV DNA suppression in Asian treatment-experienced chronic hepatitis $B$ patients after three years of tenofovir treatment. J Hepatol 2013;59:709716.

287. Fung S, Kwan P, Fabri M, Horban A, Pelemis M, Hann HW, et al. Randomized comparison of tenofovir disoproxil fumarate vs emtricitabine and tenofovir disoproxil fumarate in patients with lamivudine-resistant chronic hepatitis B. Gastroenterology 2014;146:980988.

288. Peters MG, Hann Hw H, Martin P, Heathcote EJ, Buggisch P, Rubin R, et al. Adefovir dipivoxil alone or in combination with lamivudine in patients with lamivudine-resistant chronic hepatitis B. Gastroenterology 2004;126:91-101.

289. Rapti I, Dimou E, Mitsoula P, Hadziyannis SJ. Adding-on versus switching-to adefovir therapy in lamivudine-resistant $\mathrm{HBeAg}$ negative chronic hepatitis B. Hepatology 2007;45:307-313.

290. Suzuki F, Hosaka T, Suzuki Y, Akuta N, Sezaki H, Hara T, et al. Long-term efficacy and emergence of multidrug resistance in patients with lamivudine-refractory chronic hepatitis B treated by combination therapy with adefovir plus lamivudine. J Gastroenterol 2014:49:1094-1104.

291. Huang ZB, Zhao SS, Huang Y, Dai XH, Zhou RR, Yi PP, et al. Com- parison of the efficacy of Lamivudine plus adefovir versus entecavir in the treatment of Lamivudine-resistant chronic hepatitis B: a systematic review and meta-analysis. Clin Ther 2013;35:1997-2006.

292. Ha M, Zhang G, Diao S, Lin M, Wu J, Sun L, et al. Rescue therapy for lamivudine-resistant chronic hepatitis B: adefovir monotherapy, adefovir plus lamivudine or entecavir combination therapy. Intern Med 2012;51:1509-1515.

293. Seto WK, Liu K, Fung J, Wong DK, Yuen JC, Hung IF, et al. Outcome of lamivudine-resistant chronic hepatitis $B$ after up to 5 years of combination therapy with adefovir. Antivir Ther 2012;17:12551262.

294. Ahn SH, Kweon YO, Paik SW, Sohn JH, Lee KS, Kim DJ, et al. Telbivudine in combination with adefovir versus adefovir monotherapy in HBeAg-positive, lamivudine-resistant chronic hepatitis B. Hepatol Int 2012;6:696-706.

295. Lin MT, Chou YP, Hu TH, Yu HC, Hsu YC, Tsai MC, et al. Telbivudine and adefovir combination therapy for patients with chronic lamivudine-resistant hepatitis B virus infections. Arch Virol 2014;159:2937.

296. Park H, Park JY, Kim SU, Kim do Y, Han KH, Chon CY, et al. Efficacy of switching to telbivudine plus adefovir in suboptimal responders to lamivudine plus adefovir. World J Gastroenterol 2013;19:76717679 .

297. Chang TT, Gish RG, Hadziyannis SJ, Cianciara J, Rizzetto M, Schiff $E R$, et al. A dose-ranging study of the efficacy and tolerability of entecavir in Lamivudine-refractory chronic hepatitis B patients. Gastroenterology 2005;129:1198-1209.

298. Sherman M, Yurdaydin C, Sollano J, Silva M, Liaw YF, Cianciara $J$, et al. Entecavir for treatment of lamivudine-refractory, HBeAgpositive chronic hepatitis B. Gastroenterology 2006;130:20392049.

299. Sheng YJ, Liu JY, Tong SW, Hu HD, Zhang DZ, Hu P, et al. Lamivudine plus adefovir combination therapy versus entecavir monotherapy for lamivudine-resistant chronic hepatitis B: a systematic review and meta-analysis. Virol J 2011;8:393.

300. Yim HJ, Seo YS, Yoon EL, Kim CW, Lee CD, Park SH, et al. Adding adefovir vs. switching to entecavir for lamivudine-resistant chronic hepatitis B (ACE study): a 2-year follow-up randomized controlled trial. Liver Int 2013;33:244-254.

301. Lee SJ, Yim HJ, Hwang SG, Seo YS, Kim JH, Yoon EL, et al. Treatment of lamivudine-resistant chronic hepatitis B infection: a multicenter retrospective study. Scand I Gastroenterol 2013;48:196204.

302. Seo SY, Kim IH, Sohn JY, Lee S, Kim SH, Kim SW, et al. Long-term efficacy of entecavir plus adefovir combination therapy versus entecavir monotherapy in adefovir refractory chronic hepatitis B patients with prior lamivudine resistance. Intervirology 2014;57:816. 
303. Sun J, Hou JL, Xie Q, Li XH, Zhang JM, Wang YM, et al. Randomised clinical trial: efficacy of peginterferon alfa-2a in $\mathrm{HBeAg}$ positive chronic hepatitis $B$ patients with lamivudine resistance. Aliment Pharmacol Ther 2011;34:424-431.

304. Suh DJ, Lee HC, Byun KS, Cho M, Kweon YO, Tak WY, et al. Efficacy and safety of pegylated interferon-alpha2a in patients with lamivudine-resistant HBeAg-positive chronic hepatitis B. Antivir Ther 2013;18:765-773.

305. Zhang Y, Lian JQ, Li Y, Wang JP, Huang CX, Bai XF, et al. Telbivudine plus adefovir therapy for chronic hepatitis $B$ patients with virological breakthrough or genotypic resistance to telbivudine. Eur J Gastroenterol Hepatol 2013;25:814-819.

306. Angus $P$, Vaughan $R$, Xiong S, Yang H, Delaney W, Gibbs $C$, et al. Resistance to adefovir dipivoxil therapy associated with the selection of a novel mutation in the HBV polymerase. Gastroenterology 2003;125:292-297.

307. Fung SK, Andreone P, Han SH, Rajender Reddy K, Regev A, Keeffe $E B$, et al. Adefovir-resistant hepatitis $B$ can be associated with viral rebound and hepatic decompensation. J Hepatol 2005;43:937-943.

308. Marcellin P, Chang TT, Lim SG, Sievert W, Tong M, Arterburn S, et al. Long-term efficacy and safety of adefovir dipivoxil for the treatment of hepatitis B e antigen-positive chronic hepatitis B. Hepatology 2008;48:750-758.

309. Fung SK, Chae HB, Fontana RJ, Conjeevaram H, Marrero J, Oberhelman $\mathrm{K}$, et al. Virologic response and resistance to adefovir in patients with chronic hepatitis B. J Hepatol 2006;44:283-290.

310. Lu JJ, Liu K, Ma YJ, Wang J, Chen EQ, Tang H. Efficacy and safety of telbivudine plus adefovir dipivoxil combination therapy and entecavir monotherapy for HBeAg-positive chronic hepatitis B patients with resistance to adefovir dipivoxil. J Viral Hepat 2013;20 Suppl 1:40-45.

311. Heo NY, Lim YS, Lee HC, Chung YH, Lee YS, Suh DJ. Lamivudine plus adefovir or entecavir for patients with chronic hepatitis B resistant to lamivudine and adefovir. J Hepatol 2010;53:449-454.

312. Reijnders JG, Deterding K, Petersen J, Zoulim F, Santantonio T, Buti $M$, et al. Antiviral effect of entecavir in chronic hepatitis $B$ : influence of prior exposure to nucleos(t)ide analogues. J Hepatol 2010;52:493-500

313. Shim JH, Suh DJ, Kim KM, Lim YS, Lee HC, Chung YH, et al. Efficacy of entecavir in patients with chronic hepatitis $B$ resistant to both lamivudine and adefovir or to lamivudine alone. Hepatology 2009;50:1064-1071.

314. Marcellin P, Heathcote EJ, Buti M, Gane E, de Man RA, Krastev Z, et al. Tenofovir disoproxil fumarate versus adefovir dipivoxil for chronic hepatitis B. N Engl J Med 2008;359:2442-2455.

315. Berg T, Marcellin P, Zoulim F, Moller B, Trinh H, Chan S, et al. Tenofovir is effective alone or with emtricitabine in adefovir-treated patients with chronic-hepatitis B virus infection. Gastroenterology
2010;139:1207-1217.

316. Berg T, Zoulim F, Moeller B, Trinh H, Marcellin P, Chan S, et al. Long-term efficacy and safety of emtricitabine plus tenofovir DF vs. tenofovir DF monotherapy in adefovir-experienced chronic hepatitis B patients. J Hepatol 2014;60:715-722.

317. Brunelle MN, Jacquard AC, Pichoud C, Durantel D, Carrouee-Durantel $S$, Villeneuve JP, et al. Susceptibility to antivirals of a human HBV strain with mutations conferring resistance to both lamivudine and adefovir. Hepatology 2005;41:1391-1398.

318. Villet S, Pichoud C, Villeneuve JP, Trepo C, Zoulim F. Selection of a multiple drug-resistant hepatitis B virus strain in a liver-transplanted patient. Gastroenterology 2006;131:1253-1261.

319. Qi X, Xiong S, Yang H, Miller M, Delaney WEt. In vitro susceptibility of adefovir-associated hepatitis $B$ virus polymerase mutations to other antiviral agents. Antivir Ther 2007;12:355-362.

320. Patterson SJ, George J, Strasser SI, Lee AU, Sievert W, Nicoll AJ, et al. Tenofovir disoproxil fumarate rescue therapy following failure of both lamivudine and adefovir dipivoxil in chronic hepatitis B. Gut 2011;60:247-254.

321. Lim YS, Byun KS, Yoo BC, Kwon SY, Kim YJ, An J, et al. Tenofovir monotherapy versus tenofovir and entecavir combination therapy in patients with entecavir-resistant chronic hepatitis B with multiple drug failure: results of a randomised trial. Gut 2015 [Epub ahead of print].

322. Lim YS, Yoo BC, Byun KS, Kwon SY, Kim YJ, An J, et al. Tenofovir monotherapy versus tenofovir and entecavir combination therapy in adefovir-resistant chronic hepatitis B patients with multiple drug failure: results of a randomised trial. Gut 2015 [Epub ahead of print].

323. Tenney DJ, Levine SM, Rose RE, Walsh AW, Weinheimer SP, Discotto $\mathrm{L}$, et al. Clinical emergence of entecavir-resistant hepatitis $B$ virus requires additional substitutions in virus already resistant to Lamivudine. Antimicrob Agents Chemother 2004;48:3498-3507.

324. Villet S, Ollivet A, Pichoud C, Barraud L, Villeneuve JP, Trepo C, et al. Stepwise process for the development of entecavir resistance in a chronic hepatitis B virus infected patient. J Hepatol 2007;46:531538.

325. Zoulim F, Locarnini S. Management of treatment failure in chronic hepatitis B. J Hepatol 2012;56 Suppl 1:S112-S122.

326. Lim YS, Lee TH, Heo NY, Shim JH, Lee HC, Suh DJ. Entecavir plus adefovir combination treatment for chronic hepatitis B patients after failure of nucleoside/nucleotide analogues. Antivir Ther 2012;17:53-60.

327. Yang HJ, Lee JH, Kim YJ, Yoon JH, Lee HS. Antiviral efficacy of combination therapy with entecavir and adefovir for entecavir/ lamivudine-resistant hepatitis B virus with or without adefovir resistance. J Med Virol 2012;84:424-430.

328. Lee YB, Lee JH, Choi WM, Cho YY, Yoo JJ, Lee M, et al. Efficacy of 
adefovir-based combination therapy for patients with Lamivudineand entecavir-resistant chronic hepatitis B virus infection. Antimicrob Agents Chemother 2013;57:6325-6332.

329. Petersen J, Ratziu V, Buti M, Janssen HL, Brown A, Lampertico P, et al. Entecavir plus tenofovir combination as rescue therapy in pretreated chronic hepatitis B patients: an international multicenter cohort study. J Hepatol 2012;56:520-526.

330. Lim YS, Lee TH, Heo NY, Shim JH, J. LH, Suh DJ. Entecavir plus adefovir combination for chronic hepatitis B patients after failure of nucleos(t)ide analogue. Korean J Gastroenterol 2010;56:293.

331. Kim SS, Lee DM, Jeong JY, Hong SP, Yoo WD, Kim SO, et al. Efficacy of lamivduine plus adefovir therapy or adefovir add on therapy for entecavir-resistant hepatitisn B patients. Korean J Hepatol 2010;16:S48.

332. Yim HJ, Lee HJ, Suh SJ, Seo YS, Kim CW, Lee CD, et al. Adefovir and Lamivudine combination therapy in patients with entecavirresistant chronic hepatitis $B$ : antiviral responses and evolution of mutations. Intervirology 2014;57:239-247.

333. van Bommel F, de Man RA, Wedemeyer H, Deterding K, Petersen J, Buggisch $P$, et al. Long-term efficacy of tenofovir monotherapy for hepatitis B virus-monoinfected patients after failure of nucleoside/ nucleotide analogues. Hepatology 2010;51:73-80.

334. Lim YS, Byun KS, Yoo BC, Kwon SY, Kim YJ, An J, et al. Tenofovir monotherapy versus tenofovir and entecavir combination therapy in patients with entecavir-resistant chronic hepatitis B with multiple drug failure: results of a randomised trial. Gut 2015 [Epub ahead of print].

335. Kitrinos KM, Corsa A, Liu Y, Flaherty J, Snow-Lampart A, Marcellin $P$, et al. No detectable resistance to tenofovir disoproxil fumarate after 6 years of therapy in patients with chronic hepatitis B. Hepatology 2014;59:434-442.

336. Delaney WEt, Ray AS, Yang H, Qi X, Xiong S, Zhu Y, et al. Intracellular metabolism and in vitro activity of tenofovir against hepatitis B virus. Antimicrob Agents Chemother 2006;50:2471-2477.

337. Amini-Bavil-Olyaee S, Herbers U, Sheldon J, Luedde T, Trautwein C, Tacke F. The rtA194T polymerase mutation impacts viral replication and susceptibility to tenofovir in hepatitis B e antigen-positive and hepatitis B e antigen-negative hepatitis B virus strains. Hepatology 2009:49:1158-1165.

338. Villeneuve JP, Durantel D, Durantel S, Westland C, Xiong S, Brosgart $C L$, et al. Selection of a hepatitis $B$ virus strain resistant to adefovir in a liver transplantation patient. J Hepatol 2003;39:10851089

339. Angus $P$, Vaughan $R$, Xiong S, Yang $H$, Delaney W, Gibbs $C$, et al. Resistance to adefovir dipivoxil therapy associated with the selection of a novel mutation in the HBV polymerase. Gastroenterology 2003;125:292-297.

340. Pawlotsky JM. Is hepatitis virus resistance to antiviral drugs a threat? Gastroenterology 2012;142:1369-1372.

341. Locarnini S, Mason WS. Cellular and virological mechanisms of HBV drug resistance. J Hepatol 2006;44:422-431.

342. Locarnini S, Omata M. Molecular virology of hepatitis B virus and the development of antiviral drug resistance. Liver Int 2006;26:1122.

343. Fukai K, Zhang KY, Imazeki F, Kurihara T, Mikata R, Yokosuka 0. Association between lamivudine sensitivity and the number of substitutions in the reverse transcriptase region of the hepatitis B virus polymerase. J Viral Hepat 2007;14:661-666.

344. Yuen MF, Sablon E, Hui CK, Yuan HJ, Decraemer H, Lai CL. Factors associated with hepatitis $B$ virus DNA breakthrough in patients receiving prolonged lamivudine therapy. Hepatology 2001;34:785791.

345. European Association For The Study Of The L. EASL clinical practice guidelines: Management of chronic hepatitis B virus infection. J Hepatol 2012;57:167-185.

346. Lok AS. How to diagnose and treat hepatitis B virus antiviral drug resistance in the liver transplant setting. Liver Transpl 2008;14 Suppl 2:S8-S14.

347. Keeffe EB, Zeuzem S, Koff RS, Dieterich DT, Esteban-Mur R, Gane $E J$, et al. Report of an international workshop: roadmap for management of patients receiving oral therapy for chronic hepatitis B. Clinical Gastroenterology and Hepatology 2007;5:890-897.

348. Yang YJ, Shim JH, Kim KM, Lim YS, Lee HC. Assessment of current criteria for primary nonresponse in chronic hepatitis B patients receiving entecavir therapy. Hepatology 2014;59:1303-1310.

349. Bang SJ, Kim BG, Shin JW, Ju HU, Park BR, Kim MH, et al. Clinical course of patients with insufficient viral suppression during entecavir therapy in genotype C chronic hepatitis B. Dig Liver Dis 2013;45:600-605.

350. Heo J, Park JY, Lee HJ, Tak WY, Um SH, Kim do Y, et al. A 96-week randomized trial of switching to entecavir in chronic hepatitis $\mathrm{B}$ patients with a partial virological response to lamivudine. Antivir Ther 2012;17:1563-1570.

351. Lee JH, Cho Y, Lee DH, Lee M, Yoo JJ, Choi WM, et al. Prior exposure to lamivudine increases entecavir resistance risk in chronic hepatitis B Patients without detectable lamivudine resistance. Antimicrob Agents Chemother 2014;58:1730-1737.

352. Marcellin P, Heathcote EJ, Buti M, Gane E, de Man RA, Krastev Z, et al. Tenofovir disoproxil fumarate versus adefovir dipivoxil for chronic hepatitis B. N Engl J Med 2008;359:2442-2455.

353. Snow-Lampart A, Chappell B, Curtis M, Zhu Y, Myrick F, Schawalder J, et al. No resistance to tenofovir disoproxil fumarate detected after up to 144 weeks of therapy in patients monoinfected with chronic hepatitis B virus. Hepatology 2011;53:763-773.

354. Tan J, Degertekin B, Wong SN, Husain M, Oberhelman K, Lok AS. Tenofovir monotherapy is effective in hepatitis $B$ patients with 
antiviral treatment failure to adefovir in the absence of adefovirresistant mutations J Hepatol 2008;48:391-398.

355. Locarnini S, Qi X, Arterburn S, Snow A, Brosgart CL, Currie G, et al. Incidence and predictors of emergence of adefovir resistant HBV during four years of adefovir dipivoxil (ADV) therapy for patients with chronic hepatitis B (CHB) [Abstract]. J hepatol 2005;42:17.

356. Chen EQ, Zhou TY, Bai L, Wang JR, Yan LB, Liang LB, et al. Lamivudine plus adefovir or telbivudine plus adefovir for chronic hepatitis B patients with suboptimal response to adefovir. Antivir Ther 2012;17:973-979.

357. Chen $\mathrm{CH}$, Wang JH, Lu SN, Hu TH, Hung CH, Chang MH, et al. Treatment response and evolution of HBV resistance during lamivudine plus adefovir or entecavir therapy in patients with adefovirresistant mutants. Antivir Ther 2012;17:701-709.

358. Zoutendijk R, Reijnders JG, Brown A, Zoulim F, Mutimer D, Deterding $\mathrm{K}$, et al. Entecavir treatment for chronic hepatitis $\mathrm{B}$ : adaptation is not needed for the majority of naive patients with a partial virological response. Hepatology 2011;54:443-451.

359. Ko SY, Choe WH, Kwon SY, Kim JH, Seo JW, Kim KH, et al. Longterm impact of entecavir monotherapy in chronic hepatitis $\mathrm{B}$ patients with a partial virologic response to entecavir therapy. Scand J Gastroenterol 2012;47:1362-1367.

360. Kwon DH, Kim IH, Choung BS, Ahn DS, Yoo SH, Park SB, et al. Continuous long-term entecavir therapy in naive chronic hepatitis $B$ patients showing partial virologic response. Gut Liver 2013;7:712718.

361. Luo J, Li X, Wu Y, Lin G, Pang Y, Zhang X, et al. Efficacy of entecavir treatment for up to 5 years in nucleos(t)ide-naive chronic hepatitis B patients in real life. Int J Med Sci 2013;10:427-433.

362. Pan CQ, Hu KQ, Yu AS, Chen W, Bunchorntavakul C, Reddy KR. Response to tenofovir monotherapy in chronic hepatitis $B$ patients with prior suboptimal response to entecavir. J Viral Hepat 2012;19:213-219.

363. Yuki N, Nagaoka T, Yamashiro M, Mochizuki K, Kaneko A, Yamamoto $K$, et al. Long-term histologic and virologic outcomes of acute self-limited hepatitis B. Hepatology 2003;37:1172-1179.

364. Shiffman ML. Management of acute hepatitis B. Clin Liver Dis 2010;14:75-91; viii-ix.

365. Böcher W, HERZOG-HAUFF S, Herr W, Heermann K, Gerken G, MEYER ZUM BÜSCHENFELDE KH, et al. Regulation of the neutralizing anti-hepatitis B surface (HBs) antibody response in vitro in $\mathrm{HBs}$ vaccine recipients and patients with acute or chronic hepatitis $B$ virus (HBV) infection. Clinical \& Experimental Immunology 1996;105:52-58.

366. Kumar M, Satapathy S, Monga R, Das K, Hissar S, Pande C, et al. A randomized controlled trial of lamivudine to treat acute hepatitis $B$. Hepatology 2007;45:97-101.

367. Wiegand J, Wedemeyer H, Franke A, Rossler S, Zeuzem S, Teuber
$G$, et al. Treatment of severe, nonfulminant acute hepatitis B with lamivudine vs placebo: a prospective randomized double-blinded multicentre trial. J Viral Hepat 2014;21:744-750.

368. Tillmann HL, Hadem J, Leifeld L, Zachou K, Canbay A, Eisenbach $C$, et al. Safety and efficacy of lamivudine in patients with severe acute or fulminant hepatitis B, a multicenter experience. J Viral Hepat 2006;13:256-263.

369. De Socio GVL, Sgrelli A, Tosti A, Baldelli F. Severe acute hepatitis $B$ treated with entecavir. Mediterr J Hematol Infect Dis 2011;3:e2011010.

370. Christopeit $M$, Weber T, Abendroth J, Dollinger M, Lübbert C, Oehme $A$, et al. HBs seroconversion in a patient with acute hepatitis $B$ treated with entecavir during immunosuppression against severe bronchiolitis obliterans in the course of chronic graft versus host disease. J Clin Virol 2010;48:218-219.

371. Begini P, Cox MC, Angeletti S, Gigante E, Baccini F, Di Fonzo M, et al. Effectiveness of entecavir in the management of acute hepatitis $B$ developing in a patient with Hodgkin's lymphoma: a case report. Scand J Infect Dis 2011;43:750-752.

372. Demetris A, Jaffe R, Sheahan D, Burnham J, Spero J, Iwatsuki S, et al. Recurrent hepatitis $B$ in liver allograft recipients. Differentiation between viral hepatitis B and rejection. Am J Pathol 1986;125:161172.

373. Demetris A, Todo S, Van Thiel D, Fung J, Iwaki Y, Sysyn G, et al. Evolution of hepatitis $B$ virus liver disease after hepatic replacement. Practical and theoretical considerations. Am J Pathol 1990;137:667.

374. Davies SE, Portmann BC, Aldis PM, Chaggar K, Alexander GJ, Williams R. Hepatic histological findings after transplantation for chronic hepatitis $B$ virus infection, including a unique pattern of fibrosing cholestatic hepatitis. Hepatology 1991;13:150-157.

375. FREEMAN RB, SANCHEZ H, LEWIS WD, SHERBURNE B, DZIK WH, KHETTRY $U$, et al. Serologic and DNA follow-up data from HBsAgpositive patients treated with orthotopic liver transplantation. Transplantation 1991;51:793-796.

376. Lake JR, Wright TL. Liver transplantation for patients with hepatitis B: what have we learned from our results? Hepatology 1991;13:796-799.

377. O'Grady JG, Smith HM, Davies SE, Daniels HM, Donaldson PT, Tan KC, et al. Hepatitis B virus reinfection after orthotopic liver transplantation: serological and clinical implications. J Hepatol 1992;14:104-111.

378. Rizzetto M, Recchia S, Salizzoni M. Liver transplantation in carriers of the HBsAg. J Hepatol 1991;13:5-7.

379. Todo S, Demetris AJ, Van Thiel D, Teperman L, Fung JJ, Starzl TE. Orthotopic liver transplantation for patients with hepatitis B virusrelated liver disease. Hepatology 1991;13:619-626.

380. Samuel D, Muller R, Alexander G, Fassati L, Ducot B, Benhamou JP, 
et al. Liver transplantation in European patients with the hepatitis B surface antigen. N Engl J Med 1993;329:1842-1847.

381. Roche B, Feray C, Gigou M, Roque-Afonso AM, Arulnaden JL, Delvart $\mathrm{V}$, et al. HBV DNA persistence 10 years after liver transplantation despite successful anti-HBS passive immunoprophylaxis. Hepatology 2003;38:86-95.

382. Terrault NA, Zhou S, Combs C, Hahn JA, Lake JR, Roberts JP, et al. Prophylaxis in liver transplant recipients using a fixed dosing schedule of hepatitis B immunoglobulin. Hepatology 1996;24:13271333.

383. McGory RW, Ishitani MB, Oliveira WM, Stevenson WC, McCullough CS, Dickson RC, et al. Improved outcome of orthotopic liver transplantation for chronic hepatitis B cirrhosis with aggressive passive immunization. Transplantation 1996;61:1358-1364.

384. Han SH, Ofman J, Holt C, King K, Kunder G, Chen P, et al. An efficacy and cost-effectiveness analysis of combination hepatitis $B$ immune globulin and lamivudine to prevent recurrent hepatitis $B$ after orthotopic liver transplantation compared with hepatitis B immune globulin monotherapy. Liver Transpl 2000;6:741-748.

385. Markowitz JS, Martin P, Conrad AJ, Markmann JF, Seu P, Yersiz $\mathrm{H}$, et al. Prophylaxis against hepatitis $B$ recurrence following liver transplantation using combination lamivudine and hepatitis B immune globulin. Hepatology 1998;28:585-589.

386. Marzano A, Salizzoni M, Debernardi-Venon W, Smedile A, Franchello $A$, Ciancio $A$, et al. Prevention of hepatitis $B$ virus recurrence after liver transplantation in cirrhotic patients treated with lamivudine and passive immunoprophylaxis. J Hepatol 2001;34:903910.

387. Steinmüller T, Seehofer $D$, Rayes $N$, Müller AR, Settmacher $U$, Jonas $S$, et al. Increasing applicability of liver transplantation for patients with hepatitis B-related liver disease. Hepatology 2002;35:15281535.

388. Katz LH, Paul M, Guy DG, Tur-Kaspa R. Prevention of recurrent hepatitis $B$ virus infection after liver transplantation: hepatitis $B$ immunoglobulin, antiviral drugs, or both? Systematic review and meta-analysis. Transpl Infect Dis 2010;12:292-308.

389. Loomba R, Rowley AK, Wesley R, Smith KG, Liang TJ, Pucino F, et al. Hepatitis $B$ immunoglobulin and Lamivudine improve hepatitis B-related outcomes after liver transplantation: meta-analysis. Clin Gastroenterol Hepatol 2008;6:696-700.

390. Cholongitas E, Goulis J, Akriviadis E, Papatheodoridis GV. Hepatitis $B$ immunoglobulin and/or nucleos(t)ide analogues for prophylaxis against hepatitis b virus recurrence after liver transplantation: a systematic review. Liver Transpl 2011;17:1176-1190.

391. Mutimer D, Dusheiko G, Barrett C, Grellier L, Ahmed M, Anschuetz $G$, et al. Lamivudine without HBlg for prevention of graft reinfection by hepatitis $B$ : long-term follow-up. Transplantation 2000;70:809-815.
392. Perrillo RP, Wright T, Rakela J, Levy G, Schiff E, Gish R, et al. A multicenter United States-Canadian trial to assess lamivudine monotherapy before and after liver transplantation for chronic hepatitis $B$. Hepatology 2001;33:424-432.

393. Gane EJ, Patterson S, Strasser SI, McCaughan GW, Angus PW. Combination of lamivudine and adefovir without hepatitis B immune globulin is safe and effective prophylaxis against hepatitis $B$ virus recurrence in hepatitis $B$ surface antigen-positive liver transplant candidates. Liver Transpl 2013;19:268-274.

394. Fung J, Chan SC, Cheung C, Yuen MF, Chok KS, Sharr W, et al. Oral nucleoside/nucleotide analogs without hepatitis B immune globulin after liver transplantation for hepatitis B. Am J Gastroenterol 2013;108:942-948.

395. Fung J, Cheung C, Chan SC, Yuen MF, Chok KS, Sharr W, et al. Entecavir monotherapy is effective in suppressing hepatitis $B$ virus after liver transplantation. Gastroenterology 2011;141:1212-1219.

396. Wang P, Tam N, Wang H, Zheng H, Chen P, Wu L, et al. Is hepatitis $B$ immunoglobulin necessary in prophylaxis of hepatitis $B$ recurrence after liver transplantation? A meta-analysis. PLoS One 2014;9:e104480.

397. Cholongitas E, Papatheodoridis GV. High genetic barrier nucleos $(\mathrm{t})$ ide analogue(s) for prophylaxis from hepatitis B virus recurrence after liver transplantation: a systematic review. Am J Transplant 2013;13:353-362.

398. Gane EJ, Angus PW, Strasser S, Crawford DH, Ring J, Jeffrey GP, et al. Lamivudine plus low-dose hepatitis B immunoglobulin to prevent recurrent hepatitis B following liver transplantation. Gastroenterology 2007;132:931-937.

399. Buti M, Mas A, Prieto M, Casafont F, Gonzalez A, Miras M, et al. Adherence to Lamivudine after an early withdrawal of hepatitis $B$ immune globulin plays an important role in the long-term prevention of hepatitis B virus recurrence. Transplantation 2007;84:650654.

400. Wong SN, Chu CJ, Wai CT, Howell T, Moore C, Fontana RJ, et al. Low risk of hepatitis $B$ virus recurrence after withdrawal of longterm hepatitis $B$ immunoglobulin in patients receiving maintenance nucleos ( $t$ ) ide analogue therapy. Liver Transpl 2007;13:374-381.

401. Dodson SF, de Vera ME, Bonham CA, Geller DA, Rakela J, Fung JJ. Lamivudine after hepatitis $B$ immune globulin is effective in preventing hepatitis $B$ recurrence after liver transplantation. Liver Transpl 2000;6:434-439.

402. Angus PW, Patterson SJ, Strasser SI, McCaughan GW, Gane E. A randomized study of adefovir dipivoxil in place of HBIG in combination with lamivudine as post-liver transplantation hepatitis B prophylaxis. Hepatology 2008;48:1460-1466.

403. Cholongitas E, Vasiliadis T, Antoniadis N, Goulis I, Papanikolaou V, Akriviadis E. Hepatitis B prophylaxis post liver transplantation with newer nucleos(t)ide analogues after hepatitis B immunoglobulin 
discontinuation. Transpl Infect Dis 2012;14:479-487.

404. Cholongitas E, Goulis I, Antoniadis N, Fouzas I, Imvrios G, Papanikolaou $\mathrm{V}$, et al. New nucleos(t)ide analogue monoprophylaxis after cessation of hepatitis $B$ immunoglobulin is effective against hepatitis B recurrence. Transpl Int 2014;27:1022-1028.

405. Wesdorp DJ, Knoester M, Braat AE, Coenraad MJ, Vossen AC, Claas EC, et al. Nucleoside plus nucleotide analogs and cessation of hepatitis B immunoglobulin after liver transplantation in chronic hepatitis B is safe and effective. J Clin Virol 2013;58:67-73.

406. Stravitz RT, Shiffman ML, Kimmel M, Puri P, Luketic VA, Sterling RK, et al. Substitution of tenofovir/emtricitabine for Hepatitis B immune globulin prevents recurrence of Hepatitis B after liver transplantation. Liver Int 2012;32:1138-1145.

407. Fontana RJ, Hann HWL, Wright T, Everson G, Baker A, Schiff ER, et al. A multicenter study of lamivudine treatment in 33 patients with hepatitis B after liver transplantation. Liver Transpl 2001;7:504510.

408. Ben-Ari Z, Mor E, Shapira Z, Tur-Kaspa R. Long-term experience with lamivudine therapy for hepatitis B virus infection after liver transplantation. Liver Transpl 2001;7:113-117.

409. Perrillo R, Rakela J, Dienstag J, Levy G, Martin P, Wright T, et al. Multicenter study of lamivudine therapy for hepatitis $B$ after liver transplantation. Hepatology 1999;29:1581-1586.

410. Ben-Ari Z, Pappo 0, Zemel R, Mor E, Tur-Kaspa R. Association of lamivudine resistance in recurrent hepatitis $B$ after liver transplantation with advanced hepatic fibrosis. Transplantation 1999;68:232-236.

411. Neff GW, O'Brien CB, Nery J, Shire N, Montalbano M, Ruiz P, et al. Outcomes in liver transplant recipients with hepatitis $B$ virus: resistance and recurrence patterns from a large transplant center over the last decade. Liver Transpl 2004;10:1372-1378.

412. Karlas T, Hartmann J, Weimann A, Maier M, Bartels M, Jonas S, et al. Prevention of lamivudine-resistant hepatitis $B$ recurrence after liver transplantation with entecavir plus tenofovir combination therapy and perioperative hepatitis B immunoglobulin only. Transplant Infectious Disease 2011;13:299-302.

413. Schiff E, Lai CL, Hadziyannis S, Neuhaus P, Terrault N, Colombo M, et al. Adefovir dipivoxil for wait-listed and post-liver transplantation patients with lamivudine-resistant hepatitis B: Final long-term results. Liver Transpl 2007;13:349-360.

414. Rao W, Xie M, Shen Z. Tenofovir disoproxil fumarate rescue therapy for HBV recurrence in two liver transplant recipients with previous multiple nucleo(s/t)ide treatment failures. Transpl Int 2014;27:e102104.

415. Cholongitas E, Papatheodoridis GV, Burroughs AK. Liver grafts from anti-hepatitis B core positive donors: a systematic review. J Hepatol 2010;52:272-279.

416. Chotiyaputta W, Pelletier SJ, Fontana RJ, Lok AS. Long-term ef- ficacy of nucleoside monotherapy in preventing HBV infection in HBsAg-negative recipients of anti-HBc-positive donor livers. Hepatol Int 2010;4:707-715.

417. Avelino-Silva VI, D'Albuquerque LA, Bonazzi PR, Song AT, Miraglia $J L$, De Brito Neves A, et al. Liver transplant from Anti-HBc-positive, HBsAg-negative donor into HBsAg-negative recipient: is it safe? A systematic review of the literature. Clin Transplant 2010;24:735746.

418. Chang MS, Olsen SK, Pichardo EM, Stiles JB, Rosenthal-Cogan L, Brubaker WD, et al. Prevention of de novo hepatitis $B$ in recipients of core antibody-positive livers with lamivudine and other nucleos(t)ides: a 12-year experience. Transplantation 2013;95:960965.

419. Wright AJ, Fishman JA, Chung RT. Lamivudine compared with newer antivirals for prophylaxis of hepatitis B core antibody positive livers: a cost-effectiveness analysis. Am J Transplant 2014;14:629634.

420. Gupta S, Govindarajan S, Fong TL, Redeker AG. Spontaneous reactivation in chronic hepatitis B: patterns and natural history. J Clin Gastroenterol 1990;12:562-568.

421. Lok AS, McMahon BJ. Chronic hepatitis B: update of recommendations. Hepatology 2004;39:857-861.

422. Yeo W, Johnson PJ. Diagnosis, prevention and management of hepatitis $B$ virus reactivation during anticancer therapy. Hepatology 2006:43:209-220.

423. Yeo W, Zee B, Zhong S, Chan PK, Wong WL, Ho WM, et al. Comprehensive analysis of risk factors associating with Hepatitis $B$ virus (HBV) reactivation in cancer patients undergoing cytotoxic chemotherapy. Br J Cancer 2004;90:1306-1311.

424. Hwang JP, Lok AS. Management of patients with hepatitis B who require immunosuppressive therapy. Nat Rev Gastroenterol Hepatol 2014;11:209-219.

425. Lok AS, Liang RH, Chiu EK, Wong KL, Chan TK, Todd D. Reactivation of hepatitis $B$ virus replication in patients receiving cytotoxic therapy. Report of a prospective study. Gastroenterology 1991;100:182-188.

426. Yeo W, Chan PK, Zhong S, Ho WM, Steinberg JL, Tam JS, et al. Frequency of hepatitis $B$ virus reactivation in cancer patients undergoing cytotoxic chemotherapy: a prospective study of 626 patients with identification of risk factors. J Med Virol 2000;62:299-307.

427. Loomba R, Rowley A, Wesley R, Liang TJ, Hoofnagle JH, Pucino $F$, et al. Systematic review: the effect of preventive lamivudine on hepatitis $B$ reactivation during chemotherapy. Ann Intern Med 2008;148:519-528.

428. Kwak LW, Halpern J, Olshen RA, Horning SJ. Prognostic significance of actual dose intensity in diffuse large-cell lymphoma: results of a tree-structured survival analysis. J Clin Oncol 1990;8:963-977.

429. Bonadonna G, Valagussa P, Moliterni A, Zambetti M, Brambilla 
C. Adjuvant cyclophosphamide, methotrexate, and fluorouracil in node-positive breast cancer: the results of 20 years of follow-up. $\mathrm{N}$ Engl J Med 1995;332:901-906.

430. Yeo W, Chan PK, Hui P, Ho WM, Lam KC, Kwan WH, et al. Hepatitis $B$ virus reactivation in breast cancer patients receiving cytotoxic chemotherapy: a prospective study. J Med Virol 2003;70:553-561.

431. Jang JW. Hepatitis B virus reactivation in patients with hepatocellular carcinoma undergoing anti-cancer therapy. World J Gastroenterol 2014;20:7675-7685.

432. Takai S, Tsurumi H, Ando K, Kasahara S, Sawada M, Yamada T, et al. Prevalence of hepatitis $B$ and $C$ virus infection in haematological malignancies and liver injury following chemotherapy. Eur J Haematol 2005;74:158-165.

433. Hsu C, Hsiung CA, Su IJ, Hwang WS, Wang MC, Lin SF, et al. A revisit of prophylactic lamivudine for chemotherapy-associated hepatitis B reactivation in non-Hodgkin's lymphoma: a randomized trial. Hepatology 2008;47:844-853.

434. Engels EA, Cho ER, Jee SH. Hepatitis B virus infection and risk of non-Hodgkin lymphoma in South Korea: a cohort study. Lancet Oncol 2010;11:827-834.

435. Cheng AL, Hsiung CA, Su IJ, Chen PJ, Chang MC, Tsao CJ, et al. Steroid-free chemotherapy decreases risk of hepatitis $B$ virus (HBV) reactivation in HBV-carriers with lymphoma. Hepatology 2003:37:1320-1328.

436. Yeo W, Chan TC, Leung NW, Lam WY, Mo FK, Chu MT, et al. Hepatitis $B$ virus reactivation in lymphoma patients with prior resolved hepatitis $B$ undergoing anticancer therapy with or without rituximab. J Clin Oncol 2009;27:605-611.

437. Kim SJ, Hsu C, Song YQ, Tay K, Hong XN, Cao J, et al. Hepatitis B virus reactivation in $B$-cell lymphoma patients treated with rituximab: analysis from the Asia Lymphoma Study Group. Eur J Cancer 2013;49:3486-3496.

438. Hsu C, Tsou HH, Lin SJ, Wang MC, Yao M, Hwang WL, et al. Chemotherapy-induced hepatitis $B$ reactivation in lymphoma patients with resolved HBV infection: a prospective study. Hepatology 2014;59:2092-2100.

439. Dong HJ, Ni LN, Sheng GF, Song HL, Xu JZ, Ling Y. Risk of hepatitis $B$ virus (HBV) reactivation in non-Hodgkin lymphoma patients receiving rituximab-chemotherapy: a meta-analysis. J Clin Virol 2013;57:209-214.

440. Chen XQ, Peng JW, Lin GN, Li M, Xia ZJ. The effect of prophylactic lamivudine on hepatitis $B$ virus reactivation in $\mathrm{HBs} A g$-positive patients with diffuse large B-cell lymphoma undergoing prolonged rituximab therapy. Med Oncol 2012;29:1237-1241.

441. Zurawska U, Hicks LK, Woo G, Bell CM, Krahn M, Chan KK, et al. Hepatitis B virus screening before chemotherapy for lymphoma: a cost-effectiveness analysis. J Clin Oncol 2012;30:3167-3173.

442. Lau GK, Leung YH, Fong DY, Au WY, Kwong YL, Lie A, et al. High hepatitis B virus (HBV) DNA viral load as the most important risk factor for HBV reactivation in patients positive for HBV surface antigen undergoing autologous hematopoietic cell transplantation. Blood 2002;99:2324-2330.

443. Lau GK, He ML, Fong DY, Bartholomeusz A, Au WY, Lie AK, et al. Preemptive use of lamivudine reduces hepatitis $B$ exacerbation after allogeneic hematopoietic cell transplantation. Hepatology 2002;36:702-709.

444. Chen FW, Coyle L, Jones BE, Pattullo V. Entecavir versus lamivudine for hepatitis B prophylaxis in patients with haematological disease. Liver Int 2013;33:1203-1210.

445. Dai MS, Wu PF, Shyu RY, Lu JJ, Chao TY. Hepatitis B virus reactivation in breast cancer patients undergoing cytotoxic chemotherapy and the role of preemptive lamivudine administration. Liver Int 2004;24:540-546.

446. Kim S, Kim HY, Lee S, Kim SW, Sohn S, Kim K, et al. Hepatitis B virus $x$ protein induces perinuclear mitochondrial clustering in microtubule- and Dynein-dependent manners. J Virol 2007;81:17141726.

447. Park JW, Park KW, Cho SH, Park HS, Lee WJ, Lee DH, et al. Risk of hepatitis $B$ exacerbation is low after transcatheter arterial chemoembolization therapy for patients with HBV-related hepatocellular carcinoma: report of a prospective study. Am J Gastroenterol 2005;100:2194-2200.

448. Jang JW, Choi JY, Bae SH, Yoon SK, Chang UI, Kim CW, et al. A randomized controlled study of preemptive lamivudine in patients receiving transarterial chemo-lipiodolization. Hepatology 2006;43:233-240.

449. Lao XM, Wang D, Shi M, Liu G, Li S, Guo R, et al. Changes in hepatitis $B$ virus DNA levels and liver function after transcatheter arterial chemoembolization of hepatocellular carcinoma. Hepatol Res 2011:41:553-563.

450. Lao XM, Luo G, Ye LT, Luo C, Shi M, Wang D, et al. Effects of antiviral therapy on hepatitis $B$ virus reactivation and liver function after resection or chemoembolization for hepatocellular carcinoma. Liver Int 2013;33:595-604.

451. Jang JW, Kwon JH, You CR, Kim JD, Woo HY, Bae SH, et al. Risk of $\mathrm{HBV}$ reactivation according to viral status and treatment intensity in patients with hepatocellular carcinoma. Antivir Ther 2011;16:969-977.

452. Shim JH, Park JW, Choi JI, Park BJ, Kim CM. Practical efficacy of sorafenib monotherapy for advanced hepatocellular carcinoma patients in a Hepatitis B virus-endemic area. J Cancer Res Clin Oncol 2009;135:617-625

453. Hui CK, Cheung WW, Zhang HY, Au WY, Yueng YH, Leung AY, et al. Kinetics and risk of de novo hepatitis B infection in HBsAgnegative patients undergoing cytotoxic chemotherapy. Gastroenterology 2006;131:59-68. 
454. El-Sayed MH, Mohamed MM, Karim A, Maina AM, Oliveri F, Brunetto MR, et al. Severe liver disease is caused by HBV rather than HCV in children with hematological malignancies. Hematol J 2003;4:321-327.

455. Yeo W, Chan PK, Ho WM, Zee B, Lam KC, Lei KI, et al. Lamivudine for the prevention of hepatitis $B$ virus reactivation in hepatitis $B \mathrm{~s}$ antigen seropositive cancer patients undergoing cytotoxic chemotherapy. J Clin Oncol 2004;22:927-934.

456. Chung SJ, Kim JK, Park MC, Park YB, Lee SK. Reactivation of hepatitis B viral infection in inactive HBsAg carriers following anti-tumor necrosis factor-alpha therapy. J Rheumatol 2009;36:2416-2420.

457. Esteve M, Saro C, Gonzalez-Huix F, Suarez F, Forne M, Viver JM. Chronic hepatitis $B$ reactivation following infliximab therapy in Crohn's disease patients: need for primary prophylaxis. Gut 2004;53:1363-1365.

458. Kim YJ, Bae SC, Sung YK, Kim TH, Jun JB, Yoo DH, et al. Possible reactivation of potential hepatitis $B$ virus occult infection by tumor necrosis factor-alpha blocker in the treatment of rheumatic diseases. J Rheumatol 2010;37:346-350.

459. Alexopoulou A, Theodorou M, Dourakis SP, Karayiannis P, Sagkana $E$, Papanikolopoulos $K$, et al. Hepatitis $B$ virus reactivation in patients receiving chemotherapy for malignancies: role of precore stop-codon and basic core promoter mutations. J Viral Hepat 2006;13:591-596.

460. Sugauchi F, Tanaka Y, Kusumoto S, Matsuura K, Sugiyama M, Kurbanov $F$, et al. Virological and clinical characteristics on reactivation of occult hepatitis B in patients with hematological malignancy. J Med Virol 2011;83:412-418.

461. Steinberg JL, Yeo W, Zhong S, Chan JY, Tam JS, Chan PK, et al. Hepatitis $B$ virus reactivation in patients undergoing cytotoxic chemotherapy for solid tumours: precore/core mutations may play an important role. J Med Virol 2000;60:249-255.

462. Borentain P, Colson P, Coso D, Bories E, Charbonnier A, Stoppa $A M$, et al. Clinical and virological factors associated with hepatitis $\mathrm{B}$ virus reactivation in $\mathrm{HBs} \mathrm{Ag}$-negative and anti-HBC antibodiespositive patients undergoing chemotherapy and/or autologous stem cell transplantation for cancer. J Viral Hepat 2010;17:807-815.

463. Lee YH, Bae SC, Song GG. Hepatitis B virus reactivation in HBsAgpositive patients with rheumatic diseases undergoing anti-tumor necrosis factor therapy or DMARDs. Int J Rheum Dis 2013;16:527531.

464. Perez-Alvarez R, Diaz-Lagares C, Garcia-Hernandez F, Lopez-Roses $L$, Brito-Zeron P, Perez-de-Lis M, et al. Hepatitis B virus (HBV) reactivation in patients receiving tumor necrosis factor (TNF)-targeted therapy: analysis of 257 cases. Medicine (Baltimore) 2011;90:359371

465. Rossi G, Pelizzari A, Motta M, Puoti M. Primary prophylaxis with lamivudine of hepatitis $B$ virus reactivation in chronic $\mathrm{HbsAg}$ car- riers with lymphoid malignancies treated with chemotherapy. $\mathrm{Br} J$ Haematol 2001;115:58-62.

466. Lau GK, Yiu HH, Fong DY, Cheng HC, Au WY, Lai LS, et al. Early is superior to deferred preemptive lamivudine therapy for hepatitis B patients undergoing chemotherapy. Gastroenterology 2003;125:1742-1749.

467. Saab S, Dong MH, Joseph TA, Tong MJ. Hepatitis B prophylaxis in patients undergoing chemotherapy for lymphoma: a decision analysis model. Hepatology 2007;46:1049-1056.

468. Hui CK, Cheung WW, Au WY, Lie AK, Zhang HY, Yueng YH, et al. Hepatitis $B$ reactivation after withdrawal of pre-emptive lamivudine in patients with haematological malignancy on completion of cytotoxic chemotherapy. Gut 2005;54:1597-1603.

469. Li HR, Huang JJ, Guo HQ, Zhang X, Xie Y, Zhu HL, et al. Comparison of entecavir and lamivudine in preventing hepatitis $B$ reactivation in lymphoma patients during chemotherapy. J Viral Hepat 2011;18:877-883.

470. Niitsu N, Hagiwara Y, Tanae K, Kohri M, Takahashi N. Prospective analysis of hepatitis $B$ virus reactivation in patients with diffuse large B-cell lymphoma after rituximab combination chemotherapy. J Clin Oncol 2010;28:5097-5100.

471. Tanaka Y, Esumi M, Shikata T. Persistence of hepatitis B virus DNA after serological clearance of hepatitis B virus. Liver 1990;10:6-10.

472. Koo YX, Tan DS, Tan IB, Tao M, Chow WC, Lim ST. Hepatitis B virus reactivation and role of antiviral prophylaxis in lymphoma patients with past hepatitis B virus infection who are receiving chemoimmunotherapy. Cancer 2010;116:115-121.

473. Liu HL, Zhao Z, Yang H, Liu FF, Liu Q, Luo Q, et al. The effects of nucleoside analogue prophylactic treatment on HBV activation in $\mathrm{HBCA}+$ + patients undergoing immunosuppressive therapy. J Viral Hepat 2013;20:645-649.

474. Lopez-Alcorocho JM, Barril G, Ortiz-Movilla N, Traver JA, Bartolome J, Sanz $P$, et al. Prevalence of hepatitis $B$, hepatitis C, GB virus $C$ /hepatitis $G$ and TT viruses in predialysis and hemodialysis patients. J Med Virol 2001;63:103-107.

475. Finelli L, Miller JT, Tokars JI, Alter MJ, Arduino MJ. National surveillance of dialysis-associated diseases in the United States, 2002. Semin Dial 2005;18:52-61.

476. Johnson DW, Dent H, Yao Q, Tranaeus A, Huang CC, Han DS, et al. Frequencies of hepatitis $B$ and $C$ infections among haemodialysis and peritoneal dialysis patients in Asia-Pacific countries: analysis of registry data. Nephrol Dial Transplant 2009;24:1598-1603.

477. Burdick RA, Bragg-Gresham JL, Woods JD, Hedderwick SA, Kurokawa $\mathrm{K}$, Combe $\mathrm{C}$, et al. Patterns of hepatitis B prevalence and seroconversion in hemodialysis units from three continents: the DOPPS. Kidney Int 2003;63:2222-2229.

478. Minuk GY, Sun DF, Greenberg R, Zhang M, Hawkins K, Uhanova J, et al. Occult hepatitis $B$ virus infection in a North American adult 
hemodialysis patient population. Hepatology 2004;40:1072-1077.

479. Gwak GY, Huh W, Lee DH, Min BH, Koh KC, Kim JJ, et al. Occult hepatitis B virus infection in chronic hemodialysis patients in Korea. Hepatogastroenterology 2008;55:1721-1724.

480. Kellerman S, Alter MJ. Preventing hepatitis B and hepatitis C virus infections in end-stage renal disease patients: back to basics. Hepatology 1999;29:291-293.

481. Miller ER, Alter MJ, Tokars Jl. Protective effect of hepatitis $B$ vaccine in chronic hemodialysis patients. Am J Kidney Dis 1999:33:356-360.

482. DaRoza G, Loewen A, Djurdjev O, Love J, Kempston C, Burnett $S$, et al. Stage of chronic kidney disease predicts seroconversion after hepatitis B immunization: earlier is better. Am J Kidney Dis 2003:42:1184-1192.

483. Bel'eed K, Wright M, Eadington D, Farr M, Sellars L. Vaccination against hepatitis $B$ infection in patients with end stage renal disease. Postgrad Med J 2002;78:538-540.

484. Lin CY. Treatment of hepatitis B virus-associated membranous nephropathy with recombinant alpha-interferon. Kidney Int 1995:47:225-230.

485. Campistol JM, Esforzado N, Martinez J, Rosello L, Veciana L, Modol J, et al. Efficacy and tolerance of interferon-alpha(2b) in the treatment of chronic hepatitis $C$ virus infection in haemodialysis patients. Pre- and post-renal transplantation assessment. Nephrol Dial Transplant 1999;14:2704-2709.

486. Chan TM, Ho SK, Tang CS, Tse KC, Lam MF, Lai KN, et al. Pilot study of pegylated interferon-alpha $2 \mathrm{a}$ in dialysis patients with chronic hepatitis C virus infection. Nephrology (Carlton) 2007;12:11-17

487. Ben-Ari Z, Broida E, Kittai Y, Chagnac A, Tur-Kaspa R. An openlabel study of lamivudine for chronic hepatitis $B$ in six patients with chronic renal failure before and after kidney transplantation. Am J Gastroenterol 2000;95:3579-3583.

488. Boyacioglu S, Gur G, Gursoy M, Ozdemir N. Lamivudine in renal transplant candidates with chronic hepatitis B infection. Transplant Proc 2002;34:2131-2132.

489. Schmilovitz-Weiss H, Melzer E, Tur-Kaspa R, Ben-Ari Z. Excellent outcome of Lamivudine treatment in patients with chronic renal failure and hepatitis B virus infection. J Clin Gastroenterol 2003;37:64-67.

490. Fontaine H, Thiers V, Chretien Y, Zylberberg H, Poupon RE, Brechot $C$, et al. HBV genotypic resistance to lamivudine in kidney recipients and hemodialyzed patients. Transplantation 2000;69:20902094.

491. Yap DY, Tang CS, Yung S, Choy BY, Yuen MF, Chan TM. Longterm outcome of renal transplant recipients with chronic hepatitis B infection-impact of antiviral treatments. Transplantation 2010;90:325-330
492. Kamar N, Milioto O, Alric L, El Kahwaji L, Cointault O, Lavayssiere $L$, et al. Entecavir therapy for adefovir-resistant hepatitis $B$ virus infection in kidney and liver allograft recipients. Transplantation 2008;86:611-614.

493. Ha NB, Garcia RT, Trinh HN, Vu AA, Nguyen HA, Nguyen KK, et al. Renal dysfunction in chronic hepatitis $B$ patients treated with adefovir dipivoxil. Hepatology 2009;50:727-734.

494. Verhelst D, Monge M, Meynard JL, Fouqueray B, Mougenot B, Girard PM, et al. Fanconi syndrome and renal failure induced by tenofovir: a first case report. Am J Kidney Dis 2002;40:1331-1333.

495. Heathcote EJ, Marcellin P, Buti M, Gane E, De Man RA, Krastev $Z$, et al. Three-year efficacy and safety of tenofovir disoproxil fumarate treatment for chronic hepatitis B. Gastroenterology 2011;140:132-143.

496. Gaeta GB, Stornaiuolo G, Precone DF, Lobello S, Chiaramonte M, Stroffolini $T$, et al. Epidemiological and clinical burden of chronic hepatitis B virus/hepatitis C virus infection. A multicenter Italian study. J Hepatol 2003;39:1036-1041.

497. Lee G, Kim KH, Kwon JA, Yoon SY, Cho Y, Lee CK, et al. Serologic Markers of Viral Hepatitis of Korea University Medical Center Patients. Korean J Lab Med 2005;25:61-65.

498. Liaw YF. Role of hepatitis C virus in dual and triple hepatitis virus infection. Hepatology 1995;22:1101-1108.

499. Sato S, Fujiyama S, Tanaka M, Yamasaki K, Kuramoto I, Kawano S, et al. Coinfection of hepatitis C virus in patients with chronic hepatitis B infection. J Hepatol 1994;21:159-166.

500. Lee LP, Dai CY, Chuang WL, Chang WY, Hou NJ, Hsieh MY, et al. Comparison of liver histopathology between chronic hepatitis $C$ patients and chronic hepatitis B and C-coinfected patients. J Gastroenterol Hepatol 2007;22:515-517.

501. Sagnelli E, Pasquale G, Coppola N, Scarano F, Marrocco C, Scolastico $C$, et al. Influence of chronic coinfection with hepatitis B and C virus on liver histology. Infection 2004;32:144-148.

502. Kirk GD, Lesi OA, Mendy M, Akano AO, Sam O, Goedert JJ, et al. The Gambia Liver Cancer Study: Infection with hepatitis B and C and the risk of hepatocellular carcinoma in West Africa. Hepatology 2004;39:211-219.

503. Benvegnu L, Fattovich G, Noventa F, Tremolada F, Chemello L, Cecchetto $A$, et al. Concurrent hepatitis $B$ and $C$ virus infection and risk of hepatocellular carcinoma in cirrhosis. A prospective study. Cancer 1994;74:2442-2448.

504. Hung CH, Lee CM, Lu SN, Wang JH, Tung HD, Chen $\mathrm{CH}$, et al. Combination therapy with interferon-alpha and ribavirin in patients with dual hepatitis B and hepatitis C virus infection. J Gastroenterol Hepatol 2005;20:727-732.

505. Liu CJ, Chen PJ, Lai MY, Kao JH, Jeng YM, Chen DS. Ribavirin and interferon is effective for hepatitis $C$ virus clearance in hepatitis $B$ and C dually infected patients. Hepatology 2003;37:568-576. 
506. Villa E, Grottola A, Buttafoco P, Colantoni A, Bagni A, Ferretti I, et al. High doses of alpha-interferon are required in chronic hepatitis due to coinfection with hepatitis B virus and hepatitis C virus: long term results of a prospective randomized trial. Am J Gastroenterol 2001;96:2973-2977.

507. Potthoff A, Wedemeyer H, Boecher WO, Berg T, Zeuzem S, Arnold J, et al. The HEP-NET B/C co-infection trial: A prospective multicenter study to investigate the efficacy of pegylated interferon-alpha2b and ribavirin in patients with HBV/HCV co-infection. J Hepatol 2008:49:688-694.

508. Liu CJ, Chuang WL, Lee CM, Yu ML, Lu SN, Wu SS, et al. Peginterferon alfa-2a plus ribavirin for the treatment of dual chronic infection with hepatitis B and C viruses. Gastroenterology 2009;136:496-504 e493.

509. Kim YJ, Kim JH, Kim YS, Lim HJ, Park YM, Kim BH, et al. Hepatitis B virus coinfected chronic hepatitis $C$ patients: Clinical features and treatment efficacy of peginterferon Alfa-2a plus ribavirin. Korean $\rfloor$ Hepatol 2010;16(3s):60

510. Hadziyannis SJ. Review: hepatitis delta. J Gastroenterol Hepatol 1997;12:289-298.

511. Radjef N, Gordien E, Ivaniushina V, Gault E, Anais P, Drugan T, et al. Molecular phylogenetic analyses indicate a wide and ancient radiation of African hepatitis delta virus, suggesting a deltavirus genus of at least seven major clades. J Virol 2004;78:2537-2544.

512. Jeong SH, Kim JM, Ahn HJ, Park MJ, Paik KH, Choi W, et al. The prevalence and clinical characteristics of hepatitis-delta infection in Korea. Korean J Hepatol 2005;11:43-50.

513. Kim KH, Jung JB, Kang JK, Park IS, Choi HJ, Song KS, et al. Prevalence of Delta antigen among chronic hepatitis B virus infected patients in Korea. Korean J Int Med 1985;29:30-36.

514. Suh DJ. Delta infection in HBV carriers with chronic liver diseases in Korea. Korean J Intern Med 1985:29:57-61.

515. Fattovich G, Bortolotti F, Donato F. Natural history of chronic hepatitis B: special emphasis on disease progression and prognostic factors. J Hepatol 2008;48:335-352.

516. Fattovich G, Giustina G, Christensen E, Pantalena M, Zagni I, Realdi $G$, et al. Influence of hepatitis delta virus infection on morbidity and mortality in compensated cirrhosis type B. The European Concerted Action on Viral Hepatitis (Eurohep). Gut 2000;46:420426

517. Castelnau C, Le Gal F, Ripault MP, Gordien E, Martinot-Peignoux M, Boyer $\mathrm{N}$, et al. Efficacy of peginterferon alpha-2b in chronic hepatitis delta: relevance of quantitative RT-PCR for follow-up. Hepatology 2006;44:728-735.

518. Farci P. Treatment of chronic hepatitis D: New advances, old challenges. Hepatology 2006;44:536-539.

519. Farci P, Chessa L, Balestrieri C, Serra G, Lai ME. Treatment of chronic hepatitis D. J Viral Hepat 2007;14 Suppl 1:58-63.
520. Farci P, Mandas A, Coiana A, Lai ME, Desmet V, Van Eyken $P$, et al. Treatment of chronic hepatitis $D$ with interferon alfa-2a. N Engl J Med 1994;330:88-94.

521. Niro GA, Ciancio A, Gaeta GB, Smedile A, Marrone A, Olivero $A$, et al. Pegylated interferon alpha-2b as monotherapy or in combination with ribavirin in chronic hepatitis delta. Hepatology 2006:44:713-720

522. Erhardt A, Gerlich W, Starke C, Wend U, Donner A, Sagir A, et al. Treatment of chronic hepatitis delta with pegylated interferonalpha2b. Liver Int 2006;26:805-810,

523. Yurdaydin C, Bozkaya H, Karaaslan H, Onder FO, Erkan OE, Yalcin $K$, et al. A pilot study of 2 years of interferon treatment in patients with chronic delta hepatitis. J Viral Hepat 2007;14:812-816.

524. Lau DT, Doo E, Park Y, Kleiner DE, Schmid P, Kuhns MC, et al. Lamivudine for chronic delta hepatitis. Hepatology 1999;30:546-549.

525. Wedemeyer H, Yurdaydin C, Dalekos GN, Erhardt A, Cakaloglu Y, Degertekin $\mathrm{H}$, et al. Peginterferon plus adefovir versus either drug alone for hepatitis delta. N Engl J Med;364:322-331.

526. Yurdaydin C, Bozkaya H, Onder FO, Senturk H, Karaaslan H, Akdogan $\mathrm{M}$, et al. Treatment of chronic delta hepatitis with lamivudine vs lamivudine + interferon vs interferon. J Viral Hepat 2008;15:314321.

527. Heidrich B, Yurdaydin C, Kabacam G, Ratsch BA, Zachou K, Bremer $B$, et al. Late HDV RNA relapse after peginterferon alpha-based therapy of chronic hepatitis delta. Hepatology 2014;60:87-97.

528. Brau N, Fox RK, Xiao P, Marks K, Naqvi Z, Taylor LE, et al. Presentation and outcome of hepatocellular carcinoma in HIV-infected patients: a U.S.-Canadian multicenter study. J Hepatol 2007;47:527537.

529. Thio CL, Seaberg EC, Skolasky R, Jr., Phair J, Visscher B, Munoz A, et al. HIV-1, hepatitis B virus, and risk of liver-related mortality in the Multicenter Cohort Study (MACS). Lancet 2002;360:1921-1926.

530. Keeffe EB, Marcellin P. New and emerging treatment of chronic hepatitis B. Clin Gastroenterol Hepatol 2007;5:285-294.

531. Benhamou Y, Bochet M, Thibault V, Di Martino V, Caumes E, Bricaire $F$, et al. Long-term incidence of hepatitis $B$ virus resistance to lamivudine in human immunodeficiency virus-infected patients. Hepatology 1999;30:1302-1306.

532. Dore GJ, Cooper DA, Pozniak AL, DeJesus E, Zhong L, Miller MD, et al. Efficacy of tenofovir disoproxil fumarate in antiretroviral therapy-naive and -experienced patients coinfected with HIV-1 and hepatitis B virus. J Infect Dis 2004;189:1185-1192.

533. Hoff J, Bani-Sadr F, Gassin M, Raffi F. Evaluation of chronic hepatitis $B$ virus (HBV) infection in coinfected patients receiving lamivudine as a component of anti-human immunodeficiency virus regimens. Clin Infect Dis 2001;32:963-969.

534. Soderstrom A, Norkrans G, Lindh M. Hepatitis B virus DNA during pregnancy and post partum: aspects on vertical transmission. 
Scand J Infect Dis 2003;35:814-819.

535. ter Borg MJ, Leemans WF, de Man RA, Janssen HL. Exacerbation of chronic hepatitis B infection after delivery. J Viral Hepat 2008;15:37-41.

536. Yang YB, Li XM, Shi ZJ, Ma L. Pregnant woman with fulminant hepatic failure caused by hepatitis B virus infection: a case report. World J Gastroenterol 2004;10:2305-2306.

537. Lin HH, Wu WY, Kao JH, Chen DS. Hepatitis B post-partum e antigen clearance in hepatitis B carrier mothers: Correlation with viral characteristics. J Gastroenterol Hepatol 2006;21:605-609.

538. Nguyen G, Garcia RT, Nguyen N, Trinh H, Keeffe EB, Nguyen MH. Clinical course of hepatitis $B$ virus infection during pregnancy. Aliment Pharmacol Ther 2009;29:755-764.

539. Patton H, Tran TT. Management of hepatitis B during pregnancy. Nat Rev Gastroenterol Hepatol 2014;11:402-409.

540. del Canho R, Grosheide PM, Mazel JA, Heijtink RA, Hop WC, Gerards $L J$, et al. Ten-year neonatal hepatitis $B$ vaccination program, The Netherlands, 1982-1992: protective efficacy and long-term immunogenicity. Vaccine 1997;15:1624-1630.

541. Ngui SL, Andrews NJ, Underhill GS, Heptonstall J, Teo CG. Failed postnatal immunoprophylaxis for hepatitis $B$ : characteristics of maternal hepatitis B virus as risk factors. Clin Infect Dis 1998;27:100106.

542. Zou H, Chen Y, Duan Z, Zhang H, Pan C. Virologic factors associated with failure to passive-active immunoprophylaxis in infants born to HBsAg-positive mothers. J Viral Hepat 2012;19:e18-25.

543. Wiseman E, Fraser MA, Holden S, Glass A, Kidson BL, Heron LG, et al. Perinatal transmission of hepatitis $B$ virus: an Australian experience. Med J Aust 2009;190:489-492.

544. Xu WM, Cui YT, Wang L, Yang H, Liang ZQ, Li XM, et al. Lamivudine in late pregnancy to prevent perinatal transmission of hepatitis B virus infection: a multicentre, randomized, double-blind, placebo-controlled study. J Viral Hepat 2009;16:94-103.

545. Yu M, Jiang Q, Ji Y, Jiang H, Wu K, Ju L, et al. The efficacy and safety of antiviral therapy with lamivudine to stop the vertical transmission of hepatitis B virus. Eur J Clin Microbiol Infect Dis 2012:31:2211-2218.

546. Pan CQ, Han GR, Jiang HX, Zhao W, Cao MK, Wang CM, et al. Telbivudine prevents vertical transmission from $\mathrm{HBeAg}$-positive women with chronic hepatitis B. Clin Gastroenterol Hepatol 2012;10:520-526.

547. Han GR, Cao MK, Zhao W, Jiang HX, Wang CM, Bai SF, et al. A prospective and open-label study for the efficacy and safety of telbivudine in pregnancy for the prevention of perinatal transmission of hepatitis B virus infection. J Hepatol 2011;55:1215-1221.

548. Greenup AJ, Tan PK, Nguyen V, Glass A, Davison S, Chatterjee $U$, et al. Efficacy and safety of tenofovir disoproxil fumarate in pregnancy to prevent perinatal transmission of hepatitis B virus. J
Hepatol 2014;61:502-507.

549. Hong SJ, Park HJ, Chu MA, Choi BS, Choe BH. The Rate of Conversion from Immune-tolerant Phase to Early Immune-clearance Phase in Children with Chronic Hepatitis B Virus Infection. Pediatr Gastroenterol Hepatol Nutr 2014;17:41-46.

550. Hsu HY, Chang MH, Chen DS, Lee CY, Sung JL. Baseline seroepidemiology of hepatitis B virus infection in children in Taipei, 1984: a study just before mass hepatitis B vaccination program in Taiwan. J Med Virol 1986;18:301-307.

551. Shah U, Kelly D, Chang MH, Fujisawa T, Heller S, Gonzalez-Peralta RP, et al. Management of chronic hepatitis B in children. J Pediatr Gastroenterol Nutr 2009;48:399-404.

552. Jonas MM, Block JM, Haber BA, Karpen SJ, London WT, Murray KF, et al. Treatment of children with chronic hepatitis B virus infection in the United States: patient selection and therapeutic options. Hepatology 2010;52:2192-2205.

553. Sokal EM, Conjeevaram HS, Roberts EA, Alvarez F, Bern EM, Goyens $\mathrm{P}$, et al. Interferon alfa therapy for chronic hepatitis $\mathrm{B}$ in children: a multinational randomized controlled trial. Gastroenterology 1998;114:988-995.

554. Hom X, Little NR, Gardner SD, Jonas MM. Predictors of virologic response to Lamivudine treatment in children with chronic hepatitis B infection. Pediatr Infect Dis J 2004;23:441-445.

555. Kobak GE, MacKenzie T, Sokol RJ, Narkewicz MR. Interferon treatment for chronic hepatitis B: enhanced response in children 5 years old or younger. J Pediatr 2004;145:340-345.

556. Bortolotti F, Jara P, Barbera C, Gregorio GV, Vegnente A, Zancan L, et al. Long term effect of alpha interferon in children with chronic hepatitis B. Gut 2000;46:715-718.

557. Lindh M, Uhnoo I, Blackberg J, Duberg AS, Friman S, Fischler B, et al. Treatment of chronic hepatitis B infection: an update of Swedish recommendations. Scand J Infect Dis 2008;40:436-450.

558. Jonas MM, Mizerski J, Badia IB, Areias JA, Schwarz KB, Little NR, et al. Clinical trial of lamivudine in children with chronic hepatitis $B$. N Engl J Med 2002;346:1706-1713.

559. Sokal EM, Kelly DA, Mizerski J, Badia IB, Areias JA, Schwarz KB, et al. Long-term lamivudine therapy for children with $\mathrm{HBeAg}$-positive chronic hepatitis B. Hepatology 2006;43:225-232.

560. Choe BH, Lee JH, Jang YC, Jang CH, Oh KW, Kwon S, et al. Longterm therapeutic efficacy of lamivudine compared with interferonalpha in children with chronic hepatitis B: the younger the better. J Pediatr Gastroenterol Nutr 2007:44:92-98.

561. Koh H, Baek SY, Chung KS. Lamivudine therapy for korean children with chronic hepatitis B. Yonsei Med J 2007;48:927-933.

562. Jonas MM, Little NR, Gardner SD. Long-term lamivudine treatment of children with chronic hepatitis B: durability of therapeutic responses and safety. J Viral Hepat 2008;15:20-27.

563. Jonas MM, Kelly D, Pollack H, Mizerski J, Sorbel J, Frederick D, et 
The Korean Association for the Study of the Liver (KASL)

Treatment guideline for hepatitis $B$

al. Safety, efficacy, and pharmacokinetics of adefovir dipivoxil in children and adolescents (age 2 to $<18$ years) with chronic hepatitis B. Hepatology 2008;47:1863-1871.

564. Jonas MM, Kelly D, Pollack H, Mizerski J, Sorbel J, Frederick D, et al. Efficacy and safety of long-term adefovir dipivoxil therapy in children with chronic hepatitis B infection. Pediatr Infect Dis J 2012;31:578-582.

565. Murray KF, Szenborn L, Wysocki J, Rossi S, Corsa AC, Dinh P, et al. Randomized, placebo-controlled trial of tenofovir disoproxil fumarate in adolescents with chronic hepatitis B. Hepatology 2012;56:2018-2026.

566. Jonas MM, Chang MH, Sokal E, Schwarz KB, Kelly D, Kim KM, et al. Randomized, controlled trial of entecavir versus placebo in children with hepatitis B envelope antigen-positive chronic hepatitis B. Hepatology 2016;63:377-387. 